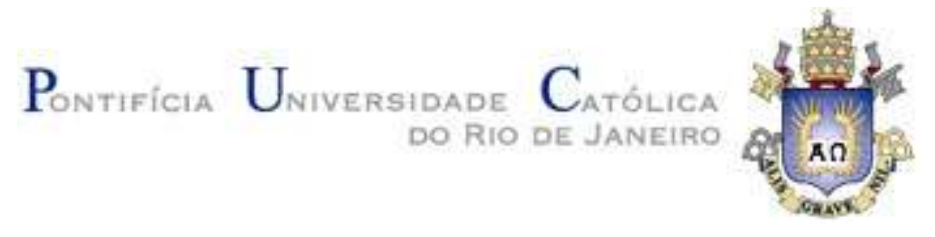

Lucas Sales Pereira Bartolomeu

Modelo de rede de capilares do escoamento de soluções poliméricas em meios porosos

Dissertação de Mestrado

Dissertação apresentada como requisito parcial para obtenção do grau de Mestre pelo Programa de Pós-graduação em Engenharia Mecânica da PUC-Rio.

Orientador: Prof. Márcio da Silveira Carvalho

Rio de Janeiro

Março de 2017 


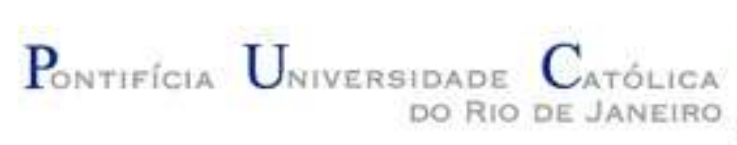

Lucas Sales Pereira Bartolomeu

\title{
Modelo de rede de capilares do escoamento de soluções poliméricas em meios porosos
}

Dissertação apresentada como requisito parcial para obtenção do grau de Mestre pelo Programa de Pós-graduação em Engenharia Mecânica do Departamento de Engenharia Mecânica do Centro Técnico Científico da PUC-Rio. Aprovada pela Comissão Examinadora abaixo assinada.

\author{
Prof. Márcio da Silveira Carvalho \\ Orientador \\ Departamento de Engenharia Mecânica - PUC - Rio
}

Prof. ${ }^{a}$ Mônica Feijó Naccache

Departamento de Engenharia Mecânica - PUC - Rio

\section{Rodrigo Neumann Barros Ferreira}

IBM Research - Brazil

Prof. Paulo Roberto de Souza Mendes

Departamento de Engenharia Mecânica - PUC - Rio

Prof. Márcio da Silveira Carvalho

Coordenador Setorial do Centro Técnico Científico - PUC - Rio

Rio de Janeiro, 24 de Março de 2017. 
Todos os direitos reservados. É proibida a reprodução total ou parcial do trabalho sem autorização da universidade, do autor e do orientador.

\section{Lucas Sales Pereira Bartolomeu}

Lucas Sales Pereira Bartolomeu graduou-se em Engenharia de Petróleo pela Pontifícia Universidade Católica do Rio de Janeiro [2013].

Ficha catalográfica

Bartolomeu, Lucas Sales Pereira

Modelo de rede de capilares do escoamento de soluções poliméricas em meios porosos / Lucas Sales Pereira Bartolomeu; orientador: Márcio da Silveira Carvalho. -2017 .

96 f.: il. (color.) ; 29,7 cm

Dissertação (mestrado) - Pontifícia Universidade Católica do Rio de Janeiro, Departamento de Engenharia Mecânica, 2017.

Inclui referências bibliográficas.

1. Engenharia Mecânica - Teses. 2. Recuperação Avançada de Óleo. 3. Soluções Poliméricas. 4. Meios porosos. 5. Modelo de rede de capilares. 6. Viscoelasticidade. I Carvalho, Márcio da Silveira. II. Pontifícia Universidade Católica do Rio de Janeiro. Departamento de Engenharia Mecânica. III. Título. 


\section{Agradecimento}

Agradeço aos meus pais, meu irmão, meus avós, minha madrinha e meus amigos pelo apoio e incentivo na busca dos meus sonhos.

Ao meu orientador Professor Márcio e ao coordenador do projeto, Danmer Maza, pela dedicação e competência com que me auxiliaram ao longo desse projeto. Aos colegas de pesquisa do Laboratório de Micro-Hidrodinâmica e Meios Porosos.

A CNPq, a Statoil e a PUC-Rio pelos auxílios concedidos, sem os quais este trabalho não poderia ter sido realizado. 


\section{Resumo}

Bartolomeu, Lucas Sales Pereira; Carvalho, Márcio da Silveira. Modelo de rede de capilares do escoamento de soluções poliméricas em meios porosos. Rio de Janeiro, 2017. 96p. Dissertação de Mestrado - Departamento de Engenharia Mecânica, Pontifícia Universidade Católica do Rio de Janeiro.

A injeção de soluções poliméricas tem sido utilizada em muitas aplicações para aumentar a viscosidade da fase aquosa e, por conseguinte, reduzir a elevada razão de mobilidade durante o deslocamento de óleo num meio poroso. Evidências experimentais mostraram também que o comportamento viscoelástico de algumas soluções poliméricas pode contribuir para um melhor deslocamento do óleo na escala de poros, reduzindo assim, a saturação de óleo residual. Este comportamento na escala de poros não é claramente compreendido já que a modelagem de um fluxo viscoelástico de uma solução polimérica em meios porosos é extremamente desafiadora. O comportamento do escoamento em escala macroscópica está diretamente associado com o fluxo extensional dominante através das gargantas e poros que formam o meio poroso. Muitos modelos têm sido desenvolvidos com o objetivo de descrever o efeito extensional observados no fluxo de soluções poliméricas de elevado peso molecular. O modelo desenvolvido neste trabalho baseia-se na relação entre a vazão e a queda de pressão do escoamento de soluções poliméricas através de capilares com garganta que servem como um modelo simples da geometria das gargantas de poro. Um modelo de rede de capilares bidimensional foi desenvolvido para obter os parâmetros macroscópicos do escoamento a partir do entendimento do comportamento microscópico. No modelo monofásico, os resultados apresentam efeitos de diferentes parâmetros reológicos no comportamento macroscópico do escoamento. Para estudar o escoamento bifásico, um modelo de rede dinâmico foi desenvolvido. Os resultados obtidos fornecem uma descrição mais detalhada do processo de deslocamento de óleo pela fase aquosa.

\section{Palavras-chave}

Recuperação avançada de óleo; soluções poliméricas; meios porosos; modelo de rede de capilar; viscoelasticidade 


\begin{abstract}
Bartolomeu, Lucas Sales Pereira; Carvalho, Márcio da Silveira (Advisor). Capillary network model of polymeric solution flow in a porous media. Rio de Janeiro, 2017. 96p. Dissertação de Mestrado - Departamento de Engenharia Mecânica, Pontifícia Universidade Católica do Rio de Janeiro.
\end{abstract}

Injection of a polymer solution is used in many applications to increase the viscosity of the water phase and therefore reduce the high mobility ratio during oil displacement in porous media. Experimental evidence has shown that the viscoelastic behavior of some polymer solutions may contribute to a better oil displacement at the pore-level, reducing the residual oil saturation. This pore-level behavior is not clearly understood. Modeling viscoelastic flow of polymeric solutions in porous media is extremely challenging. The macroscopic flow behavior is directly associated with the extensional dominant flow through pore throats that form the porous media. Accurate models should be able to describe the extensional thickening effect observed in the flow of dilute high molecular weight polymer solutions. The model developed in this work is based on the flow rate-pressure drop relationship of polymer solution flow through constricted capillaries that serves as a simple model of the geometry of pore throats. A two-dimensional capillary network model is constructed in order to obtain macroscopic parameters from upscaling of the microscopic behavior. In single-phase flow, results show the effect of different rheological parameters on the macroscopic flow behavior. To study a two-phase flow, a dynamic network model was developed. The results obtained provide a more detailed description of the oil displacement by the water phase.

\title{
Keywords
}

Enhanced oil recovery; polymeric solution; porous media; capillary network model; viscoelasticity 


\section{Sumário}

1. Introdução 16

$\begin{array}{ll}\text { 1.1. Motivação } & 16\end{array}$

$\begin{array}{ll}\text { 1.2. Processos de recuperação de petróleo } & 16\end{array}$

1.2.1. Método de recuperação primária 16

$\begin{array}{ll}\text { 1.2.2. Método de recuperação secundária } & 17\end{array}$

$\begin{array}{ll}\text { 1.2.3. Método de recuperação terciária } & 17\end{array}$

$\begin{array}{ll}\text { 1.3. Injeção de soluções poliméricas em meios porosos } & 18\end{array}$

$\begin{array}{ll}\text { 1.3.1. Exemplos na indústria } & 19\end{array}$

1.3.2. Comportamento viscoelástico de soluções poliméricas 19

$\begin{array}{ll}\text { 1.4. Análise em escala de poros } & 21\end{array}$

1.4.1. Micromodelos e sua utilização em escoamento em meios porosos 21

1.4.2. Modelo de rede de capilares $\quad 22$

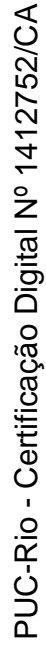

$\begin{array}{ll}\text { 1.5. Objetivos do trabalho } & 22\end{array}$

2. Modelo de rede de capilares 24

2.1. Geometria do meio poroso 24

2.1.1. Porosidade efetiva 26

2.1.2. Condutância hidráulica 26

2.2. Escoamento monofásico em regime permanente 27

$\begin{array}{ll}\text { 2.2.1. Fluido Newtoniano } & 27\end{array}$

2.2.2. Fluido não-Newtoniano 27

2.3. Descrição do modelo monofásico 32

2.3.1. Conectividade da rede 33

2.3.2. Resolvendo o sistema de solução 35

2.4. Escoamento bifásico 39

2.4.1. Modelo quasi-estático $\quad 40$

2.4.2. Modelo dinâmico 40

2.5. Descrição do modelo bifásico 41

2.5.1. Princípios do modelo dinâmico 41

2.5.2. Deslocamento pistão-pistão 42

2.5.3. Drenagem e embebição 42

2.5.4. Fluxo através de um capilar 43 
3. Resultados 50

3.1. Escoamento monofásico 50

3.1.1. Fluido Newtoniano $\quad 50$

3.1.2. Fluido não-Newtoniano 51

3.2. Escoamento bifásico 56

3.2.1. Fluido Newtoniano $\quad 57$

3.2.2. Fluido não-Newtoniano $\quad 68$

$\begin{array}{ll}\text { 3.2.3. Efeito de capilaridade } & 91\end{array}$

4. Considerações finais 93

Referência bibliográfica 95

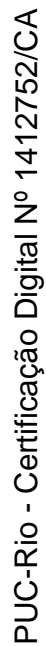




\section{Lista de Figuras}

Figura 1 (a) Formação de viscous fingering durante a injeção de solução aquosa (b) Varredura mais uniforme com a injeção de soluções poliméricas 18

Figura 2 Escoamento de uma solução polimérica através de um meio poroso 19 Figura 3 Moléculas de polímero passando por uma garganta (AL HASHMI e colab., 2013) 20

Figura 4 Micromodelo utilizado (KUMAR GUNDA e colab., 2011) 21

Figura 5 Micromodelo de vidro desenvolvido pela Dolomite 21

Figura 6 (a) Representação de uma rocha porosa (b) Rede de capilares (ØREN e BAKKE, 2003)

Figura 7 Visão macroscópica do micromodelo 2D desenvolvido pela Dolomite

Figura 8 Dimensões do micromodelo e dimensões dos canais. 25

Figura 9 Garganta de um capilar da rede $\quad 26$

Figura 10 Representação geométrica da condutância do poro i,j e do capilar 26

Figura 11 Comportamento típico de um fluido pseudoplástico. Viscosidade de cisalhamento em função da taxa de cisalhamento, $\gamma$, em escalas de log-log. $\quad 29$ Figura 12 Comportamento de um fluido tipo lei-de-potência. Viscosidade de cisalhamento em função da taxa de cisalhamento, $\gamma$, em escalas de log-log. 29 Figura 13 Geometria do capilar 31 Figura 14 Comportamento típico da viscosidade extensional, $\mu$, como uma função da taxa de extensão $\varepsilon$ em um fluxo extensional em escalas de log-log. 32 Figura 15 Conectividade de um poro 32

Figura 16 Rede de capilares contendo 7 nós e 10 capilares. A seta, por definição, saí de um nó menor e entra em um nó maior

Figura 17 Fluxograma da modelagem para fluido não-Newtoniano em regime $\begin{array}{ll}\text { permanente } & 39\end{array}$

Figura 18 Deslocamento pistão em um capilar 42

Figura 19 Deslocamento de um fluido por outro num capilar (drenagem e embibição) 43

Figura 20 Pressão capilar em função da posição da interface 44

Figura 21 Pressão capilar em função da posição da interface 44 
Figura 22 Posição das interfaces em um elemento

Figura 23 Fluido molhante invadindo um fluido não molhante 47

Figura 24 Dinâmica entre as interfaces

Figura 25 As três interfaces em uma única garganta (capilar esquerdo) são fundidas para formar uma interface

Figura 26 Fluxograma da modelagem do escoamento de soluções poliméricas através de um meio poroso saturado com óleo

Figura 27 Gráfico de permeabilidade obtido a partir de simulação

Figura 28 Queda de pressão ao longo do micromodelo

Figura 29 Curvas de vazão - queda de pressão para o modelo power law

Figura 30 Curvas para o modelo power-law comparando com a equação de Pascal e Pascal(1989)

Figura 31 Curvas para o modelo de Carreau variando os índices de potência do fluido e a viscosidade Newtoniana zero.

Figura 32 Curva de pressão em função da taxa de injeção para um modelo de viscosidade extensional

Figura 33 Simulação (1) - Mapa de saturação para um fluido Newtoniano em quatro instantes de tempo

Figura 34 Simulação (1) - Curva de saturação e pressão de entrada em função do volume poroso injetado.

Figura 35 Simulação (1) - Curva de saturação em função da posição no eixo x para diferentes instantes de tempo.

Figura 36 Simulação (2) - Mapa de saturação para um fluido Newtoniano em quatro instantes de tempo

Figura 37 Simulação (2) - Curva de saturação e pressão de entrada em função do volume poroso injetado.

Figura 38 Simulação (2) - Curva de saturação em função da posição no eixo x para diferentes instantes de tempo.

Figura 39 Simulação (3) - Mapa de saturação para um fluido Newtoniano em quatro instantes de tempo

Figura 40 Simulação (3) - Curva de saturação e pressão de entrada em função do volume poroso injetado.

Figura 41 Simulação (3) - Curva de saturação em função da posição no eixo x para diferentes instantes de tempo. 
Figura 42 Simulação (4) - Mapa de saturação para um fluido Newtoniano em quatro instantes de tempo

Figura 43 Simulação (4) - Curva de saturação e pressão de entrada em função do volume poroso injetado.

Figura 44 Simulação (4) - Curva de saturação em função da posição no eixo x para diferentes instantes de tempo.

Figura 45 Simulação (5) - Mapa de saturação para um fluido Newtoniano em quatro instantes de tempo.

Figura 46 Simulação (5) - Curva de saturação e pressão de entrada em função do volume poroso injetado.

Figura 47 Simulação (5) - Curva de saturação em função da posição no eixo x para diferentes instantes de tempo.

Figura 48 Simulação (6) - Mapa de saturação para um fluido Newtoniano em quatro instantes de tempo

Figura 49 Simulação (6) - Zoom do mapa de saturação no segundo instante. 71 Figura 50 Simulação (6) - Curva de saturação e pressão de entrada em função do volume poroso injetado.

Figura 51 Simulação (6) - Curva de saturação em função da posição no eixo x para diferentes instantes de tempo.

Figura 52 Simulação (7) - Mapa de saturação para um fluido não-Newtoniano em quatro instantes de tempo

Figura 53 Simulação (7) - Zoom do mapa de saturação no segundo instante. 73 Figura 54 Simulação (7) - Curva de saturação e pressão de entrada em função do volume poroso injetado.

Figura 55 Simulação (7) - Curva de saturação em função da posição no eixo x para diferentes instantes de tempo.

Figura 56 Simulação (8) - Mapa de saturação para um fluido não-Newtoniano em quatro instantes de tempo

Figura 57 Simulação (8) - Zoom do mapa de saturação no segundo instante. 75 Figura 58 Simulação (8) - Curva de saturação e pressão de entrada em função do volume poroso injetado.

Figura 59 Simulação (8) - Curva de saturação em função da posição no eixo x para diferentes instantes de tempo. 
Figura 60 Simulação (9) - Mapa de saturação para um fluido não-Newtoniano em quatro instantes de tempo 76

Figura 61 Simulação (9) - Zoom do mapa de saturação no segundo instante. 77

Figura 62 Simulação (9) - Curva de saturação e pressão de entrada em função do volume poroso injetado.

Figura 63 Simulação (9) - Curva de saturação em função da posição no eixo x para diferentes instantes de tempo.

Figura 64 Simulação (10) - Mapa de saturação para um fluido não-Newtoniano em quatro instantes de tempo

Figura 65 Simulação (10) - Zoom do mapa de saturação no segundo instante. 79

Figura 66 Simulação (10) - Curva de saturação e pressão de entrada em função do volume poroso injetado.

Figura 67 Simulação (10) - Curva de saturação em função da posição no eixo $\mathrm{x}$ para diferentes instantes de tempo.

Figura 68 Simulação (11) - Mapa de saturação para um fluido Newtoniano em quatro instantes de tempo

Figura 69 Simulação (11) - Zoom do mapa de saturação no segundo instante. 82 Figura 70 Simulação (11) - Curva de saturação e pressão de entrada em função do volume poroso injetado.

Figura 71 Simulação (11) - Curva de saturação em função da posição no eixo $\mathrm{x}$ para diferentes instantes de tempo.

Figura 72 Simulação (12) - Mapa de saturação para um fluido não-Newtoniano em quatro instantes de tempo

Figura 73 Simulação (12) - Zoom do mapa de saturação no segundo instante. 84 Figura 74 Simulação (12) - Curva de saturação e pressão de entrada em função do volume poroso injetado.

Figura 75 Simulação (12) - Curva de saturação em função da posição no eixo $\mathrm{x}$ para diferentes instantes de tempo.

Figura 76 Simulação (13) - Mapa de saturação para um fluido não-Newtoniano em quatro instantes de tempo

Figura 77 Simulação (13) - Zoom do mapa de saturação no segundo instante. 86 Figura 78 Simulação (13) - Curva de saturação e pressão de entrada em função do volume poroso injetado. 
Figura 79 Simulação (13) - Curva de saturação em função da posição no eixo $\mathrm{x}$ para diferentes instantes de tempo.

Figura 80 Simulação (14) - Mapa de saturação para um fluido não-Newtoniano em quatro instantes de tempo

Figura 81 Simulação (14) - Zoom do mapa de saturação no segundo instante. 88 Figura 82 Simulação (14) - Curva de saturação e pressão de entrada em função do volume poroso injetado.

Figura 83 Simulação (14) - Curva de saturação em função da posição no eixo $\mathrm{x}$ para diferentes instantes de tempo.

Figura 84 Simulação (15) - Mapa de saturação para um fluido não-Newtoniano em quatro instantes de tempo

Figura 85 Simulação (15) - Zoom do mapa de saturação no segundo instante. 90 Figura 86 Simulação (15) - Curva de saturação e pressão de entrada em função do volume poroso injetado. Figura 87 Simulação (15) - Curva de saturação em função da posição no eixo $\mathrm{x}$ para diferentes instantes de tempo.

Figura 88 Curvas de saturação em função do número de capilaridade 


\section{Lista de Tabelas}

Tabela 1 Modelos utilizados para calcular a viscosidade de um fluido nãoNewtoniano

Tabela 2 - Simulação (1) - Parâmetros e resultados finais obtidos para um fluido Newtoniano

Tabela 3 - Simulação (2) - Parâmetros e resultados finais obtidos para um fluido Newtoniano

Tabela 4 - Simulação (3) - Parâmetros e resultados finais obtidos para o escoamento de um fluido Newtoniano

Tabela 5 - Simulação (4) - Parâmetros e resultados finais obtidos para o escoamento de um fluido Newtoniano

Tabela 6 - Simulação (5) - Parâmetros e resultados finais obtidos para o escoamento de um fluido Newtoniano

Tabela 7 - Simulação (6) - Parâmetros e resultados finais obtidos para o escoamento de um fluido não-Newtoniano

Tabela 8 - Simulação (7) - Parâmetros e resultados finais obtidos para o escoamento de um fluido não-Newtoniano

Tabela 9 - Simulação (8) - Parâmetros e resultados finais obtidos para o escoamento de um fluido não-Newtoniano

Tabela 10 - Simulação (9) - Parâmetros e resultados finais obtidos para o escoamento de um fluido não-Newtoniano

Tabela 11 - Simulação (10) - Parâmetros e resultados finais obtidos para o escoamento de um fluido não-Newtoniano

Tabela 12 - Simulação (11) - Parâmetros e resultados finais obtidos para o escoamento de um fluido não-Newtoniano

Tabela 13 - Simulação (12) - Parâmetros e resultados finais obtidos para o escoamento de um fluido não-Newtoniano

Tabela 14 - Simulação (13) - Parâmetros e resultados finais obtidos para o escoamento de um fluido não-Newtoniano

Tabela 15 - Simulação (14) - Parâmetros e resultados finais obtidos para o escoamento de um fluido não-Newtoniano

Tabela 16 - Simulação (15) - Parâmetros e resultados finais obtidos para o escoamento de um fluido não-Newtoniano 
Tabela 17 - Parâmetros e resultados finais obtidos para entender os números de capilaridade 


\section{Introdução}

\subsection{Motivação}

No final do século XVIII, deu-se início a Primeira Revolução Industrial, quando a ciência descobriu a utilidade do carvão como fonte de energia. Desde então, novas tecnologias têm sido desenvolvidas para suprir essa demanda.

A indústria do petróleo está no centro das questões energéticas enfrentadas pelas sociedades modernas. O consumo mundial de energia é muito grande e continuará crescendo nos próximos anos. Em 2013, o petróleo representava cerca de 40\% desta demanda (INTERNATIONAL ENERGY AGENCY, 2015). Assim posto, torna-se primordial o desenvolvimento de técnicas diversas para expandir a eficiência da recuperação de óleo nos reservatórios.

\subsection{Processos de recuperação de petróleo}

Durante a vida produtiva de um reservatório são empregados diferentes processos de recuperação do petróleo com a finalidade de intensificar a eficiência da produção. De um modo geral, os procedimentos para a recuperação são divididos em: primário, secundário e avançado (EOR) (GREEN e WILLHITE, 1998). A seguir é apresentada uma breve descrição desses métodos.

\subsubsection{Método de recuperação primária}

Durante a fase inicial, a produção de óleo ocorre em virtude dos mecanismos naturais do reservatório. O deslocamento do óleo até a superfície acontece pela diferença de pressão entre o reservatório e o meio externo. Com o passar do tempo esta diferença de pressão cai e é necessário o fornecimento de energia externa, na forma de injeção de fluidos para aumentar a pressão do reservatório. Além disso, existem reservatórios de óleo que, embora contendo grandes quantidades de óleo, são incapazes de serem produzidos por meio de técnicas de recuperação primária. 


\subsubsection{Método de recuperação secundária}

Identificou-se que na maioria dos reservatórios, apenas uma pequena porcentagem do óleo estava sendo recuperada durante o período de produção primária, em razão do esgotamento de energia natural dos reservatórios. Com isso, técnicas de recuperação secundária foram desenvolvidas para aumentar o volume de óleo produzido. O principal método de recuperação secundária é a injeção de água, que apresenta diversas vantagens quando comparada a outros métodos. A água é pouco custosa e funciona bem no deslocamento do óleo na grande maioria dos casos.

A injeção de água foi feita pela primeira vez de forma sistemática no campo petrolífero Bradford na Pennsylvania, EUA (FETTKE, 1938). A reinjeção de água salina no reservatório surgiu como uma excelente alternativa, tanto no ponto de vista funcional quanto econômico, para o aumento da recuperação dos campos de petróleo.

Todavia, essa técnica possui baixa eficiência graças a chegada precoce de água injetada: a viscosidade da água é muito menor do que a do fluido a ser deslocado, movendo-se muito mais facilmente no meio poroso, encontrando canais preferenciais e se dirigindo rapidamente aos poços de produção. Este efeito pode ser quantificado através razão de mobilidade entre a água e o óleo, dada por:

$$
M=\frac{\left(k_{w} / \mu_{w}\right)}{\left(k_{o} / \mu_{o}\right)}=\frac{k_{w}}{\mu_{w}} \cdot \frac{\mu_{o}}{k_{o}}
$$

onde $k_{w}$ é a permeabilidade relativa a água, $k_{o}$ é a permeabilidade relativa ao óleo, $\mu_{w}$ é a viscosidade da água e $\mu_{o}$ é a viscosidade do óleo.

\subsubsection{Método de recuperação terciária}

Em busca de um processo de recuperação economicamente viável, diversos métodos de recuperação avançada de petróleo foram desenvolvidos para minimizar os problemas relacionados com a injeção de água:

- Métodos miscíveis: injeção de $\mathrm{CO}_{2}$, gás natural ou nitrogênio;

- Métodos térmicos: injeção de água quente, injeção cíclica de vapor ou combustão in-situ; 
- Métodos químicos: injeção de tensoativos, solução alcalina, polímeros ou emulsões.

Neste trabalho, será exposto um estudo detalhado da injeção de soluções poliméricas em meios porosos.

\subsection{Injeção de soluções poliméricas em meios porosos}

A injeção de soluções poliméricas no reservatório é uma técnica que vem ganhando muita visibilidade nos últimos anos em razão de resultados eficientes e da indicação do sucesso no retorno do investimento. Porém o comportamento do escoamento de soluções poliméricas em meios porosos não é totalmente compreendido (LARSON, 2013).

Este método tem como principal finalidade o aumento da viscosidade da água através da adição de polímeros, reduzindo a razão de mobilidade entre os fluidos molhante e não-molhante. Com isso, a formação de viscous fingering, isto é, caminhos preferenciais da água no óleo, é diminuída levando a uma frente de deslocamento mais uniforme. Na figura 1, podemos observar o aumento da eficiência de varrido no reservatório devido à redução do viscous fingering retardando a produção de água no poço produtor e aumentando o volume de óleo produzido.
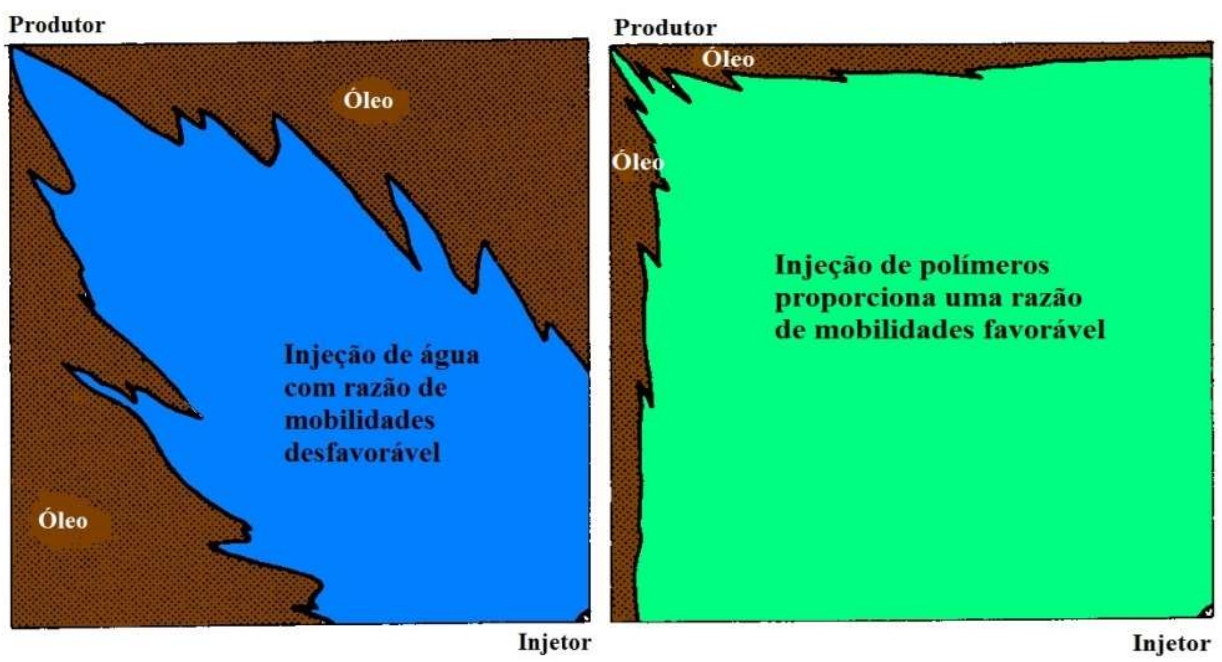

Figura 1 (a) Formação de viscous fingering durante a injeção de solução aquosa (b) Varredura mais uniforme com a injeção de soluções poliméricas

Além da formação de uma frente de deslocamento não uniforme, a injeção de água pode levar a uma alta saturação residual de óleo. Os gânglios de óleo ficam imobilizados por ação das forças capilares. Trabalhos recentes mostram que a injeção de polímeros 
pode também reduzir a saturação residual de óleo em áreas varridas inicialmente pela água. Este mecanismo é ilustrado na figura 2.

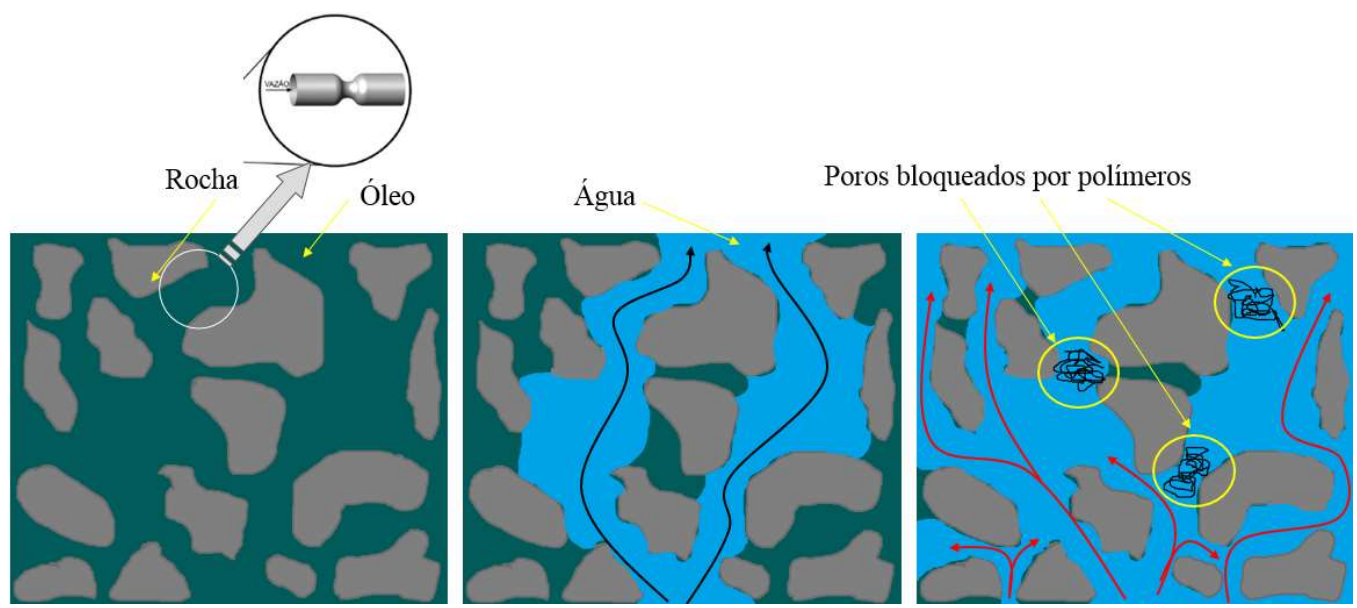

Figura 2 Escoamento de uma solução polimérica através de um meio poroso

\subsubsection{Exemplos na indústria}

Pesquisas têm sido direcionadas a entender o comportamento do escoamento de soluções poliméricas na escala de poros para aperfeiçoar a eficiência do método em questão. Exemplo disso é constatado na análise do trabalho desenvolvido por Sandiford (SANDIFORD, 1964) onde são mostrados resultados promissores sobre a utilização de alguns polímeros no incremento da recuperação de óleo.

A aplicação do método tem se tornado mais frequente em virtude das excelentes respostas reportadas de sua aplicação em larga escala no campo de petróleo de Daqing, na China, com produções incrementais de até 300.000 barris por dia (WANG e colab., 2001). O campo de Mangala, um dos maiores campos onshore da Índia, é outro exemplo bem-sucedido da injeção de polímeros que teve início em 2011. Os resultados do projeto piloto têm ajudado na obtenção de experiência operacional, estabelecendo procedimentos de controle de qualidade para aplicação em todo o campo (PRASAD e colab., 2014).

\subsubsection{Comportamento viscoelástico de soluções poliméricas}

Além do efeito causado pelo aumento de viscosidade com a adição de polímeros na água, o comportamento viscoelástico pode contribuir para o aumento da eficiência de deslocamento na escala de poro. 
Materiais viscoelásticos exibem uma dupla natureza de comportamento, apresentando comportamento de fluidos viscosos e sólidos elásticos, dependendo da taxa de deformação que são submetidos.

Um líquido sofre uma deformação extensional ao passar por uma garganta de poro, como esquematizado na figura 3. No caso de soluções poliméricas com moléculas longas e flexíveis, a extensão das moléculas leva a um aumento da diferença de pressão. Esse aumento da pressão do escoamento extensional pode contribuir para a redução da saturação residual de óleo (AFSHARPOOR e colab., 2012).

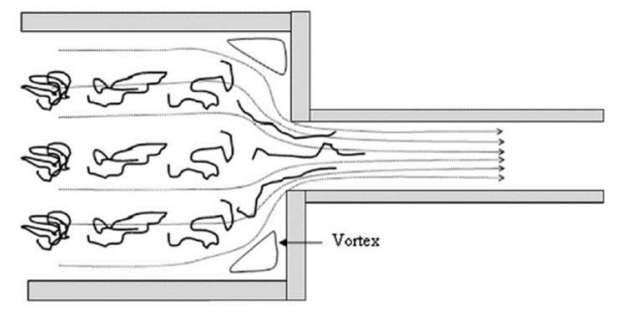

Figura 3 Moléculas de polímero passando por uma garganta (AL HASHMI e colab., 2013)

Existem dificuldades inerentes à caracterização dos efeitos não-Newtonianos de soluções de polímero no escoamento através de um meio poroso. A geometria local do meio poroso dá origem a uma rede complexa e dependente dos fluxos nos poros no qual efeitos de cisalhamento e de extensão coexistem em proporções que não podem ser quantificadas precisamente.

\subsubsection{Comportamento viscoelástico em meios porosos}

No fluxo em meio poroso, a principal manifestação de efeitos viscoelásticos em regime permanente é a queda de pressão excessiva em diferentes regimes de fluxo acima do que é contabilizado pelas forças viscosas. Qualitativamente, este comportamento foi atribuído a efeitos de memória ou a viscosidade extensional (BIRD e colab., 1987). Além disso, a geometria do meio poroso deve ser levada em conta quando se considera as respostas elásticas. Em baixas vazões, a queda de pressão é determinada em grande parte pelos efeitos viscosos. Acima de uma determinada vazão crítica, as forças elásticas (caracterizada pela viscosidade extensional) passam a ser da mesma ordem de grandeza das forças viscosas. 


\subsection{Análise em escala de poros}

\subsubsection{Micromodelos e sua utilização em escoamento em meios porosos}

O desenvolvimento da concepção de micromodelos que representam o escoamento na escala de poro deu-se após o avanço de tecnologias de produção de microcanais e microdispositivos. A fim de compreender os fenômenos na escala de poros, redes de microcanais são estudadas através de modelos transparentes. Os micromodelos bidimensionais são compostos basicamente por gargantas e poros como visto na figura 4 (KUMAR GUNDA e colab., 2011).

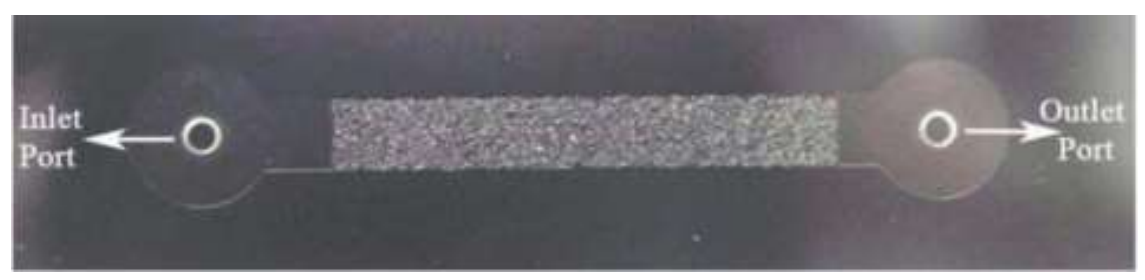

Figura 4 Micromodelo utilizado (KUMAR GUNDA e colab., 2011)

\subsubsection{Micromodelo utilizado}

Com o objetivo de analisar o deslocamento de óleo através da injeção de soluções poliméricas em escala de poro, Lima e Carvalho (LIMA e CARVALHO, 2015) utilizaram um dispositivo de microfluídica que reproduz artificialmente um meio poroso. $\mathrm{O}$ dispositivo é composto de microcanais interconectados com constrições de diferentes tamanhos que simulam as gargantas de poros em um meio poroso. Este trabalho foi desenvolvido usando os parâmetros geométricos do micromodelo mostrado na figura 5 . O micromodelo é composto por 19000 capilares com três diferentes áreas na garganta. O dispositivo ainda possui dois orifícios simétricos, um para entrada e outro para saída e 9600 poros interconectados pelos capilares ao longo da rede.

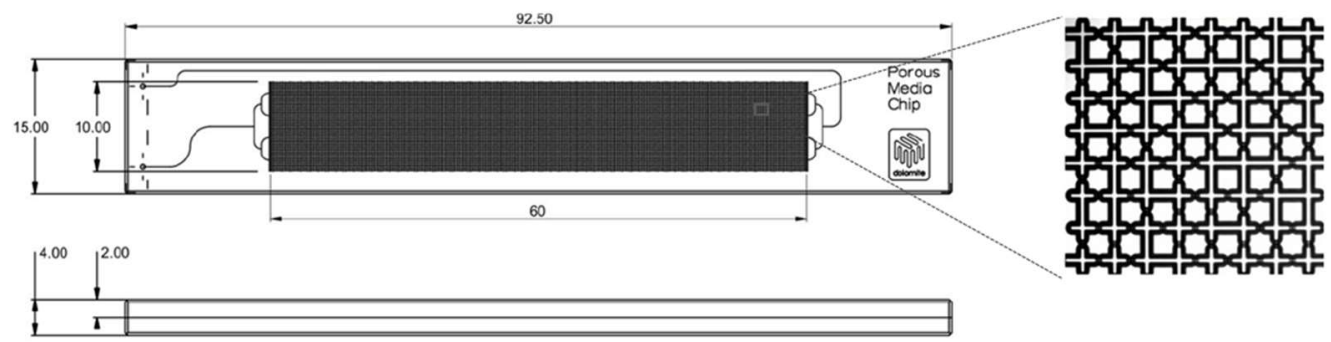

Figura 5 Micromodelo de vidro desenvolvido pela Dolomite 


\subsubsection{Modelo de rede de capilares}

Novas técnicas de análise de imagens têm sido desenvolvidas a fim de representar a geometria e topologia do meio poroso em diferentes tipos de rocha. Desta forma é possível o desenvolvimento de descrições geométricas cada vez mais realistas do espaço poroso. A figura 6 apresenta um modelo de uma amostra de arenito (ØREN e BAKKE, 2003). No modelo de redes, os poros são evidenciados por nós (verde) e as gargantas que conectam os poros são representadas por capilares (azul).
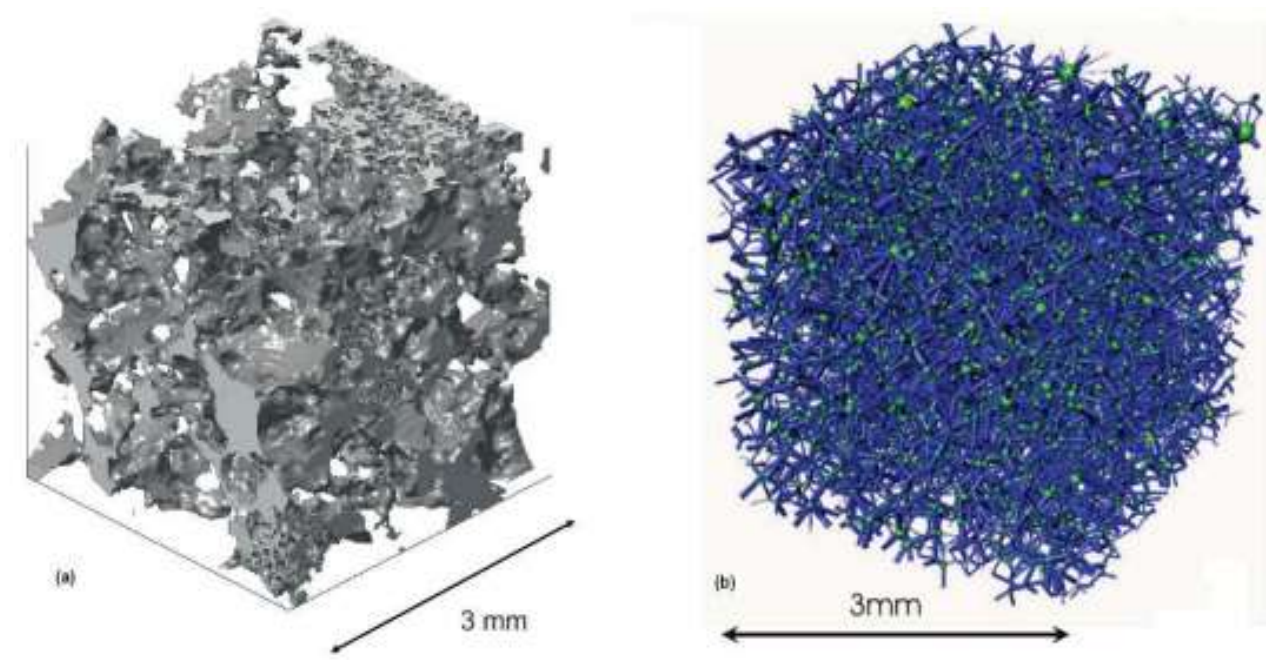

Figura 6 (a) Representação de uma rocha porosa (b) Rede de capilares (ØREN e BAKKE, 2003)

Com o trabalho de Fatt (FATT, 1956), estudar diferentes processos de deslocamento em meios porosos têm sido possível através da utilização ampla de modelo de rede de capilares. A título de exemplo, Blunt e King (BLUNT e KING, 1988) descreveram um modelo de rede hexagonal e, posteriormente, um modelo de rede em escala de poro foi desenvolvido onde os poros foram modelados como esferas e as gargantas como tubos cilíndricos (BLUNT e colab., 1992).

\subsection{Objetivos do trabalho}

Apesar dos progressos recentes, a compreensão de como as propriedades viscoelásticas de uma solução polimérica podem favorecer o aumento na recuperação de óleo não é completa. Devido à complexidade do fluxo, têm-se analisado diferentes mecanismos para a mobilização do óleo residual nos poros. A importância relativa de 
cada um destes mecanismos não está clara e o efeito do comportamento viscoelástico na mobilização de óleo na escala de poros não foi estudado de forma sistemática.

A delimitação de condições ótimas de operação é o pressuposto para o alto desempenho dos procedimentos de recuperação melhorada de petróleo. Desta forma, este trabalho tem por objetivo desenvolver um modelo de rede de capilares que considere a estrutura do espaço poroso e características das soluções poliméricas para ser usado na análise do escoamento no meio poroso, buscando enriquecer o entendimento dos mecanismos envolvidos no processo de injeção de soluções poliméricas. Como as soluções poliméricas são fluidos não-Newtonianos, foi elaborado um modelo não-linear para descrever a relação vazão - diferença de pressão no meio poroso. Para isso, desenvolvemos dois modelos de rede de capilares, um modelo para o fluxo monofásico em regime permanente e outro modelo dinâmico a fim de entender o deslocamento de óleo através da injeção de soluções poliméricas. 


\section{Modelo de rede de capilares}

Os modelos de rede têm sido usados para estudar o escoamento na escala de poros e obter parâmetros macroscópicos de escoamento baseados nos fenômenos físicos que ocorrem na escala microfluídica. As previsões são baseadas na representação do espaço vazio de uma rocha, em termos de poros ligados por gargantas estreitas que formam uma rede. A física da escala de poros adequada combinada com uma descrição geométrica representativa do espaço poroso fornecem modelos que conseguem prever o comportamento do fluido no meio poroso (BLUNT, 2001). A rede é composta por nós, que representam os poros, e capilares, que representam as gargantas de poros.

Neste trabalho foi desenvolvido um modelo de rede de capilares para prever a relação entre a viscosidade aparente e o fluxo em meios porosos, utilizando uma rede de poros conectada por capilares que representam o meio poroso. Expressões analíticas foram usadas para descrever a viscosidade efetiva em cada um dos capilares como uma função da vazão local, utilizando-se diferentes modelos de viscosidade. A utilização de modelos não-Newtonianos torna o problema não-linear, com solução bem mais complexa.

\subsection{Geometria do meio poroso}

A geometria do microdispositivo é formada por uma rede de canais com seção reta quase circular (altura do canal $=100 \mu \mathrm{m}$ e largura do canal $=110 \mu \mathrm{m}$ ) que reproduz artificialmente um meio poroso. A área porosa do microchip tem um desenho de 10 x 60 $\mathrm{mm}$ e dois orifícios simétricos, um na entrada e outro na saída do dispositivo conforme ilustrado na figura 7.

O micromodelo é formado repetindo o arranjo de capilares (150 vezes) visto na figura 8. $\mathrm{O}$ arranjo que forma o micromodelo é constituído de uma rede com 64 canais (8 x 8). Como arranjo da rede se repede, a da extração da geometria foi feita de forma manual. 


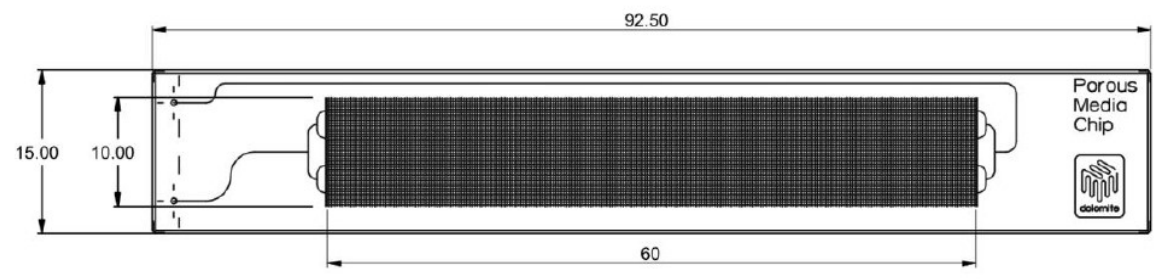

Figura 7 Visão macroscópica do micromodelo 2D desenvolvido pela Dolomite
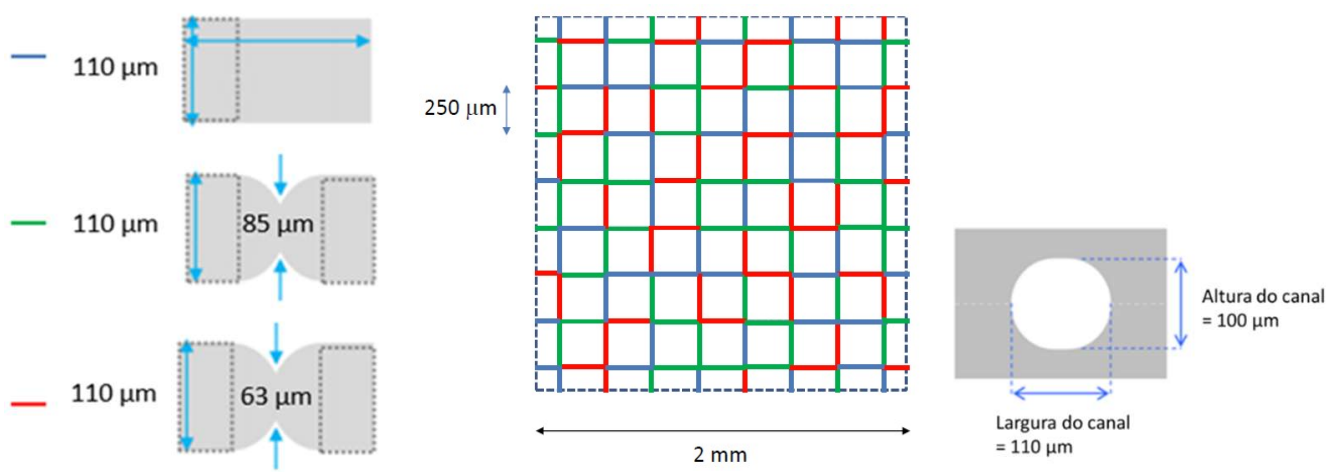

Figura 8 Dimensões do micromodelo e dimensões dos canais.

A rede é formada por capilares com 3 tamanhos de garganta como visto na figura 8. Os canais na rede são distribuídos aleatoriamente, onde temos 38 capilares com o menor diâmetro $(63 \mu \mathrm{m}), 40$ capilares com o diâmetro intermediário $(85 \mu \mathrm{m})$ e 50 capilares sem garganta $(110 \mu \mathrm{m})$.

Para compensar a descontinuidade da área cilíndrica um raio equivalente, $R_{e}$, é usado:

$$
\begin{aligned}
& \frac{L}{R_{e}{ }^{4}}=2\left(\frac{L_{x}}{R^{4}}+\int_{x l}^{x r} \frac{d x}{\left(R^{2}-x^{2}\right)^{2}}\right) \\
& R_{e}=\left(\frac{L}{2\left(\int_{x l}^{x r} \frac{d x}{\left(R^{2}-x^{2}\right)^{2}}+\frac{L_{x}}{R^{4}}\right)}\right)^{1 / 4},
\end{aligned}
$$

onde L é comprimento do capilar, $L_{x}$ é o comprimento da seção reta do capilar, R é o raio da seção reta e o intervalo $\left(x_{l}, x_{r}\right)$ é o comprimento da seção circular do capilar que estão representados na figura 9. 


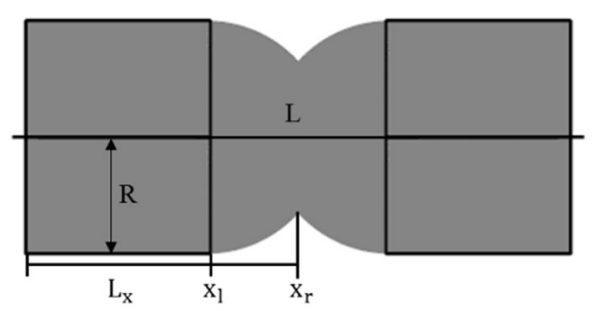

Figura 9 Garganta de um capilar da rede

\subsubsection{Porosidade efetiva}

Vargas (2014) calculou o volume poroso do microchip experimentalmente através da razão entre o volume poroso e o volume total do micromodelo. Utilizando uma balança eletrônica, pesou o meio poroso saturado. Subtraindo o peso úmido do peso seco é possível estimar o volume ocupado pelo fluido no dispositivo, isto é, seu volume poroso. O volume encontrado foi de 30 microlitros e a porosidade foi de aproximadamente $50 \%$.

\subsubsection{Condutância hidráulica}

A vazão, $q_{i j}$, entre dois poros, denominados de poro i e poro $\mathrm{j}$, conectados por um capilar, como mostrado na figura 10, e considerando as hipóteses de fluido incompressível, é dado pela seguinte equação:

$$
q_{i j}=G_{i j}\left(P_{i}-P_{i}\right)
$$

onde $G_{i j}$ é a constante de proporcionalidade entre a vazão, $q_{i j}$, e a diferença de pressão, $\Delta P_{i j}$, também conhecido como condutância hidráulica entre os dois poros conectados. $P_{i}$ e $P_{j}$ são as pressões do fluido nos poros i e j, respectivamente.

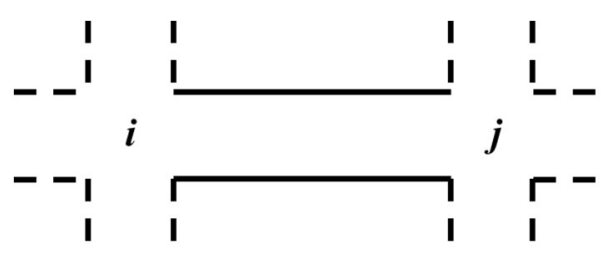

Figura 10 Representação geométrica da condutância do poro i, j e do capilar

Para estabelecer a condutância hidráulica em um escoamento monofásico de um fluido Newtoniano em tubos de seção transversal uniforme é possível usar a equação de 
Hagen-Poiseuille, que é derivada das equações de Navier-Stokes considerando-se as hipóteses de escoamento laminar, desenvolvido, incompressível, isotérmico e em regime permanente. Com isso, a condutância hidráulica, $G$, de um capilar é dada pela equação:

$$
G=\frac{\pi R_{e}^{4}}{8 \mu L}
$$

onde $R_{e}$ é o raio equivalente do capilar, $\mu$ é a viscosidade da configuração do fluido no capilar e $L$ é o comprimento do capilar.

\subsection{Escoamento monofásico em regime permanente}

Muitos pesquisadores têm procurado relacionar as propriedades reológicas de fluidos complexos com o seu escoamento em um meio poroso. No caso de um fluido Newtoniano, a viscosidade é conhecida. Já para o caso de um fluido não-Newtoniano, um modelo de viscosidade em função da taxa de deformação deve ser utilizado para determinar a viscosidade efetiva em cada capilar em função da vazão e geometria local.

\subsubsection{Fluido Newtoniano}

Fluidos Newtonianos são definidos como sendo aqueles que apresentam uma relação linear entre a tensão, $\tau$, e taxa de deformação, $\dot{\gamma}$, em fluxo laminar:

$$
\tau=\mu \dot{\gamma}
$$

onde a viscosidade, $\mu$, é independente da taxa de deformação embora possa ser afetada por outros parâmetros físicos, tais como a temperatura e a pressão, para um dado fluido.

\subsubsection{Fluido não-Newtoniano}

Os modelos de rede foram originalmente desenvolvidos para estudar o fluxo multifásico de fluidos Newtonianos. No entanto, a mesma abordagem foi utilizada por diversos autores para investigar fenômenos de transporte de fluidos não-Newtonianos em que a viscosidade segue uma lei da potência (power-law). 
Pearson e Tardy (PEARSON e TARDY, 2002) estudaram o fluxo de um fluido power-law em uma rede bidimensional. Uma série de conclusões foram tiradas a partir de seus cálculos.

Fluidos não-Newtonianos não apresentam o comportamento linear descrito na equação 2.3. O comportamento não-Newtoniano mais comum é a variação de viscosidade com a taxa de cisalhamento, $\mu=\mu(\dot{\gamma})$. A forma da relação tensão/taxa de cisalhamento depende da natureza do fluido. Soluções poliméricas podem também apresentar um comportamento viscoelástico. Este comportamento pode se manifestar por um aumento da viscosidade extensional (constante e igual a $3 \mu$ para fluidos Newtonianos) com a taxa de extensão.

A maioria dos fluidos viscoelásticos são soluções de polímeros e, por conseguinte, possuem características cisalhantes. No entanto, há uma classe de fluidos viscoelásticos, conhecida como fluidos de Boger, nos quais a viscosidade é quase independente da taxa de cisalhamento (BOGER, 1978). Os fluidos de Boger são particularmente importantes porque permitem que os efeitos elásticos sejam estudados separadamente dos efeitos cisalhantes. Comparando os resultados do fluxo de um fluido de Boger com os do fluxo de um fluido newtoniano ao mesmo número de Reynolds permite-se avaliar a influência da viscoelasticidade. Com isso, a capacidade de distinguir entre efeitos elásticos e visuais tem avançado significativamente no campo da reologia experimental e computacional, pois a influência da elasticidade pode ser isolada de maneira direta (JAMES, 2009).

A complexidade do fluxo através de meios porosos, em geral, decorre da coexistência de deformação cisalhante e extensional no escoamento através das gargantas de poros. Tipicamente, soluções poliméricas apresentam um comportamento pseudoplástico. A viscosidade varia com a taxa de cisalhamento como pode ser visto de forma esquematizada na figura 11. A viscosidade é constante a baixas e altas taxas de cisalhamento entre os casos limites. 


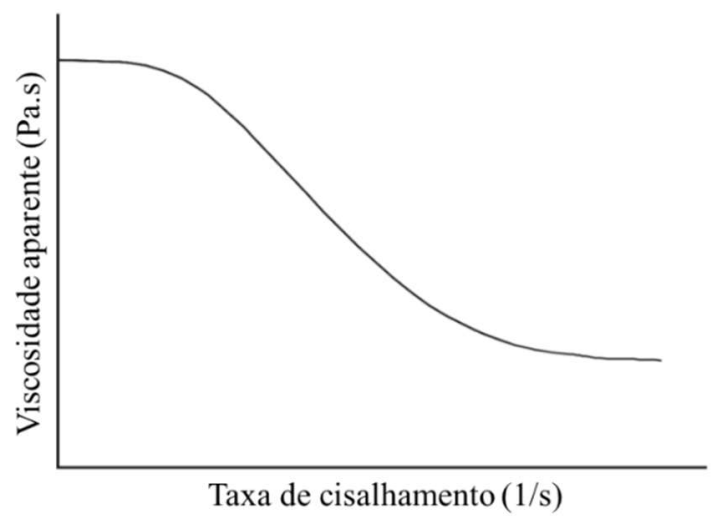

Figura 11 Comportamento típico de um fluido pseudoplástico. Viscosidade de cisalhamento em função da taxa de cisalhamento, $\dot{\gamma}$, em escalas de log-log.

\subsubsection{Modelo de lei da potência (power-law)}

A principal vantagem deste modelo reside na simplicidade, uma vez que contém apenas dois parâmetros. É relativamente fácil incorporar modelos que descrevem escoamentos simples.

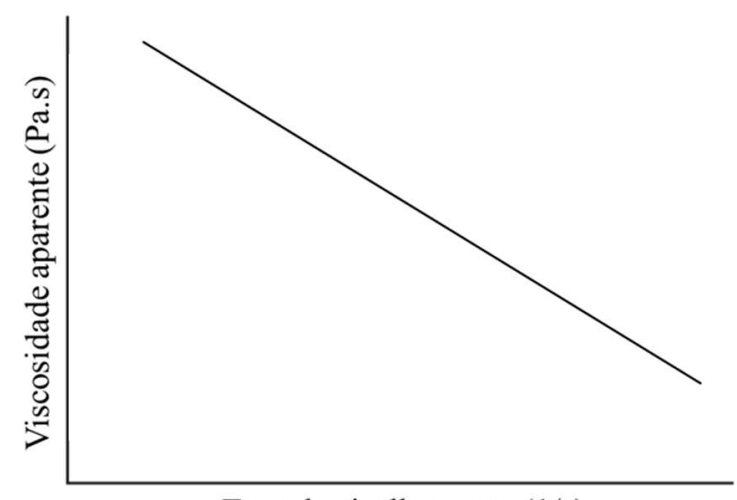

Taxa de cisalhamento $(1 / \mathrm{s})$

Figura 12 Comportamento de um fluido tipo lei-de-potência. Viscosidade de cisalhamento em função da taxa de cisalhamento, $\dot{\gamma}$, em escalas de log-log.

A variação da viscosidade é descrita pela relação:

$$
\mu=m \dot{\gamma}^{n-1}
$$

onde $\mu$ é a viscosidade, $m$ é o índice de consistência, $n$ é o índice power-law e $\dot{\gamma}$ é a taxa de cisalhamento. Para um tubo circular, a taxa de cisalhamento na parede do tubo é função do raio, $R$, e da vazão, $q_{\text {cap }}$, como apresentado na equação 2.6 : 


$$
\dot{\gamma}=\left(\frac{4 q_{\text {cap }}}{\pi R^{3}}\right)\left(\frac{1}{n}+3\right)
$$

O fluxo de um fluido power-law em um meio poroso também pode ser descrito por uma lei de Darcy modificada. Esta equação (Pascal \& Pascal, 1989) pode ser escrita incluindo o comportamento reológico do fluido, como visto na equação 2.7:

$$
u=\left(\frac{1}{2 m}\left(\frac{n \varepsilon}{1+3 n}\right)^{n}\left(\frac{8 k}{\varepsilon}\right)^{n+1 / 2}\left(\frac{\Delta P}{L}\right)\right)^{1 / n}
$$

Onde $u$ é a velocidade média do modelo empírico, $m$ é o índice de consistência do fluido, $\Delta P$ é a diferença de pressão no meio poroso, $k$ é a permeabilidade, $\varepsilon$ é a porosidade, $L$ é o comprimento do meio e $n$ é índice de potência do fluido.

No entanto, o modelo power-law não pode descrever o comportamento fora da região pseudoplástica, ou seja, para valores pequenos ou grandes de taxas de cisalhamento, onde ele prevê valores de viscosidade que tendem para infinito ou para zero.

\subsubsection{Carreau-Yasuda}

Vários outros modelos de viscosidade foram desenvolvidos no passado para descrever o comportamento reológico completo de soluções pseudoplásticas. O modelo mais importante é o de Carreau-Yasuda (CARREAU, 1972). Este modelo descreve os valores limites de viscosidade para taxas de cisalhamento elevadas ou baixas.

O modelo de Carreau-Yasuda na sua forma geral é escrito como:

$$
\frac{\mu-\mu_{\infty}}{\mu_{0}-\mu_{\infty}}=\left[1+(\lambda \dot{\gamma})^{2}\right]^{\frac{n-1}{\alpha}}
$$

O modelo apresenta 5 parâmetros: $\mu_{\infty}$ é a viscosidade Newtoniana a altas taxas de cisalhamento, $\mu_{0}$ é a viscosidade Newtoniana a baixas taxas de cisalhamento, $\lambda$ é o tempo de relaxação, o $n$ é índice de potência, $\alpha$ é um parâmetro que descreve a transição entre a região de viscosidade constante (altas e baixas taxas de cisalhamento) e a região de 
potência. O modelo de Carreau-Yasuda é muitas vezes reduzido a sua expressão quando $\alpha=2$, também chamado simplesmente modelo de Carreau.

\subsubsection{Viscosidade extensional}

Resultados experimentais mostram que a queda de pressão do escoamento de soluções poliméricas através de canais com contração e expansão pode aumentar com a vazão (ROTHSTEIN e MCKINLEY, 1999). Este comportamento está diretamente relacionado a viscosidade extensional do fluido. Soluções poliméricas de alto peso molecular apresentam uma viscosidade extensional que aumenta com a taxa de extensão (extensional thickening) devido a energia necessária para esticar as cadeias moleculares.

Como um meio poroso pode ser modelado como uma rede de tubos com gargantas, o comportamento do escoamento de uma solução polimérica através do meio pode apresentar um aumento da resistência ao escoamento com o aumento da vazão.

O comportamento de soluções viscoelásticas é descrito neste trabalho por um modelo que assume uma resistência ao escoamento em cada capilar (representado pela viscosidade) em função da taxa de extensão, $\dot{\varepsilon}$. Esta é uma função da geometria do capilar, como pode ser visto na figura 13 , e da vazão, $Q$.

$$
\dot{\varepsilon}=\frac{Q}{L D_{1}^{2}}\left(\left(\frac{D_{1}}{D_{2}}\right)^{2}-1\right)
$$

onde $D_{1}$ é o diâmetro do capilar, $D_{2}$ é o diâmetro da garganta e $L$ é o comprimento do capilar.

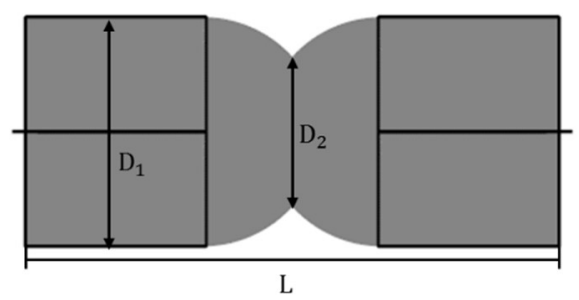

Figura 13 Geometria do capilar

O comportamento típico da viscosidade extensional em função da taxa de extensão é apresentado na figura 14. 


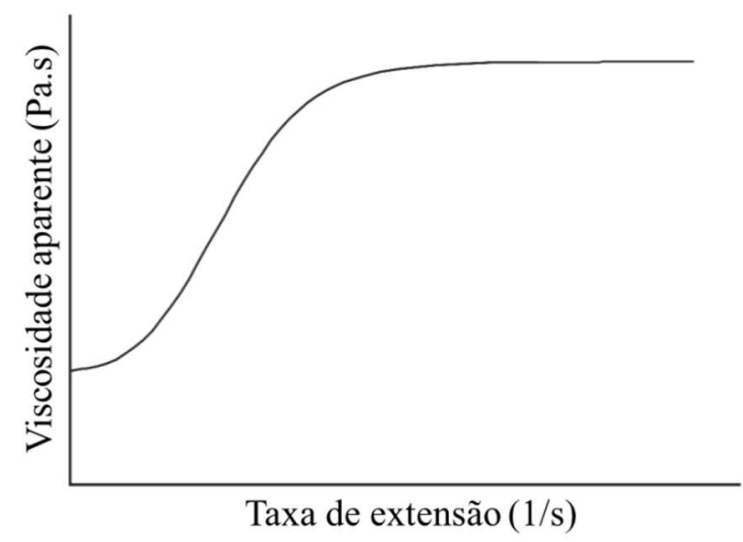

Figura 14 Comportamento típico da viscosidade extensional, $\mu$, como uma função da taxa de extensão $\dot{\varepsilon}$ em um fluxo extensional em escalas de log-log.

\subsection{Descrição do modelo monofásico}

A seguir vamos relatar a formulação matemática usada para criar o modelo implementado nesse trabalho. Para cada poro, têm-se uma equação equivalente à de Kirchhoff. Cada equação que se refere a um poro $i$ denota a soma das vazões, $q_{i j}$, analisadas nos capilares que o conecta aos poros vizinhos $j$ como pode ser visto na equação 2.10 .

$$
\sum_{j=1}^{N_{c}} q_{i j}=0
$$

onde $N_{c}$ é o número de capilares que chegam no nó i. De forma sistêmica, a figura 15 representa a conectividade do poro $i$.

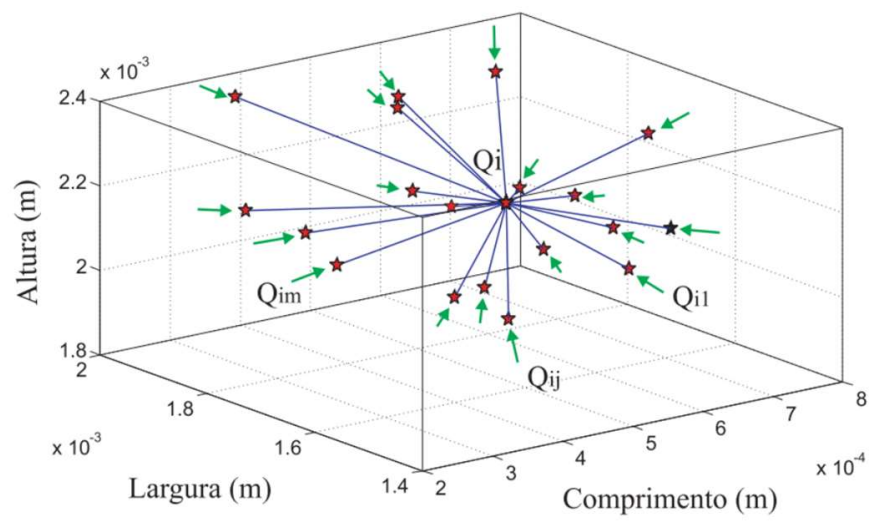

Figura 15 Conectividade de um poro 
A vazão, $q_{i j}$ em um capilar que conecta os poros $i$ e $j$ é escrita em função da diferença de pressão entre os nós. Ao definir uma equação para cada poro, chega-se a um sistema em que o número de equações é igual ao de poros, $N_{p}$, bem como o número de incógnitas é determinado pelas pressões em cada poro, como averiguado na equação a seguir:

$$
\begin{gathered}
\sum_{j=1}^{N_{c}} q_{i j}=0, \quad i=1, \ldots, N_{p} \\
q_{i j}=G_{i j} \Delta P_{i j} \\
\sum_{j=1}^{N_{c}} G_{i j}\left(P_{i}-P_{j}\right)=0, \quad i=1, \ldots, N_{p}
\end{gathered}
$$

Em uma visão mascroscópica do problema, a queda de pressão, $\nabla p$, e a vazão, $Q$, podem ser relacionadas pela lei de Darcy. A resistência ao escoamento é caracterizada por um parâmetro macroscópico $K$, chamada de permeabilidade absoluta do meio poroso:

$$
Q=\frac{K A \rho g \nabla p}{\mu}
$$

onde $A$ é a área de entrada da rede, $\rho$ é a densidade, $g$ é a gravidade e $\mu$ é a viscosidade do fluido.

A seguir, será apresentada a formulação matemática da conectividade da rede. Como a rede usada nesse trabalho é muito grande, o contexto geral será apresentado usando uma rede com número de poros e capilares reduzidos como exemplo. Além disso, foi adotado um fluxo monofásico de um fluido Newtoniano.

\subsubsection{Conectividade da rede}

A geometria de um meio poroso pode ser mapeada através de uma rede que descreve o espaço poroso. As propriedades geométricas do espaço poroso que mais influenciam no comportamento do escoamento são: o número de coordenação (quantidade de poros vizinhos conectados a cada poro) e a distribuição dos tamanhos dos canais internos, caracterizada no modelo de rede pelos raios inscritos nos capilares. 
Um exemplo simples é apresentado a fim de uma melhor visualização do método como visto na figura 16 . As setas, por definição, saem do nó com menor número e entram no nó com maior número.

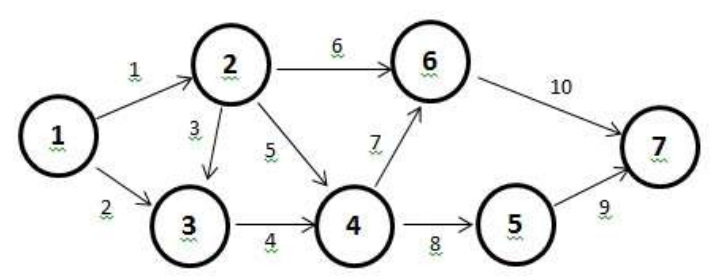

Figura 16 Rede de capilares contendo 7 nós e 10 capilares. A seta, por definição, saí de um nó menor e entra em um nó maior

A conectividade de rede é matematicamente representada por uma matriz de incidência, $\boldsymbol{C}$, onde as linhas se referem aos nós e cada coluna da matriz se refere a um capilar da rede. Como um capilar conecta apenas dois nós, cada coluna da matriz só possui 2 elementos diferente de zero. Em cada linha $i$, os elementos diferentes de zero correspondem aos capilares $j$ que são conectados ao nó $i$. A matriz $\boldsymbol{C}$ do exemplo acima, é representada por:

$\boldsymbol{C}=\quad$\begin{tabular}{ccccccccccc}
1 & 1 & 0 & 0 & 0 & 0 & 0 & 0 & 0 & 0 \\
-1 & 0 & 1 & 0 & 1 & 1 & 0 & 0 & 0 & 0 \\
0 & -1 & -1 & 1 & 0 & 0 & 0 & 0 & 0 & 0 \\
0 & 0 & 0 & -1 & -1 & 0 & 1 & 1 & 0 & 0 \\
0 & 0 & 0 & 0 & 0 & 0 & 0 & -1 & 1 & 0 \\
0 & 0 & 0 & 0 & 0 & -1 & -1 & 0 & 0 & 1 \\
0 & 0 & 0 & 0 & 0 & 0 & 0 & 0 & -1 & -1 \\
\hline
\end{tabular}

onde $\boldsymbol{C}=[\#$ nós, \# capilares], neste caso, $\boldsymbol{C}=[7 \times 10]$. Os elementos da matriz são definidos pelas seguintes premissas:

- $C_{\mathrm{ij}}=0$, se o capilar $\mathrm{j}$ não está ligado ao nó $\mathrm{i}$

- $\quad C_{\mathrm{ij}}=1$, se o capilar j sai do nó i

- $C_{\mathrm{ij}}=-1$, se o capilar $\mathrm{j}$ entra do nó i.

Para compreender melhor a conectividade da rede, fazemos o produto da matriz $\boldsymbol{C}$ com a matriz transposta $\boldsymbol{C}^{\boldsymbol{T}}$, obtendo a matriz, $\boldsymbol{C} \boldsymbol{C}^{\boldsymbol{T}}$, mostrada a seguir: 
$\boldsymbol{C} \boldsymbol{C}^{\boldsymbol{T}}=$\begin{tabular}{cccccccc|} 
& -1 & -1 & 0 & 0 & 0 & 0 \\
-1 & 4 & -1 & -1 & 0 & -1 & 0 \\
-1 & -1 & 3 & -1 & 0 & 0 & 0 \\
0 & -1 & -1 & 4 & -1 & -1 & 0 \\
0 & 0 & 0 & -1 & 2 & 0 & -1 \\
0 & -1 & 0 & -1 & 0 & 3 & -1 \\
0 & 0 & 0 & 0 & -1 & -1 & 2 \\
\hline
\end{tabular}

Para cada elemento da nova matriz, $\boldsymbol{C} \boldsymbol{C}^{\boldsymbol{T}}$, temos os seguintes valores: $\left(C C^{T}\right)_{i j}=-1$, se o nó i está conectado ao nó $\mathrm{j}$ e $\left(C C^{T}\right)_{i i}=$ número de capilares ligados ao nó i.

\subsubsection{Resolvendo o sistema de solução}

Duas variáveis principais são usadas para descrever o escoamento, a pressão em cada nó, $P_{i}$, e a vazão em cada capilar, $q_{j}$. Assim, temos:

$$
\begin{gathered}
q_{1}=G\left(P_{1}-P_{2}\right) \\
q_{2}=G\left(P_{1}-P_{3}\right) \\
\vdots \\
q_{7}=G\left(P_{6}-P_{7}\right)
\end{gathered}
$$

Para resolver o sistema de equações, dois tipos de condições de contorno podem ser implementadas. (i) Podemos impor o fluxo na saída da rede e fixar a pressão na entrada da rede. (ii) Ou, ainda, pressão na entrada e na saída da rede também pode ser usada como uma condição de contorno para resolver o sistema. Este trabalho foi desenvolvido utilizando a terceira condição de contorno, onde a pressão imposta na saída é nula e a vazão na entrada é constante. Usando conservação de massa em cada nó, temos as seguintes equações:

$$
\begin{gathered}
\text { nó } 1: q_{1}+q_{2}-Q_{I N}=0 \\
\text { nó } 2:-q_{1}+q_{2}+q_{5}+q_{6}=0 \\
\text { nó } 3:-q_{2}+q_{3}+q_{4}=0
\end{gathered}
$$

Escrevendo as equações acima em função da pressão nos nós, temos: 


$$
\begin{gathered}
\text { nó } 1: G_{1}\left(P_{1}-P_{2}\right)+G_{2}\left(P_{1}-P_{3}\right)-Q_{I N}=0 \\
\text { nó } 2:-G_{1}\left(P_{1}-P_{2}\right)-G_{3}\left(P_{2}-P_{3}\right)+G_{5}\left(P_{2}-P_{4}\right)+\cdots \\
\ldots G_{6}\left(P_{2}-P_{6}\right)=0 \\
\vdots \\
\text { nó } 7:-G_{9}\left(P_{5}-0\right)-G_{10}\left(P_{6}-0\right)=0
\end{gathered}
$$

Esse sistema pode ser escrito de forma matricial como:

$$
\boldsymbol{A} \boldsymbol{P}=\boldsymbol{b}
$$

onde $\boldsymbol{A}$ é a matriz dos coeficientes $\left(N_{p} \times N_{p}\right), \boldsymbol{P}$ e $\boldsymbol{b}$ são vetores $\left(N_{p} \times 1\right)$, sendo $n$ o número de poros na rede, neste caso, $N_{p}=7$.

A diferença de pressão em cada capilar pode ser escrita de forma vetorial como $\boldsymbol{C}^{\boldsymbol{T}} \boldsymbol{P}=\boldsymbol{\Delta P}$, onde $\boldsymbol{P}$ é o vetor que contém a pressão de cada nó e $\boldsymbol{\Delta P}$ é o vetor que contém a diferença de pressão nos capilares. O sistema matricial pode ser visto na equação 2.19.

$\left[\begin{array}{ccccc}1 & -1 & 0 & \ldots & 0 \\ 1 & 0 & -1 & \ldots & 0 \\ \vdots & \vdots & \vdots & \ddots & \vdots\end{array}\right] \quad\left[\begin{array}{c}\mathrm{P} 1 \\ \mathrm{P} 2 \\ \vdots\end{array}\right]=\left[\begin{array}{c}\mathrm{P} 1-\mathrm{P} 2 \\ \mathrm{P} 1-\mathrm{P} 3 \\ \vdots\end{array}\right]$

Após obter a diferença de pressão em cada capilar, devemos agora definir uma matriz diagonal $\boldsymbol{G}\left(N_{p} \times N_{p}\right)$, que em sua diagonal principal deve conter a condutância, $G_{i i}$, de cada capilar.

$$
\boldsymbol{G}=\left[\begin{array}{ccc}
G_{11} & 0 & 0 \\
0 & \ddots & 0 \\
0 & 0 & G_{N_{p} N_{p}}
\end{array}\right]
$$

A vazão em cada capilar pode ser escrita pela simples multiplicação entre a matriz $\boldsymbol{G}$ e o vetor $\boldsymbol{\Delta P}$ :

$$
\boldsymbol{q}=\boldsymbol{G} \boldsymbol{\Delta} \boldsymbol{P}=\left[\begin{array}{c}
G_{1}\left(P_{1}-P_{2}\right) \\
G_{2}\left(P_{1}-P_{3}\right) \\
\vdots
\end{array}\right]
$$


Através da aplicação de conservação da massa, em cada nó, um sistema linear de equação (para o fluxo Newtoniano) descreve a pressão em cada nó da rede:

$$
C G C^{T} P=b
$$

Como $\boldsymbol{C}$ é a matriz responsável por fazer a conversão nó-capilar, o expressão matricial $\boldsymbol{C} \boldsymbol{G}^{\boldsymbol{T}}$ pode ser visto como uma mudança de base de capilares $(\boldsymbol{G})$ para nós $(\boldsymbol{P})$.

Uma vez que a pressão de cada nó é determinada, a queda de pressão total para uma vazão imposta pode ser calculada. Para um fluido Newtoniano, é necessária uma única iteração para resolver o campo de pressão, já que a condutância de fluxo é conhecida antecipadamente, e a viscosidade é constante. Já para um fluido não-Newtoniano, métodos iterativos são necessários para resolver o sistema não-linear, já que $\boldsymbol{G}=\boldsymbol{G}(P)$.

Levando em consideração que soluções poliméricas são fluidos não-Newtonianos, o modelo requer técnicas iterativas para resolver o escoamento ao longo da rede. Como a queda de pressão em cada elemento de rede não é conhecida, a estratégia é começar com uma suposição arbitrária como chute inicial do método iterativo. A cada passo do método iterativo, a pressão em cada nó e, consequentemente, a vazão em cada capilar é recalculada. A viscosidade efetiva do fluido em cada elemento é atualizada usando a expressão do modelo reológico utilizado. O campo de pressão é então recalculado usando as viscosidades atualizadas. A iteração continua até que a convergência seja alcançada. Isso ocorre quando uma tolerância de erro pré-definida na pressão de entrada entre dois ciclos de iteração consecutivos é atingida. Finalmente, a vazão total e a viscosidade aparente, definida como a viscosidade calculada a partir da lei de Darcy, é obtida.

O objetivo desta análise é compreender como o comportamento reológico do líquido afeta o fluxo em escala macroscópica através de um meio poroso, ou seja, alcançar uma correção macroscópica para a equação de Darcy com base nos mecanismos físicos na escala dos poros.

A viscosidade de soluções de polímero pode ser descrita por diferentes modelos como power-law, Carreau-Yasuda (efeitos viscosos) e viscosidade extensional (efeitos elásticos). As seguintes equações serão aplicadas para estudar o efeito do comportamento viscoelástico de soluções poliméricas:

Tabela 1 Modelos utilizados para calcular a viscosidade de um fluido não-Newtoniano 


\begin{tabular}{|l|l|l|}
\hline Modelo & Viscosidade efetiva & Taxa de deformação \\
\hline power-law & $\mu=m \dot{\gamma}^{n-1}$ & $\dot{\gamma}=\left(\frac{4 q_{\text {cap }}}{\pi R^{3}}\right)\left(\frac{1}{n}+3\right)$ \\
\hline Carreau & $\frac{\mu-\mu_{\infty}}{\mu_{0}-\mu_{\infty}}=\left[1+(\lambda \dot{\gamma})^{2}\right]^{\frac{n-1}{\alpha}}$ & $\dot{\gamma}=\left(\frac{4 q_{\text {cap }}}{\pi R^{3}}\right)\left(\frac{1}{n}+3\right)$ \\
\hline $\begin{array}{l}\text { Viscosidade } \\
\text { Extensional }\end{array}$ & $\frac{\mu-\mu_{\infty}}{\mu_{0}-\mu_{\infty}}=\left[1+(\lambda \dot{\varepsilon})^{2}\right]^{\frac{n-1}{\alpha}}$ & $\dot{\varepsilon}=\frac{V_{1}}{L}\left(\left(\frac{D_{1}}{D_{2}}\right)^{2}-1\right)$ \\
\hline
\end{tabular}

O fluxograma da figura 17 demonstra o funcionamento do processo iterativo descrito anteriormente para um fluido não-Newtoniano. 


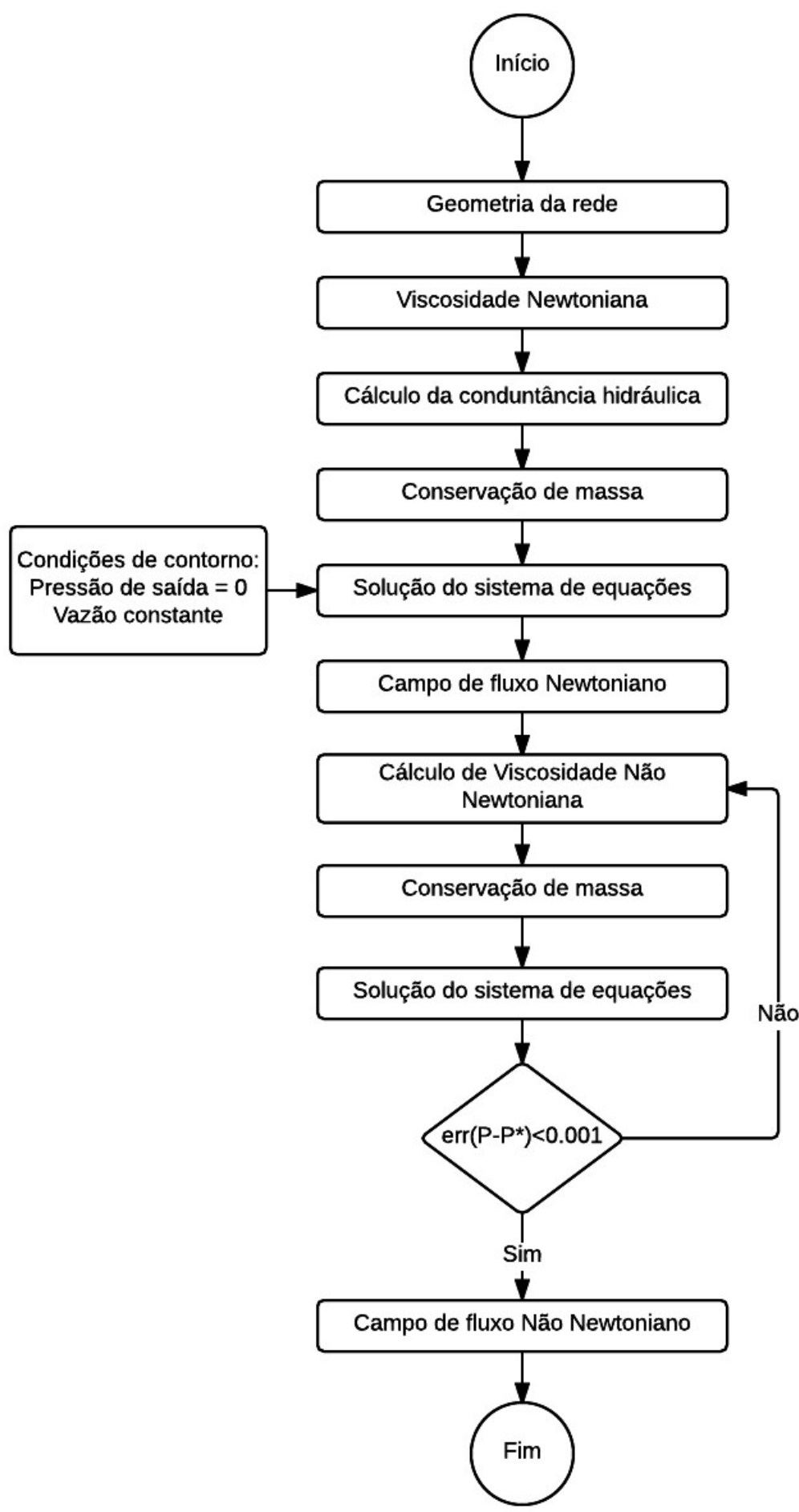

Figura 17 Fluxograma da modelagem para fluido não-Newtoniano em regime permanente

\subsection{Escoamento bifásico}

Os modelos de rede de capilares que estudam o deslocamento de um fluido por outro em meios porosos podem ser divididos em duas categorias: modelos de deslocamento quasi-estático e modelos de deslocamento dinâmico. 
Para aplicar algum destes modelos é necessário saber a faixa do número de capilaridade em que o escoamento acontece. O número de capilaridade é definido como:

$$
C_{a}=\frac{v \mu}{\sigma}
$$

onde $\mu$ é a viscosidade do fluido injetado, $v$ é a velocidade de Darcy (vazão volumétrica por unidade de área) e $\sigma$ é a tensão interfacial entre as duas fases.

\subsubsection{Modelo quasi-estático}

Os modelos quasi-estáticos podem ser executados simulando o escoamento água/óleo dominado por forças capilares, que normalmente apresentam baixo número de capilaridade, $C_{a} \lesssim 10^{-4}$. Nestes casos o campo de pressão na rede é calculado assumindo a configuração de fluidos para o equilíbrio estático.

Em modelos quasi-estáticos, a pressão capilar é imposta sobre a rede e a posição estática de todas as interfaces líquido-líquido é determinada, ignorando os aspectos dinâmicos de propagação da pressão e da interface. Os poros e as gargantas alteram a sua configuração, uma de cada vez.

Há várias circunstâncias em que o modelo de deslocamento quasi-estático não é válido como no caso de fluxos envolvendo polímeros e emulsões onde a queda de pressão devido ao escoamento é da ordem ou maior que a pressão capilar.

\subsubsection{Modelo dinâmico}

Em modelos dinâmicos, a vazão do fluido injetado é imposta e a resposta da pressão transiente subsequente e as posições da interface são calculadas. Nestes modelos, um determinado volume de fluido invasor é injetado durante um intervalo de tempo. Em cada passo de tempo, as pressões nos nós são calculadas e a evolução das interfaces ocorrem de acordo com a vazão em cada capilar. Os modelos de rede dinâmicos podem ser divididos em dois tipos principais:

1. Os que incidem sobre as gargantas, onde nenhum volume é atribuído aos poros e todo o volume é distribuído entre as gargantas (MAN e JING, 1999). 
2. Aqueles em que todo volume é distribuído entre os poros e as gargantas são tratadas como conexões sem volume entre os poros (BLUNT e KING, 1991).

Não obstante, em vários métodos de recuperação melhorada de petróleo com números de capilaridade elevados, as forças viscosas tornam-se decisivas. (DULLIEN, 1992). Em casos como este, os modelos dinâmicos tornam-se fundamentais, já que os efeitos das forças viscosas são levados em conta para o cálculo das variações de pressão.

\subsection{Descrição do modelo bifásico}

Neste subcapítulo apresenta-se o modelo dinâmico do escoamento de soluções poliméricas em uma rede de capilares que inicialmente está saturada com óleo (viscosidade, $\mu_{o}$ ). Um capilar pode estar saturado por ambos os fluidos mas um poro só poderá ser completamente saturado por um dos dois fluidos presentes. As interfaces entre os fluidos em cada capilar ou poro são atualizadas a cada intervalo de tempo através das vazões calculadas. A simulação procede com a solução polimérica deslocando o óleo. A finalidade do modelo é determinar o comportamento dos dois fluidos ao longo da rede, isto é, a saturação das fases em função do tempo para uma vazão de injeção imposta.

\subsubsection{Princípios do modelo dinâmico}

O modelo considerado neste trabalho para a modelagem dinâmica bifásica do escoamento de soluções poliméricas deslocando óleo foi desenvolvido considerando os seguintes princípios:

1. O estabelecimento de condições de contorno onde: uma vazão constante é imposta na entrada e uma pressão manométrica nula é imposta na saída.

2. Os dois fluidos são considerados imiscíveis e incompressíveis em toda a rede.

3. O único mecanismo de deslocamento utilizado é o pistão-pistão. $\mathrm{O}$ modelo não é capaz de simular uma configuração simultânea de ambos os fluidos de uma seção transversal de um tubo onde o fluido molhante escoa ao longo da parede do tubo e o fluido não-molhante escoa no centro sem ter contato com a parte sólida do meio poroso.

4. A saturação das fases e a posição da interface em cada capilar é calculada a cada passo de tempo. A posição das interfaces controla a configuração de fluidos em cada capilar. A condutividade do capilar é uma função das viscosidades dos fluidos e posição da interface. 
5. A diferença de pressão entre os poros e as condutâncias hidráulicas previamente computadas para cada fase são usadas para mover as fases ao longo da rede e, consequentemente, para atualizar a saturação de cada capilar.

\subsubsection{Deslocamento pistão-pistão}

Neste trabalho, vamos considerar apenas a invasão através do deslocamento pistãopistão. Neste processo, a pressão do fluido invasor deve ser elevada o bastante para permitir que este fluido invada o elemento em análise. O fluido deslocante (fase molhante) empurra de forma uniforme o deslocado (fase não-molhante), como pode ser verificado na figura 18 .

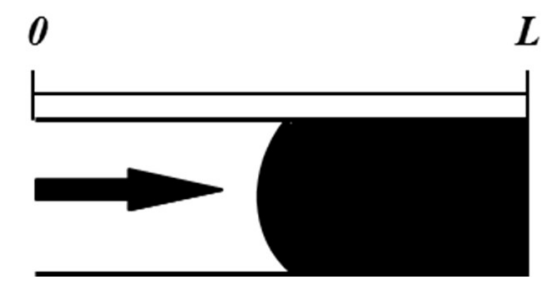

Figura 18 Deslocamento pistão em um capilar

\subsubsection{Drenagem e embebição}

A cada passo de tempo, as interfaces são movidas dentro dos capilares de acordo com a velocidade em cada elemento. Em nosso modelo, o mesmo mecanismo é usado tanto para invasão de óleo (drenagem) quanto para a invasão de água (embebição).

A técnica mais comum utilizada para deslocar o óleo no reservatório é a de injeção de água. O processo em que a fase molhante (aquosa) desloca a fase não-molhante (óleo) é conhecido como embebição. Já o processo de drenagem ocorre quando uma fase nãomolhante invade um meio saturado por uma fase molhante, isto é, quando a rocha reservatório é inicialmente saturada com água antes da migração de óleo primário. A figura 19 ilustra os processos de drenagem e embebição. 


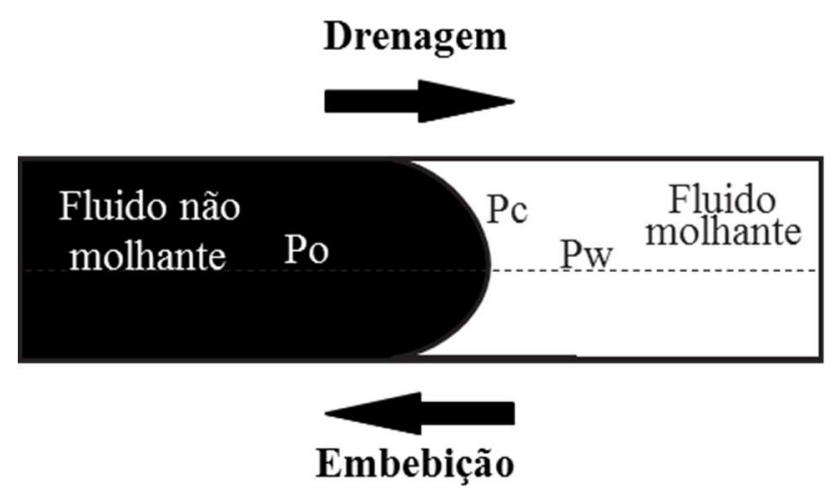

Figura 19 Deslocamento de um fluido por outro num capilar (drenagem e embibição)

\subsubsection{Fluxo através de um capilar}

Quando dois fluidos imiscíveis estão em contato, uma camada infinitamente fina, chamada de interface, separa-os. Uma tensão interfacial é estabelecida entre os fluidos e age na interface. Se a interface for curva, ocorre uma descontinuidade na pressão através da interface, denominada de pressão capilar, $P_{c}$. Em um processo de drenagem, por exemplo, se o diferencial de pressão na interface for superado, a fase não-molhante irá deslocar a fase molhante.

$$
P_{c}=p_{o}-p_{w}
$$

Em microescala, a pressão capilar tem uma função importante no deslocamento de fluidos através de um meio poroso. A pressão capilar, $P_{c}$, função da tensão interfacial do fluido e da geometria, pode ser escrita como:

$$
P_{c}=\frac{2 \sigma}{r} \cos \theta
$$

onde $\sigma$ é a tensão interfacial, r é o raio hidráulico do capilar e $\theta$ é o ângulo de contato da interface com a parede (medida na fase aquosa).

O método proposto por Aker (AKER e colab., 1998) é usado para definir a pressão capilar de cada garganta da rede. A pressão capilar depende da posição da interface no capilar, conforme a equação 2.26. Aker desenvolveu essa equação, já que nas gargantas dos capilares, a pressão capilar é muito mais presente que no restante do capilar. 


$$
P_{c}=\frac{2 \sigma}{r}(1-\cos (2 \pi x))
$$

onde $x$ é a posição da interface no tubo $(0<x<d)$. A pressão capilar se torna mais forte se a interface estiver mais perto do meio do tubo onde o raio é menor. Na figura 20 observa-se que $P_{c}=0$ nas extremidades do tubo e a pressão capilar é igual a pressão capilar máxima quando a interface está localizada no centro do tubo, isto é, $P_{c}=\frac{2 \sigma}{r}$.
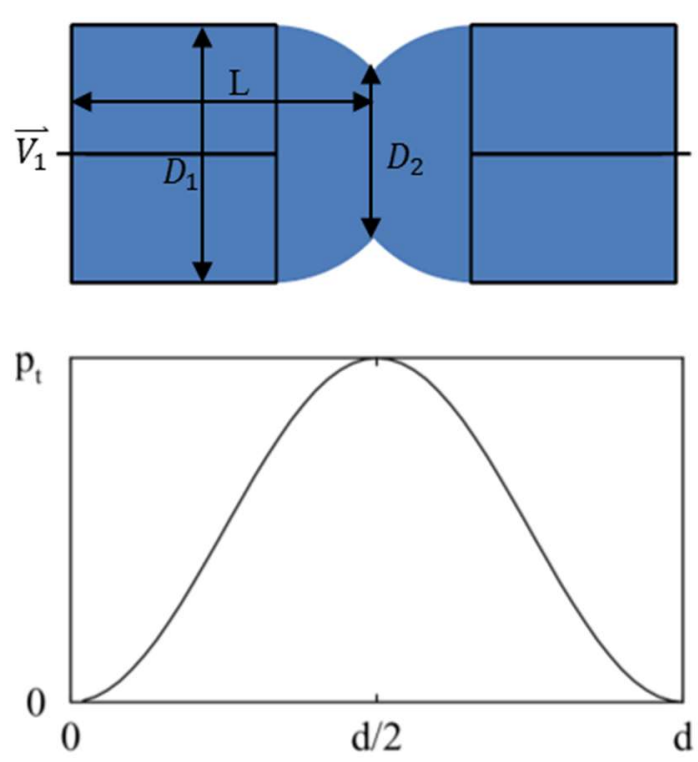

Figura 20 Pressão capilar em função da posição da interface

Até agora, tratamos o capilar contendo apenas uma interface, mas o modelo desenvolvido permite que um único capilar tenha até duas interfaces. As figuras 21.a e 21.b são usadas para exemplificar as duas situações em um capilar com duas interfaces.

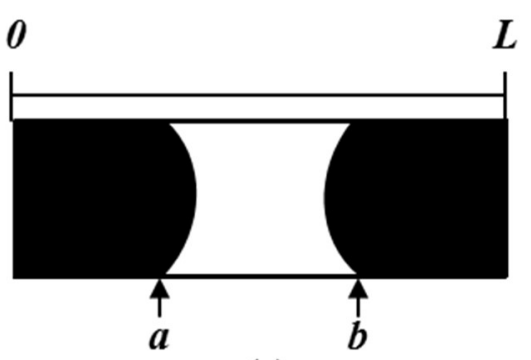

(a)

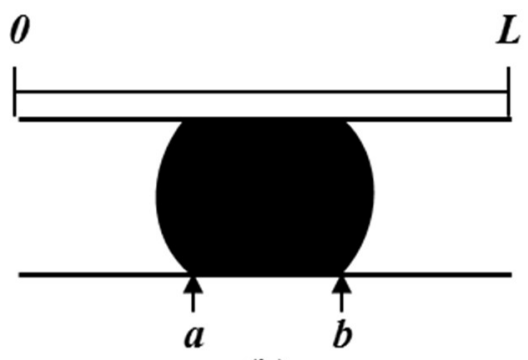

(b)

Figura 21 Pressão capilar em função da posição da interface 
A pressão capilar e a viscosidade nos capilares são descritas a partir das condições a seguir, sendo a figura 21.a descrita pela primeira equação e a figura 21.b pela segunda equação:

$$
\left\{\begin{array}{l}
p_{c}=p_{c a}-p_{c b}, \mu_{e}=\frac{\mu_{o}(a+L-b)+\mu_{w}(b-a)}{L} \\
p_{c}=-p_{c a}+p_{c b}, \mu_{e}=\frac{\mu_{w}(a+L-b)+\mu_{o}(b-a)}{L}
\end{array}\right.
$$

\subsubsection{Tubo com duas interfaces}

\subsubsection{Seleção do passo de tempo}

Um fator importante para o desempenho de modelos dinâmicos de escoamento em meios porosos é o passo de tempo utilizado. No caso da simulação de escoamento em modelo de redes é preciso aplicar passos de tempo com valor baixo o bastante para estabilizar a solução das equações de transporte. $\mathrm{O}$ algoritmo decide o passo de tempo, $\Delta t$, da simulação, baseado na seguinte condição:

$$
\Delta t=\min _{i}\left[\frac{d_{i} A_{i}}{Q_{i}}\right]
$$

onde $d_{i}$ é a posição da interface no capilar e $A_{i}$ é a área média do capilar $i$. Com isso, o máximo volume que o elemento pode receber dos elementos vizinhos é definido. $\mathrm{O}$ critério adotado permite que somente um elemento da rede seja completamente preenchido a cada passo de tempo.

\subsubsection{Atualização da saturação}

Uma vez determinado o passo de tempo, $\Delta t$, uma nova configuração dos fluidos na rede é determinada. As interfaces são deslocadas durante $\Delta t$ ocupando uma nova posição ao longo de cada elemento e, com isso, a saturação nos capilares também precisa ser recalculada. 
Primeiramente, é preciso saber a nova posição das interfaces. Como os fluidos podem entrar no capilar pelas duas extremidades, a posição das interfaces e o fluido presente precisam ser identificados.

Como um capilar pode conter duas interfaces, usaremos algumas condições para obter a saturação ao longo da rede. Considerando que um dos fluidos molhe perfeitamente as paredes dos capilares, ou seja, $\theta=0$, podemos calcular a saturação em cada capilar a partir da posição da interface como visto na figura 22. As variáveis $a$ e $b$ representam a posição das interfaces. Para um capilar com apenas uma interface, duas configurações são possíveis conforme ilustrado nas figuras 22.a e 22.b. Já para um capilar com duas interfaces, as configurações das posições podem ser vistas nas figuras 22.c e 22.d.

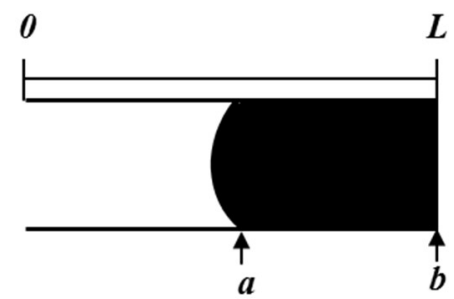

(a)

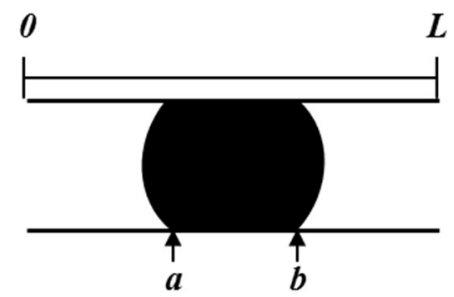

(c)

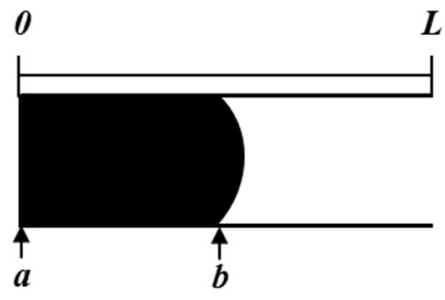

(b)

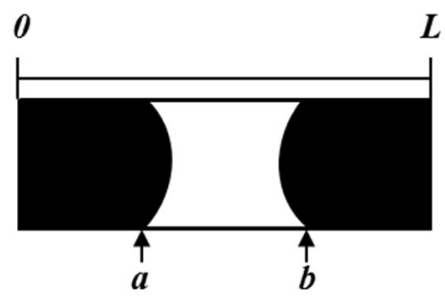

(d)

Figura 22 Posição das interfaces em um elemento

Adotando o fluido não molhante (óleo) representado pela cor preta e o fluido molhante (água) pela cor branca na figura 22, as saturações de água, $S_{w}$, para cada caso são obtidas através das equações a seguir:
a) $S_{w}=\frac{a}{L}$
b) $S_{w}=\frac{L-b}{L}$
c) $S_{w}=\frac{L-(b-a)}{L}$
d) $S_{w}=\frac{(b-a)}{L}$ 
A partir da posição das interfaces, calculamos a saturação e obtemos a configuração de cada fase no elemento. Com isso, pode ser determinada a viscosidade equivalente para cada configuração de fluido.

\subsubsection{Processo de invasão dos fluidos em um poro}

O processo observado neste trabalho consiste no deslocamento do óleo, que inicialmente está saturando a rede, pelo fluido injetado, neste caso, soluções poliméricas. A primeira situação analisada considera um fluido molhante invadindo um poro e três capilares completamente saturados de fluido não molhante. Quando a interface atinge um poro, considera-se que uma nova interface é formada a uma distância $\delta$ d $(3 \%$ do comprimento total do capilar) em cada um dos capilares vizinhos, como mostra a figura 23 (a e b).

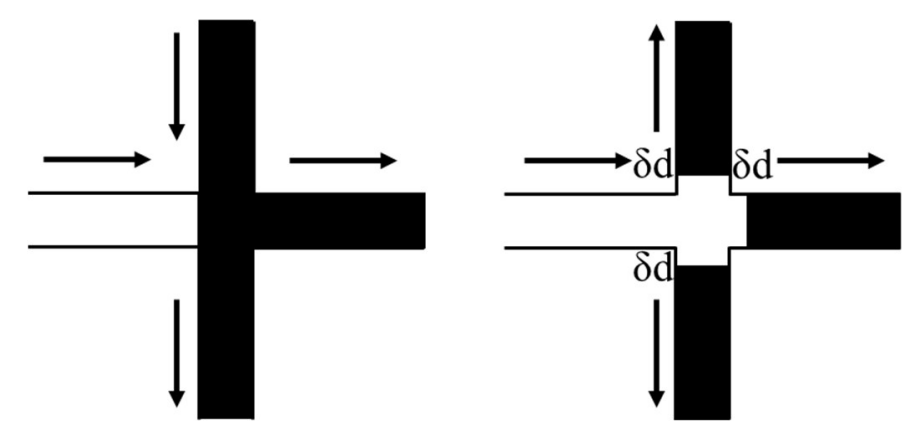

Figura 23 Fluido molhante invadindo um fluido não molhante

Outro caso é analisado na figura 24 onde dois fluidos estão escoando para um mesmo poro. Nas figuras a e b, o capilar inferior invade o nó saturado de fluido molhante. Porém, devido ao fluxo na direção oposta do capilar a direita, a interface criada é movida de volta para a extremidade do capilar, como mostrado na figura 24 (c e d) novas interfaces são formadas. Na figura 24 (e e f) a interface na garganta inferior se aproxima do poro e invade novamente os capilares vizinhos. 


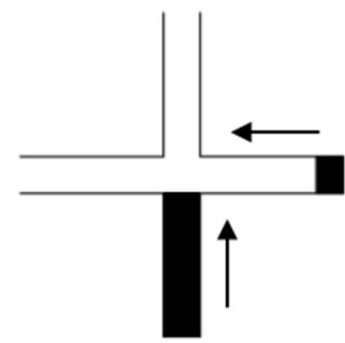

(a)

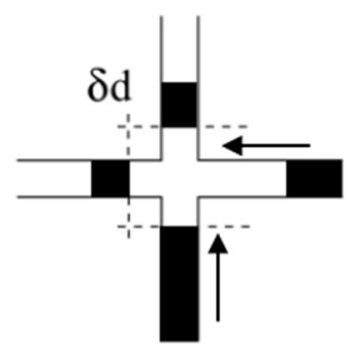

(d)

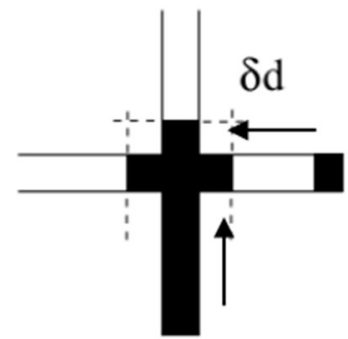

(b)

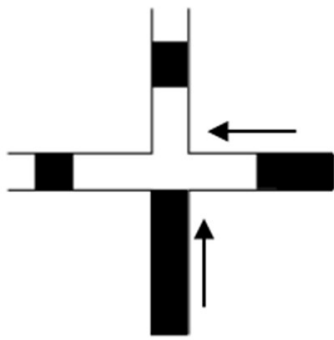

(e)

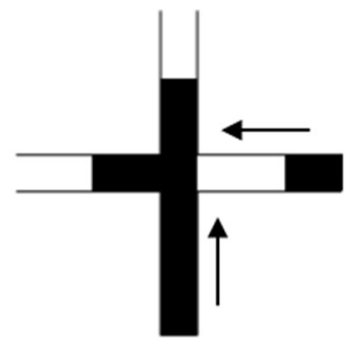

(c)

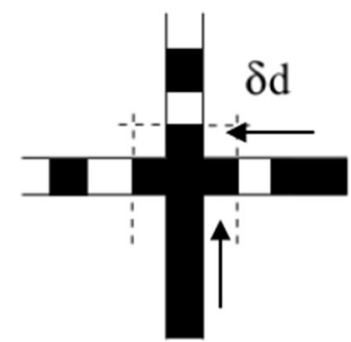

(f)

Figura 24 Dinâmica entre as interfaces

(a) fase não-molhante (preta) aproxima-se do poro. (b) $O$ fluido invade o poro e as interfaces são estabelecidas nas gargantas vizinhas. (c) A interface na garganta direita é empurrada de volta para o poro. (d) As gotas não-molhantes são formadas nas gargantas. (e) - (f) A fase não molhante aproxima-se do poro pela segunda vez e as interfaces são reestabelecidas nas gargantas vizinhas.

$\mathrm{Na}$ figura 25.a podemos observar que o capilar esquerdo possui três interfaces. Neste caso, para evitar que um capilar possua mais de duas interfaces, as três interfaces são reduzidas para uma como visto na figura 25.b.

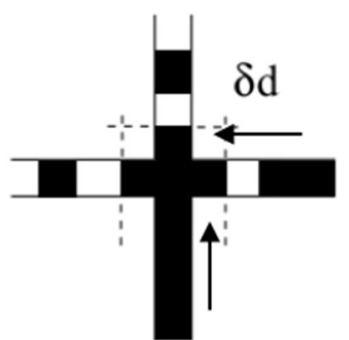

(a)

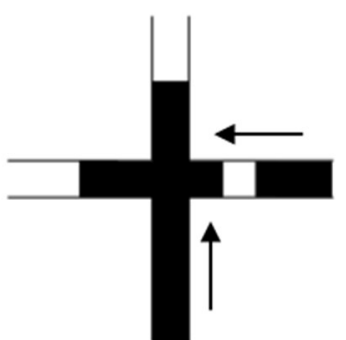

(b)

Figura 25 As três interfaces em uma única garganta (capilar esquerdo) são fundidas para formar uma interface

O processo acima repete-se para cada passo de tempo. A invasão dos elementos na rede tem fim quando a saturação tende a se manter constante. O procedimento de cálculo 
das equações utilizado para solucionar um escoamento de dois fluidos em um meio poroso pode ser visto no fluxograma da figura 26.

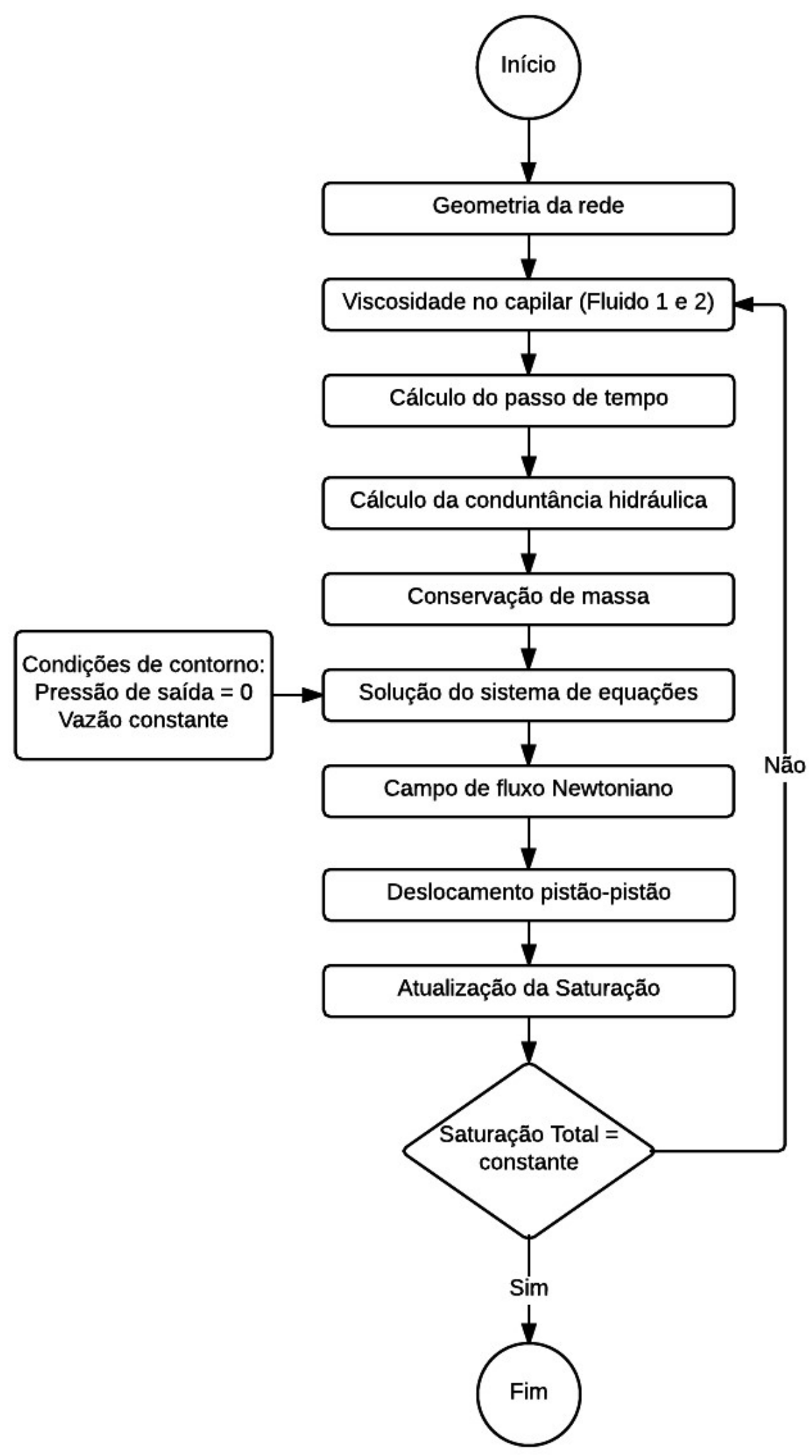

Figura 26 Fluxograma da modelagem do escoamento de soluções poliméricas através de um meio poroso saturado com óleo 


\section{Resultados}

\subsection{Escoamento monofásico}

\subsubsection{Fluido Newtoniano}

A análise do escoamento monofásico de um fluido Newtoniano através do micromodelo permite o cálculo da permeabilidade absoluta do meio poroso. A permeabilidade, $K$, de um meio poroso submetido a uma diferença de pressão, $\Delta P$, e a uma vazão volumétrica, $q$, pode ser calculada pela lei de Darcy:

$$
q=\frac{K A}{\mu}\left(\frac{\Delta P}{L}\right),
$$

onde a viscosidade da água usada foi $\mu=1,003 \mathrm{mPa}$. $\mathrm{s}$, $L$ é o comprimento da rede e $A$ é a área de entrada do micromodelo. A permeabilidade obtida pelo modelo de rede desenvolvido foi $k=79.29 D$.

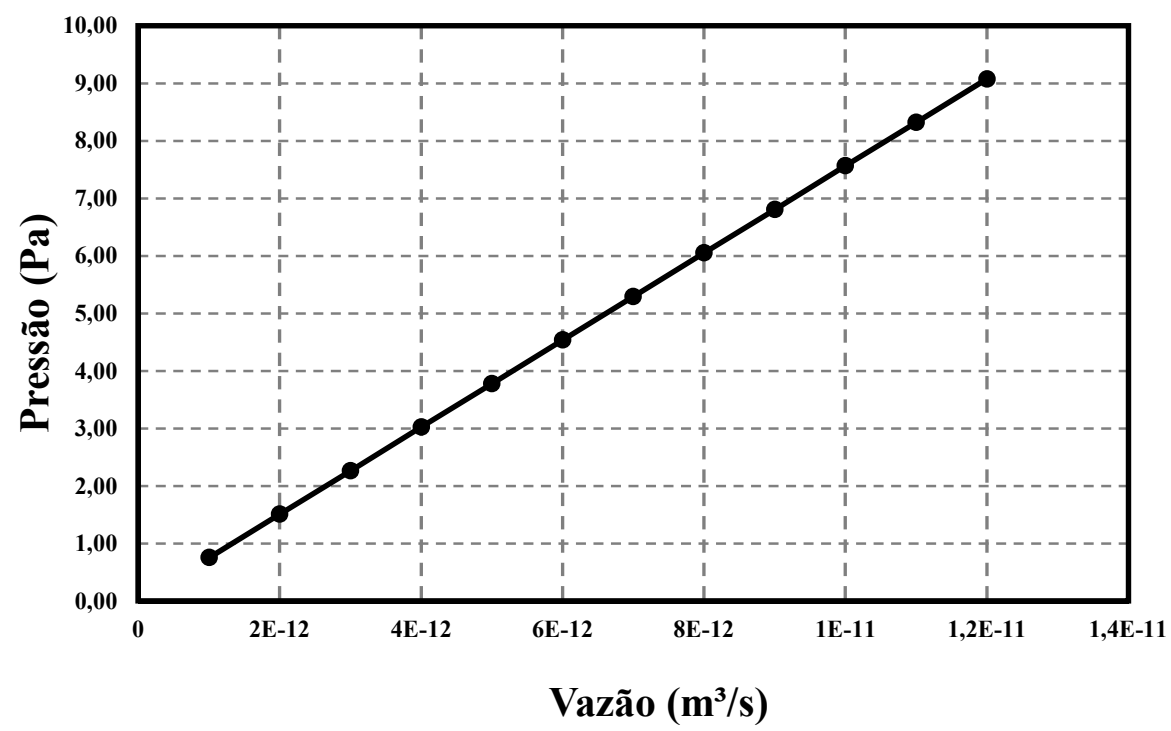

Figura 27 Gráfico de permeabilidade obtido a partir de simulação 
Os valores de permeabilidade são semelhantes a um valor aproximado obtido a partir da equação desenvolvida por Carman (CARMAN, 1937), como pode ser visto na equação 3.2:

$$
K=\frac{d_{t}^{2} \cdot \varepsilon^{2}}{32}
$$

onde $d_{t}$ é o diâmetro médio da garganta, $\varepsilon$ é a porosidade e $K$ é a permeabilidade. Para o micromodelo utilizado, obtém-se $K=71.35 D$.

No modelo, uma pressão nula é imposta no nó de saída e pode-se observar a queda de pressão ao longo do microchip. O comportamento macroscópico obtido a partir do modelo de rede fica claro observando-se a figura 28. Além disso, pode-se observar que as linhas de pressão $(\mathrm{P}=$ cte $)$ não são retas devido a heterogeneidade da rede.

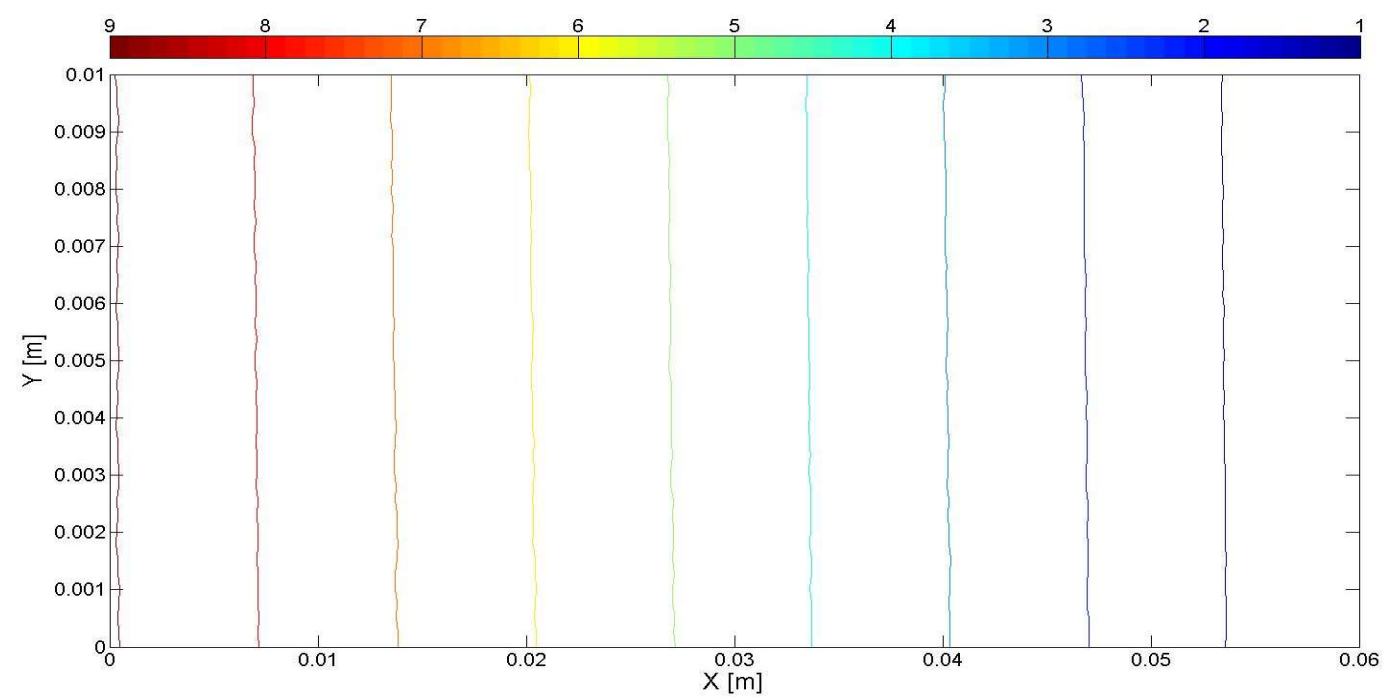

Figura 28 Queda de pressão ao longo do micromodelo

\subsubsection{Fluido não-Newtoniano}

Nesta seção, serão apresentados os resultados obtidos com o modelo de rede de capilares para prever o escoamento de soluções poliméricas. Nesta seção também é exposta a comparação dos resultados da simulação numérica utilizando o modelo de rede desenvolvido com modelos contínuos. O objetivo desta comparação é validar o modelo e o código desenvolvidos. 


\subsubsection{Efeito viscoso}

Inicialmente, o modelo de rede é aplicado para um fluido shear thinning, ou seja, um fluido que depende da taxa de cisalhamente, descrito pelo modelo de potência (powerlaw). Para estudar este comportamento, foram realizadas simulações variando a vazão de entrada no microchip para entender o efeito na queda de pressão.

Além disso, usamos o modelo para prever o comportamento do escoamento de fluidos com diferentes índices de potência: $n=0.7,0.8,0.9$ e 1,0 (Newtoniano). Os resultados destas simulações são mostrados na figura 29.

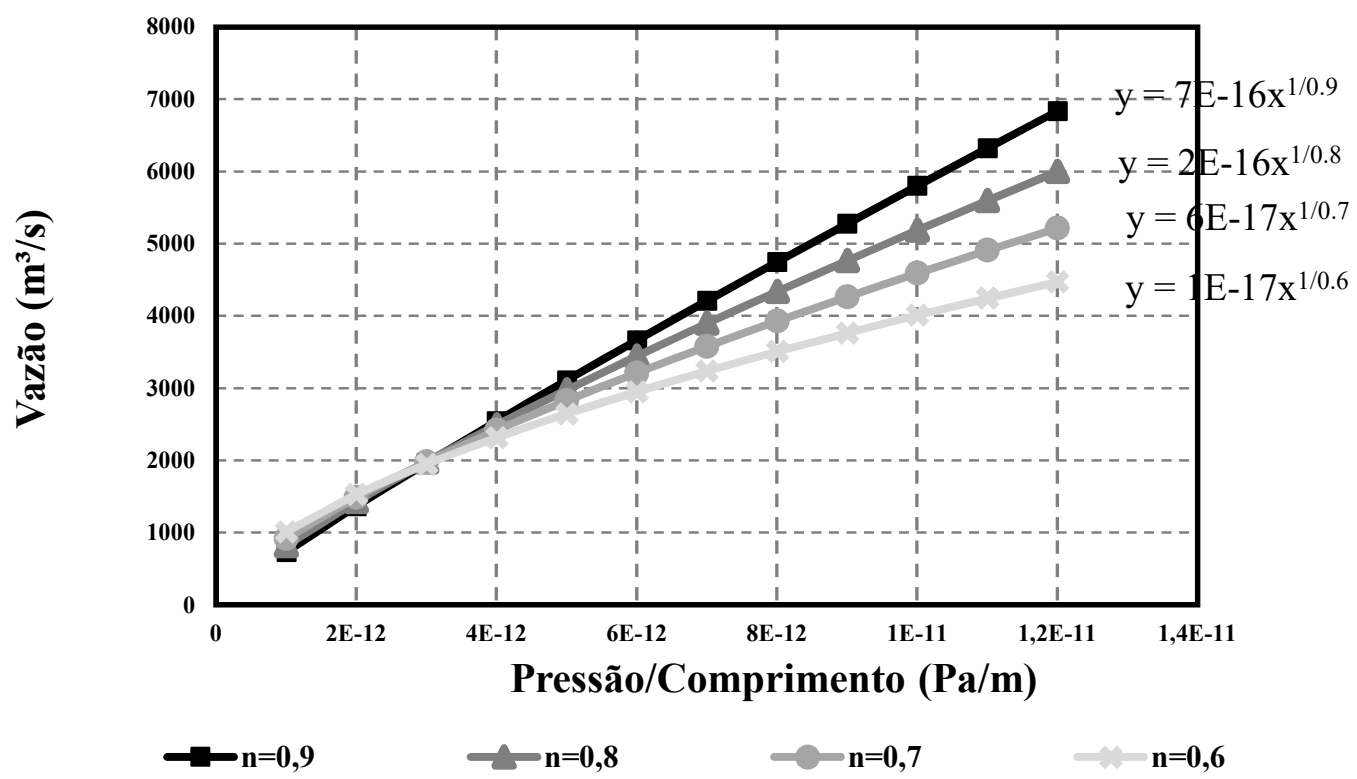

Figura 29 Curvas de vazão - queda de pressão para o modelo power law

Estas curvas mostram que as previsões do modelo de rede seguem à equação proposta por Pascal-Pascal (1989):

$$
q \propto(\Delta P / L)^{1 / n}
$$

A figura 30 compara a relação queda de pressão - vazão prevista pela equação de Pascal-Pascal (1989) e os resultados do modelo de rede. As derivadas da curvas para os resultados encontrados se aproximam para os dois casos, mas a relação Pascal-Pascal prevê a diferença de pressão maior para uma mesma velocidade média.

O modelo de Pascal-Pascal (1989) usa parâmetros macroscópicos empíricos como visto na eq. 2.6. Já o modelo de rede usa a geometria do espaço poroso. O modelo de rede pode ser usado para determinar os parâmetros do modelo de Pascal-Pascal (1989). 


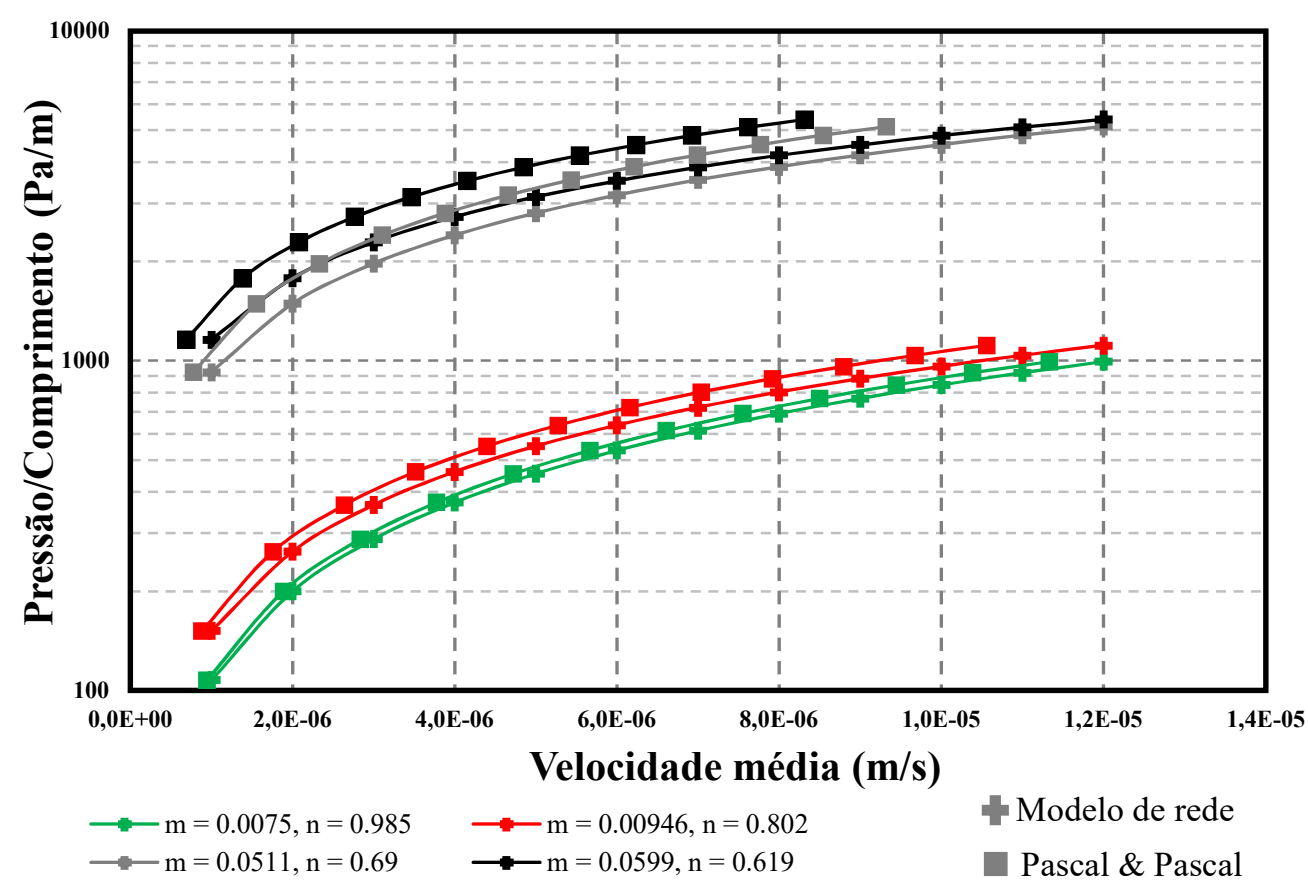

Figura 30 Curvas para o modelo power-law comparando com a equação de Pascal e Pascal(1989)

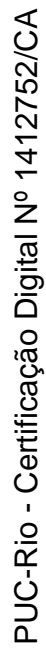

Existe um modelo mais complexo e que, diferente do modelo tipo lei de potência, não existe nenhuma equação empírica em que possa ser comparado. Este modelo é chamado de modelo de Carreau.

O modelo de rede capilares pode ser aplicado para qualquer função de viscosidade. Como uma ilustração, previsões para um modelo de viscosidade de Carreau são apresentados na figura 31 .
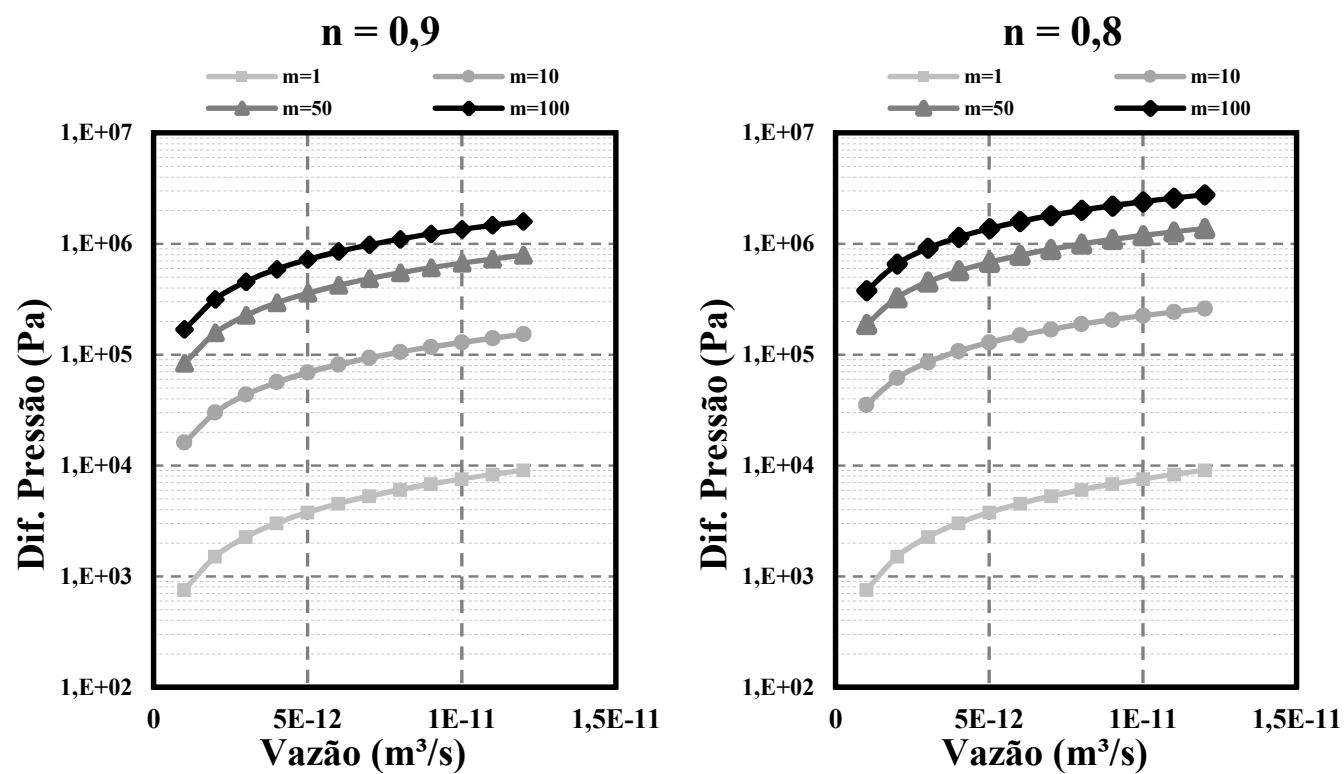

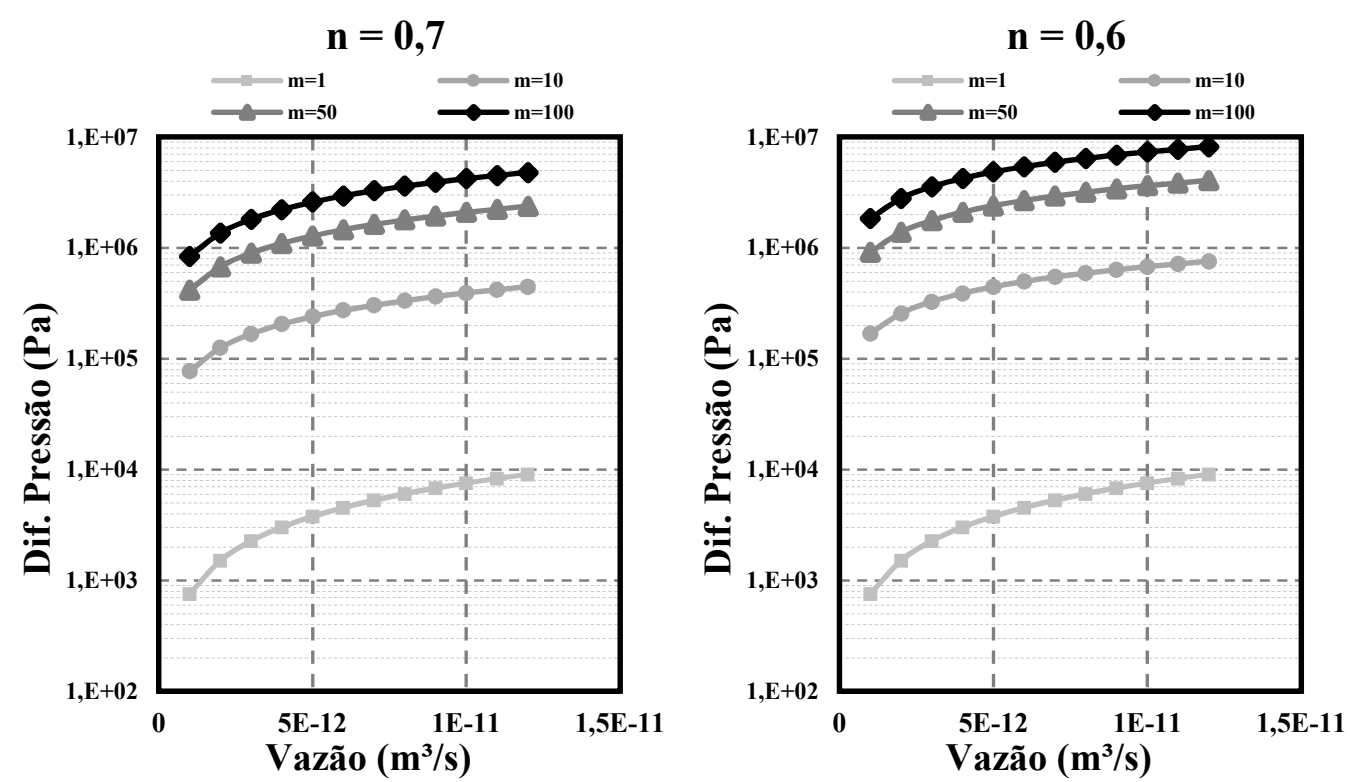

Figura 31 Curvas para o modelo de Carreau variando os índices de potência do fluido e a viscosidade Newtoniana zero.

Assim como no modelo power-law, os fluidos cisalhantes se tornam menos viscosos à medida que a taxa de cisalhamento aumenta. Com isso, a medida que a diferença de pressão aumenta em relação a vazão, a curva tem um crescimento maior do que o linear.

\subsubsection{Efeito viscoelástico}

Como discutido anteriormente, fluidos viscoelásticos apresentam um comportamento tal que a viscosidade extensional aumenta com a taxa de deformação. Desta forma, o escoamento através de capilares com garganta manifesta uma queda de pressão maior do que a observada no escoamento de um fluido puramente viscoso. Este comportamento foi modelado neste trabalho considerando uma viscosidade equivalente que aumenta com a taxa de extensão no capilar (eq. 2.8). Utilizou-se o modelo de Carreau para descrever a viscosidade equivalente (que considera efeitos elásticos) com a taxa de extensão.

O efeito da viscosidade pode ser observado na figura 32 , que mostra a queda de pressão em relação a vazão para $n=0.6,0.7,0.8 e 0.9$. Os parâmetros de viscosidade infinita, viscosidade zero e tempo de relaxação foram variados. Para os três primeiros casos, a viscosidade zero, $\mu_{0}=0,1 P a . s$, e o tempo de relaxação, $\lambda=0,2 s^{-1}$ do fluido 
são fixados e a viscosidade infinita é variada. Quanto maior a viscosidade, $\mu$, menor o efeito viscoelástico. Para o efeito da viscosidade extensional ser percebido, foi usado um tempo de relaxação alto. Na figura 29.d, é usado um tempo de relaxação menor, $\lambda=$ $10^{-2} s^{-1}$. Neste caso, para perceber o efeito elástico foram usadas uma viscosidade zero ainda menor $\left(\mu_{0}=0,001 \mathrm{~Pa} . \mathrm{s}\right)$ e uma viscosidade infinita alta $\left(\mu_{\infty}=100 \mathrm{~Pa} . \mathrm{s}\right)$. Apesar das diferenças observadas na figura 32 terem sido pequenas quando comparado com um fluido Newtoniano, para altas vazões a inclinação da curva tende a aumentar e é necessário uma diferença de pressão maior para o fluido escoar.

$$
\mu_{\infty}=\mathbf{1} ; \mu_{\mathbf{0}}=\mathbf{0}, \mathbf{1} ; \boldsymbol{\lambda}=\mathbf{0}, \mathbf{2}
$$

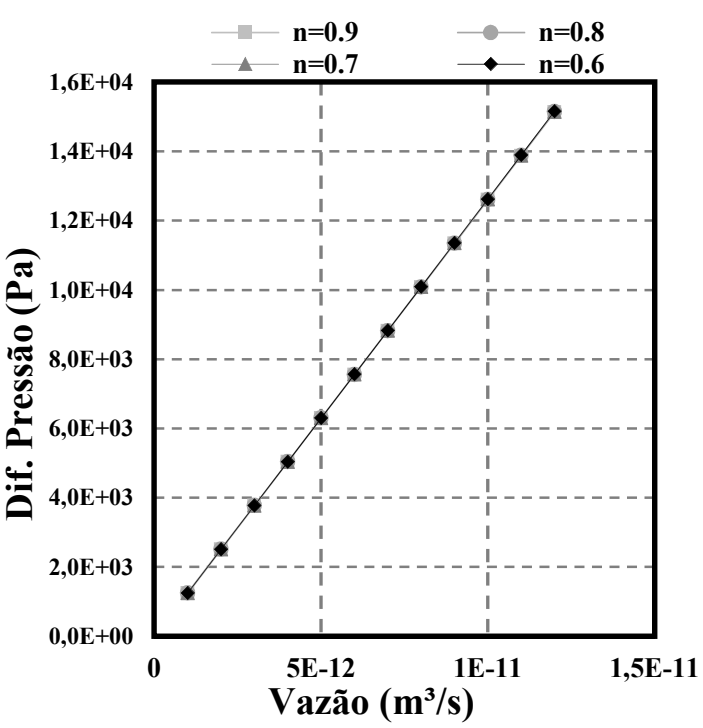

$\mu_{\infty}=\mathbf{5 0} ; \mu_{\mathbf{0}}=\mathbf{0}, \mathbf{1} ; \boldsymbol{\lambda}=\mathbf{0}, \mathbf{2}$

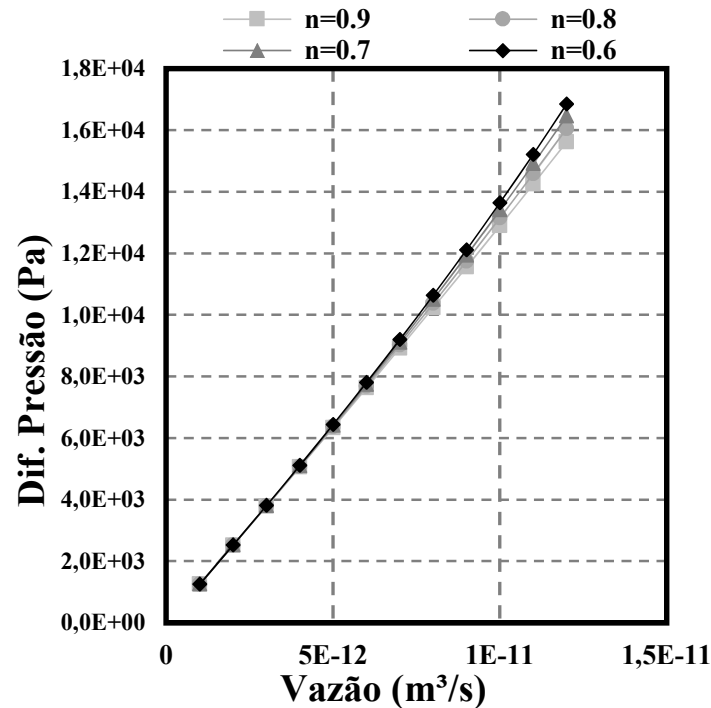

$$
\mu_{\infty}=10 ; \mu_{0}=\mathbf{0}, \mathbf{1} ; \boldsymbol{\lambda}=\mathbf{0}, \mathbf{2}
$$

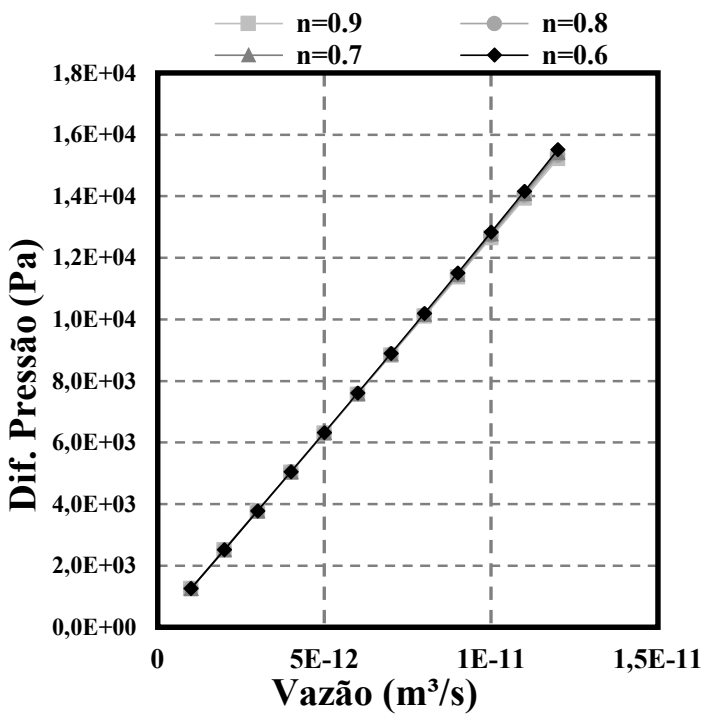

$\mu_{\infty}=100 ; \mu=0,001 ; \boldsymbol{\lambda}=\mathbf{0}, 01$

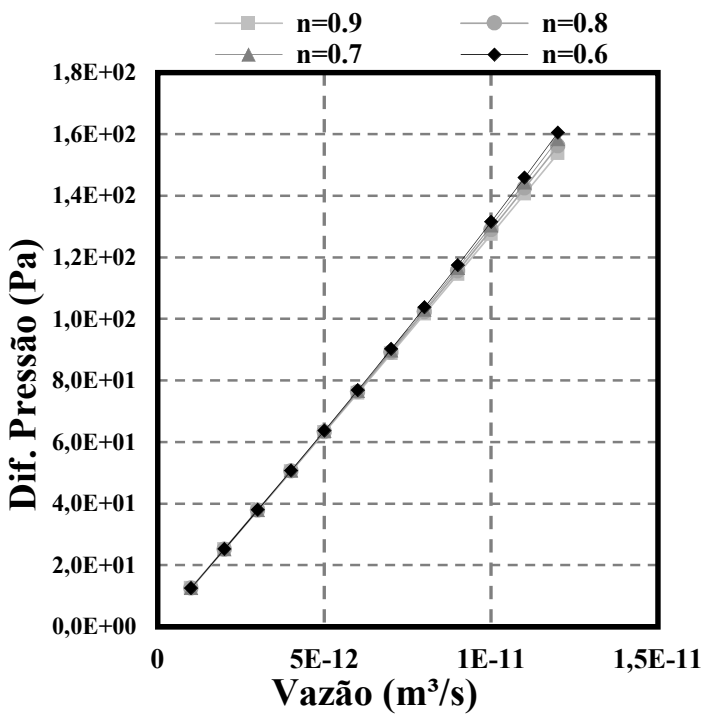

Figura 32 Curva de pressão em função da taxa de injeção para um modelo de viscosidade extensional 
Os fluidos extensionais tornam-se mais viscosos com o aumento da taxa de extensão e, portanto, têm taxas de fluxo menores do que as lineares. Resultados experimentais mostram que a queda de pressão do escoamento de soluções poliméricas através de canais com contração e expansão pode aumentar com a vazão. Além disso, neste modelo são necessárias altas taxas de extensão para poder observar o comportamento não-linear como pode ser visto na figura 32 .

\subsection{Escoamento bifásico}

O modelo foi ampliado para o estudo de escoamentos bifásicos contendo óleo-água ou óleo-solução polimérica. Deste modo, pode-se analisar o processo de deslocamento de óleo pela injeção de uma solução polimérica e entender o comportamento do fluido extensional em escala microscópica.

A seguir serão apresentados os resultados das simulações numéricas, considerando diferentes parâmetros reológicos para diferentes vazões. As simulações foram feitas considerando três fluidos: (a) fluido Newtoniano (b) fluido viscoelástico com $\mu_{\infty}=10^{-2} \mathrm{~Pa}$.s e $\mu_{0}=10^{-3} \mathrm{~Pa} . \mathrm{s}$ e (c) fluido viscoelástico com $\mu_{\infty}=10^{-1} \mathrm{~Pa} . \mathrm{s}$ e $\mu_{0}=10^{-3}$ Pa.s. Para cada fluido, foram consideradas quatro vazões de injeção: $Q_{1}=10^{-10} \mathrm{~m}^{3} / \mathrm{s}, \quad Q_{2}=10^{-8} \mathrm{~m}^{3} / \mathrm{s}, \quad Q_{3}=10^{-6} \mathrm{~m}^{3} / \mathrm{s}, \quad Q_{4}=10^{-4} \mathrm{~m}^{3} / \mathrm{s} \quad \mathrm{e}$ $Q_{5}=10^{-2} \mathrm{~m}^{3} / \mathrm{s}$. A tensão interfacial entre a solução aquosa e o óleo utilizada é $\sigma=$ $0,0338 \mathrm{~N} / \mathrm{m}$, que corresponde ao valor dos fluidos utilizados nos experimentos de (LIMA e CARVALHO, 2015).

No início de cada simulação, a rede está totalmente saturada com óleo, $\mu_{o}=$ 0,0178Pa.s. A fase aquosa começa a ser injetada e a simulação para no instante que a saturação da fase aquosa atinge um regime permanente.

A variação dos resultados com o tempo é retratada em função do volume de fluido injetado, em unidade de volume poroso total, $V p$, que representa um tempo adimensional:

$$
V p=\frac{Q_{i j} t}{V_{c a p}}
$$

onde $Q_{i j}$ é a vazão do capilar, $V_{c a p}$ é o volume do capilar e $t$ é o tempo mínimo para uma das interfaces da rede atingir o final de um capilar em cada iteração. 


\subsubsection{Fluido Newtoniano}

Inicialmente, o modelo de rede desenvolvido foi usado para analisar a influência de um fluido Newtoniano escoando ao longo do micromodelo saturado de óleo. Os parâmetros que foram considerados e os resultados obtidos são mostrados nas tabelas 2 , $3,4,5$ e 6 .

O processo de invasão é ilustrado por uma sequência de mapas de saturação em quatro instantes de tempo, onde o óleo é representado pela cor branca e a água pela cor azul no micromodelo.

Outro gráfico usado para entender o comportamento do fluido ao longo do micromodelo são as curvas de saturação em função da posição. Nestes gráficos (figuras 35, 38, 41, 44 e 47), são apresentadas as saturações ao longo do micromodelo em onze instantes de tempo do escoamento, variando a cada $10 \%$ do tempo total. Com isso, conseguimos identificar a eficiência de varrido das simulações analisadas. Pode-se observar uma frente de água bem definida, indicando um deslocamento bem uniforme para baixas vazões como visto nas figuras 35 e 38 . A medida que a vazão aumenta, a frente se torna menos uniforme devido ao maior valor do número de capilaridade como pode ser visto nas figuras 41, 44 e 47. Com isso, a presença de viscous fingering aumenta e, devido à baixa eficiência de varrido, ocorre uma produção precoce de água.

O escoamento de água em um meio poroso pode ser analisado por meio de curvas de saturação e de queda de pressão em relação ao volume poroso injetado conforme gráficos mostrados nas figuras 34, 37, 40, 43 e 46. Como a água possui uma viscosidade menor que a do óleo, pode-se observar que a pressão na entrada do micromodelo diminui em relação ao volume poroso injetado.

A figura 34 mostra que existem perturbações adicionais em função da pressão média decrescente na simulação 1 onde temos uma baixa vazão $\left(Q_{1}=10^{-10} \mathrm{~m}^{3} / \mathrm{s}\right)$ de fluido injetado. As pequenas flutuações são devidas às mudanças da pressão capilar como uma função da posição interfacial em cada tubo. Quando o fluido invasor se move para o meio de um tubo, a pressão capilar aumenta, o que resulta num pequeno aumento na pressão total. Por conseguinte, há uma pequena redução da pressão quando a interface se move para fora do tubo. A pressão capilar não afeta muito o resultado. As flutuações são pequenas quando comparadas com o valor da pressão das forças viscosas e não são vistas nas figuras 37, 40, 43 e 46 devido as altas vazões nestas simulações. 
Tabela 2 - Simulação (1) - Parâmetros e resultados finais obtidos para um fluido Newtoniano

\begin{tabular}{|c|c|c|}
\hline & Parâmetro & Valor \\
\hline \multirow{3}{*}{ 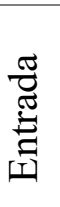 } & Viscosidade do fluido injetado & $10^{-3}$ Pa.s \\
\hline & Viscosidade do óleo & $1,78.10^{-2}$ Pa.s \\
\hline & Vazão de entrada & $10^{-10} \mathrm{~m}^{3} / \mathrm{s}$ \\
\hline \multirow{5}{*}{ 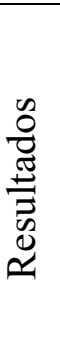 } & Número de Capilaridade & $5,26.10^{-5}$ \\
\hline & Saturação final de água & $77,03 \%$ \\
\hline & Volume poroso injetado & 0,003 \\
\hline & Tempo de escoamento & $3,32 s$ \\
\hline & Número de iterações & 35912 \\
\hline
\end{tabular}

t1

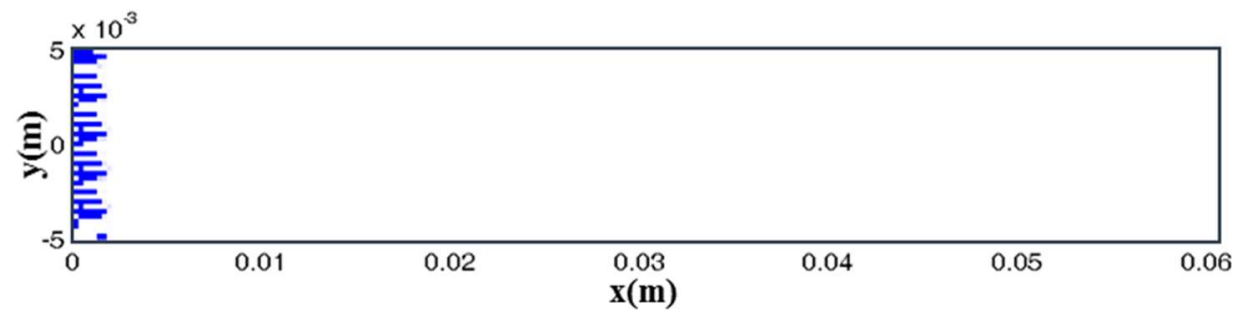

t4

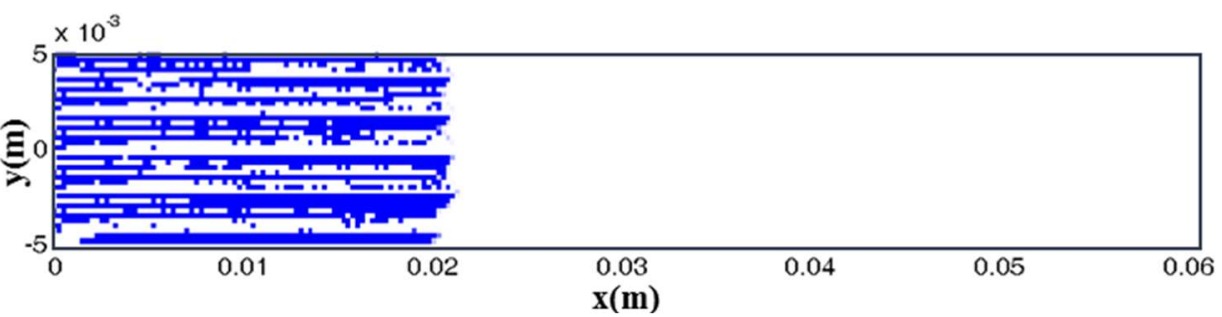

$\mathrm{t} 7$

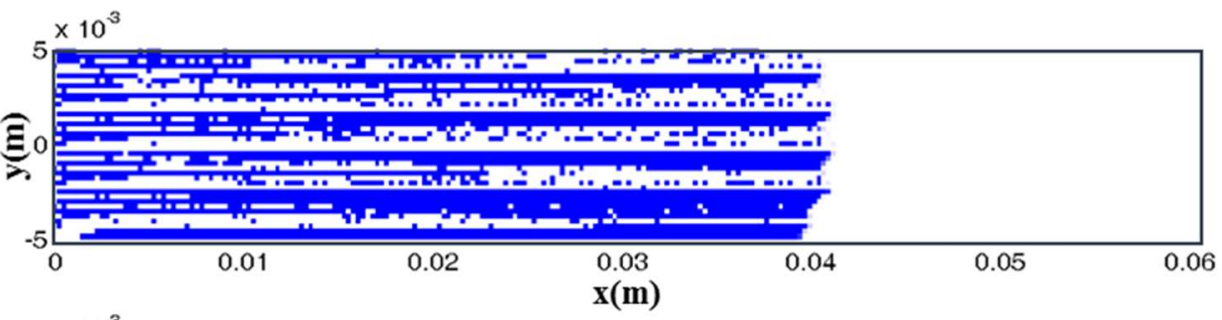

t10

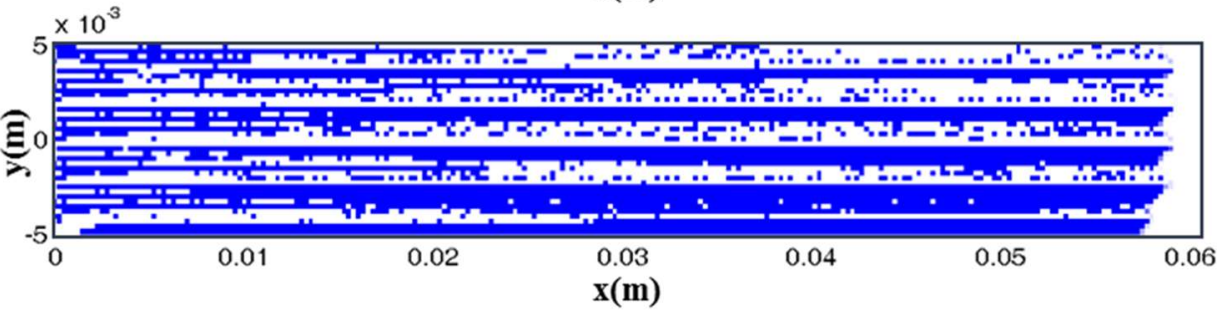

Figura 33 Simulação (1) - Mapa de saturação para um fluido Newtoniano em quatro instantes de tempo 

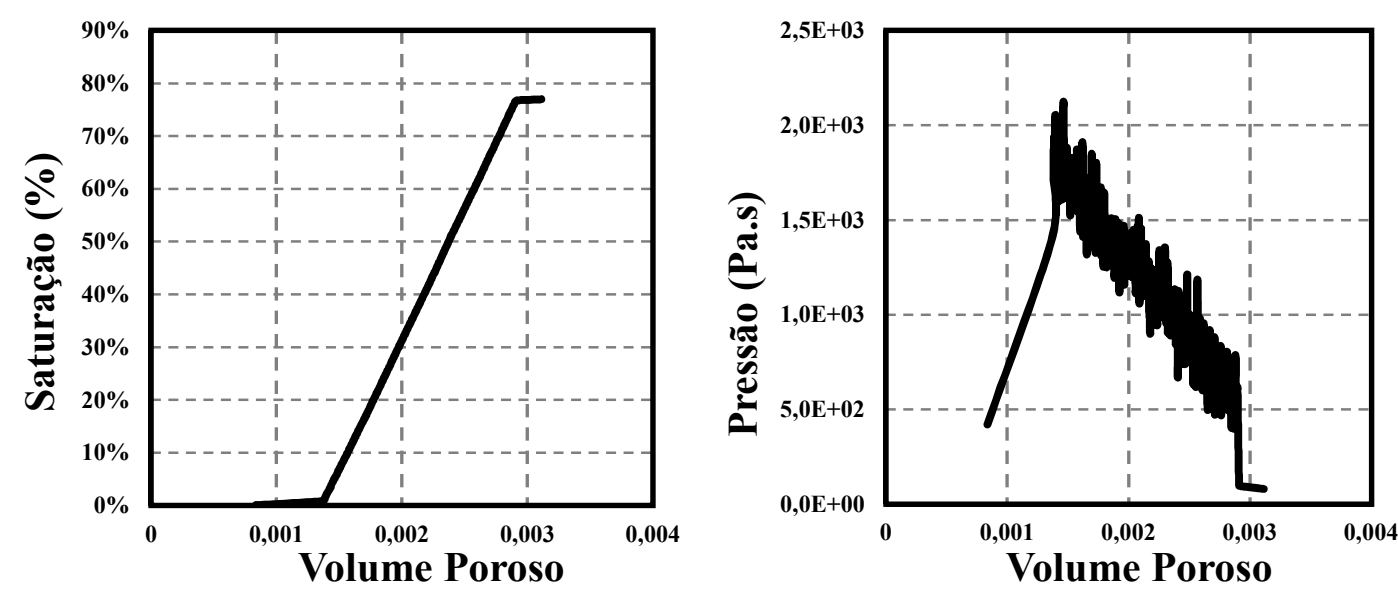

Figura 34 Simulação (1) - Curva de saturação e pressão de entrada em função do volume poroso injetado.

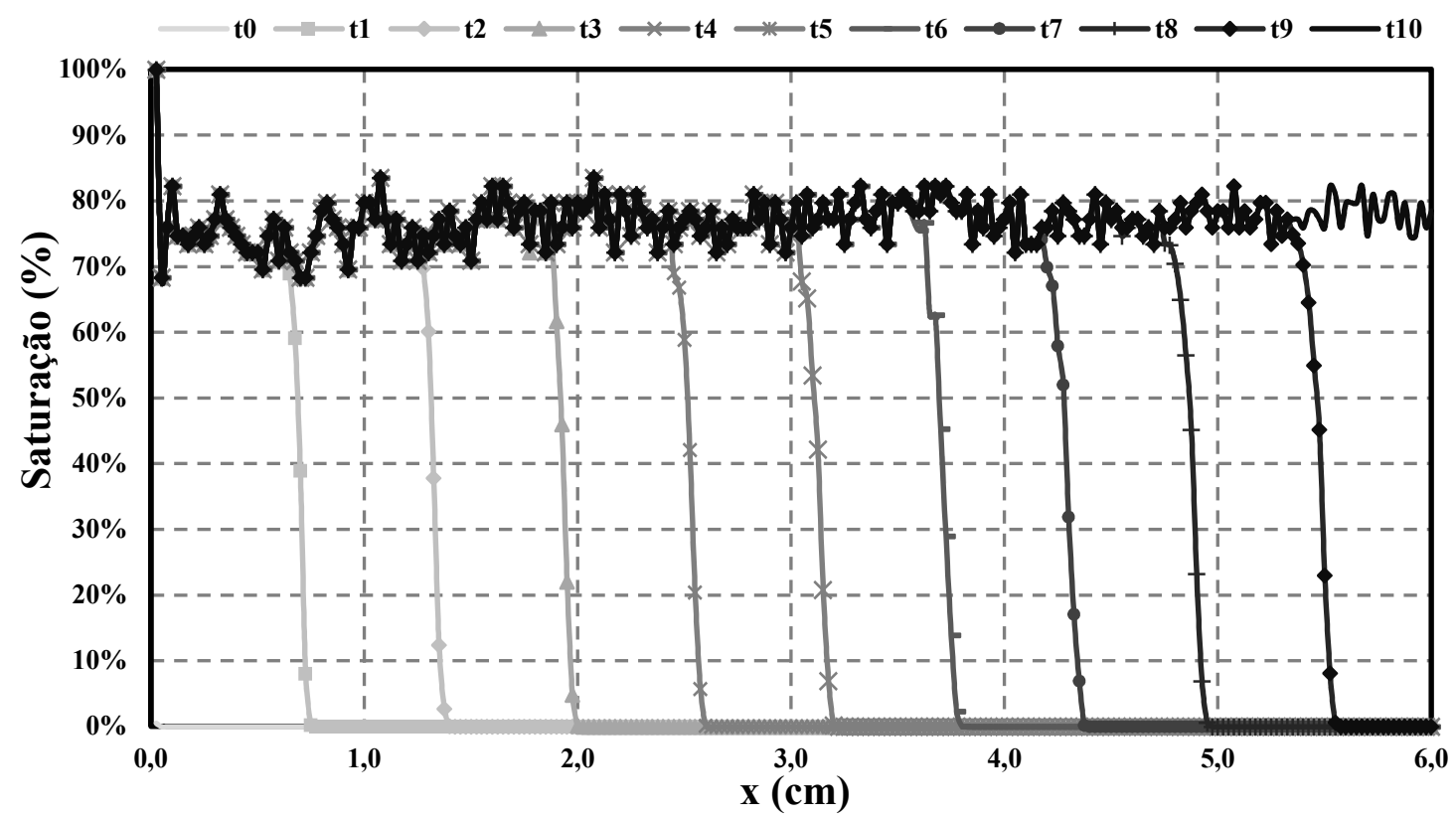

Figura 35 Simulação (1) - Curva de saturação em função da posição no eixo x para diferentes instantes de tempo. 
Tabela 3 - Simulação (2) - Parâmetros e resultados finais obtidos para um fluido Newtoniano

\begin{tabular}{|c|c|c|}
\hline & Parâmetro & Valor \\
\hline \multirow{3}{*}{ 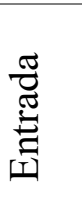 } & Viscosidade do fluido injetado & $10^{-3}$ Pa.s \\
\hline & Viscosidade do óleo & $1,78.10^{-2}$ Pa.s \\
\hline & Vazão de entrada & $10^{-8} \mathrm{~m}^{3} / \mathrm{s}$ \\
\hline \multirow{5}{*}{ 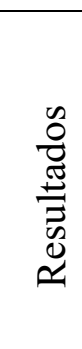 } & Número de Capilaridade & $5,26.10^{-3}$ \\
\hline & Saturação final de água & $79,14 \%$ \\
\hline & Volume poroso injetado & 0,085 \\
\hline & Tempo de escoamento & $0,24 s$ \\
\hline & Número de iterações & 36578 \\
\hline
\end{tabular}
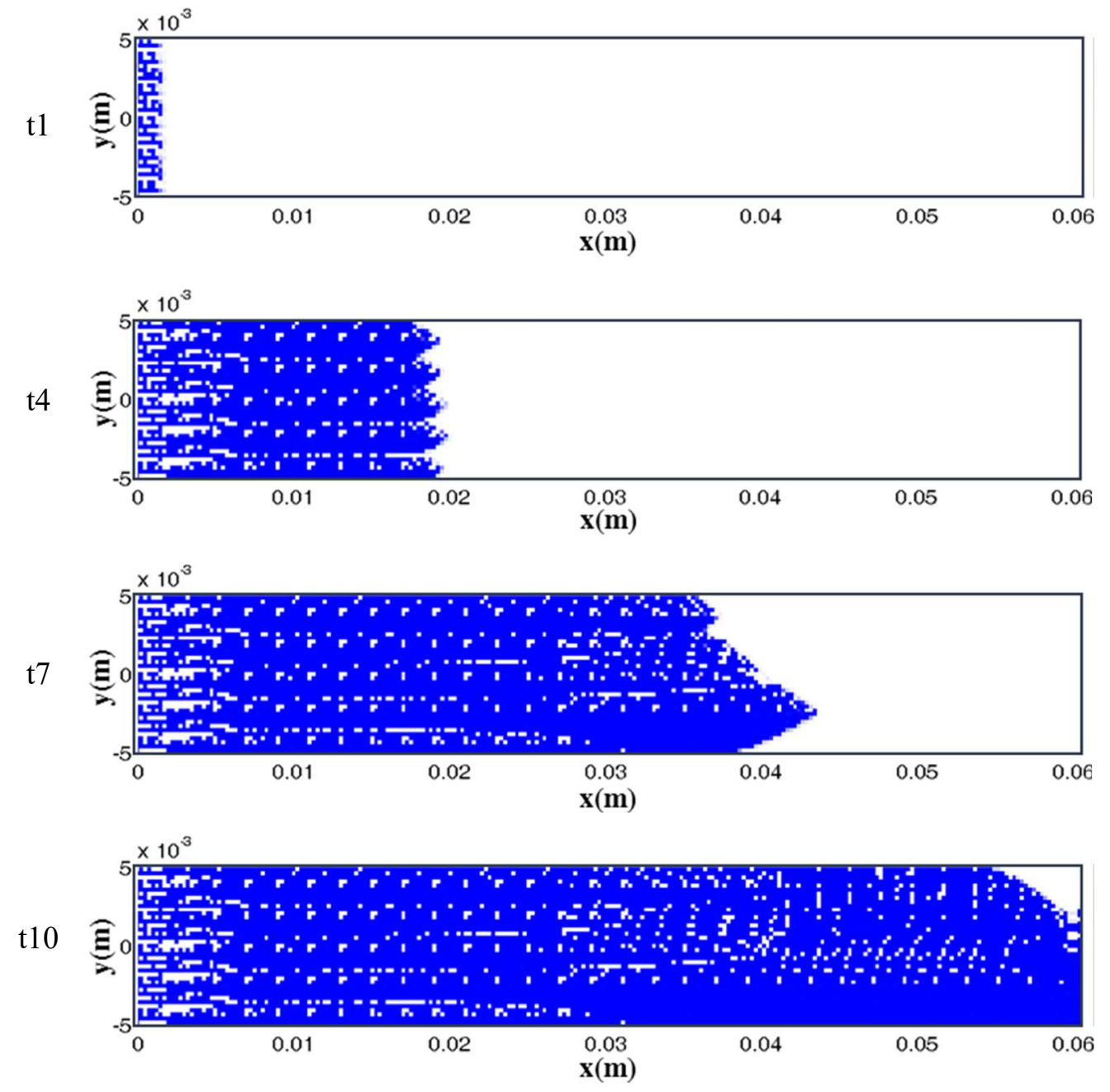

Figura 36 Simulação (2) - Mapa de saturação para um fluido Newtoniano em quatro instantes de tempo 

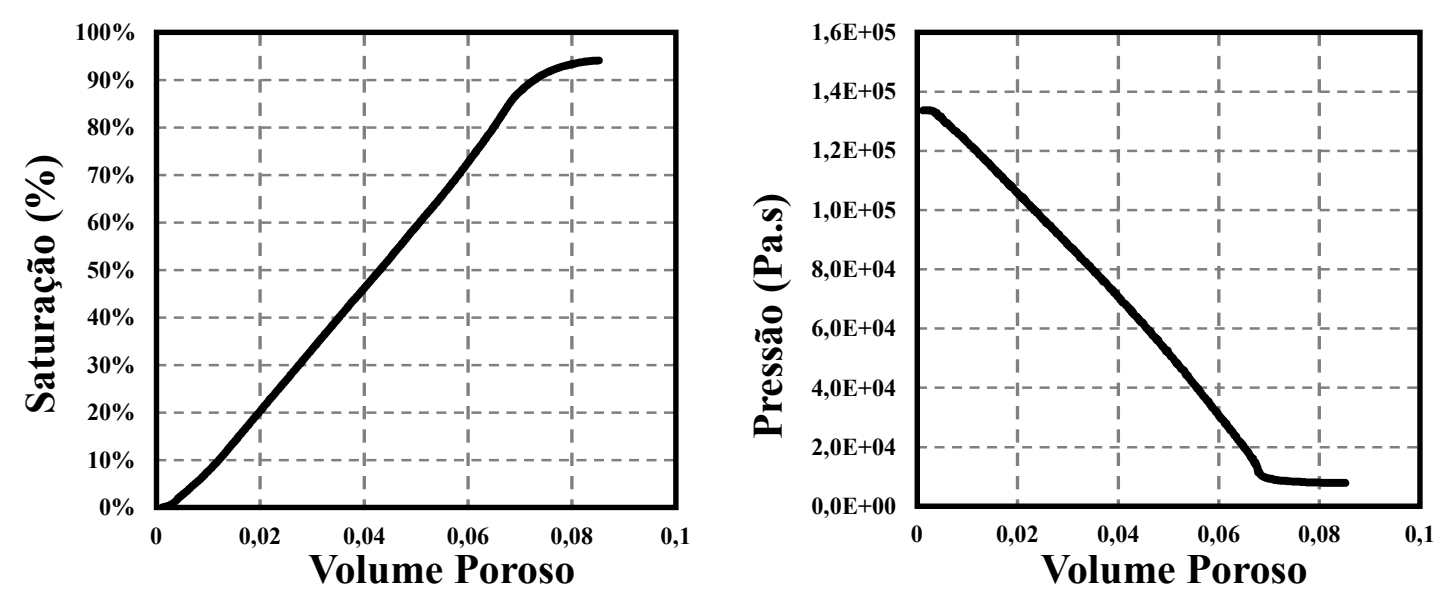

Figura 37 Simulação (2) - Curva de saturação e pressão de entrada em função do volume poroso injetado.

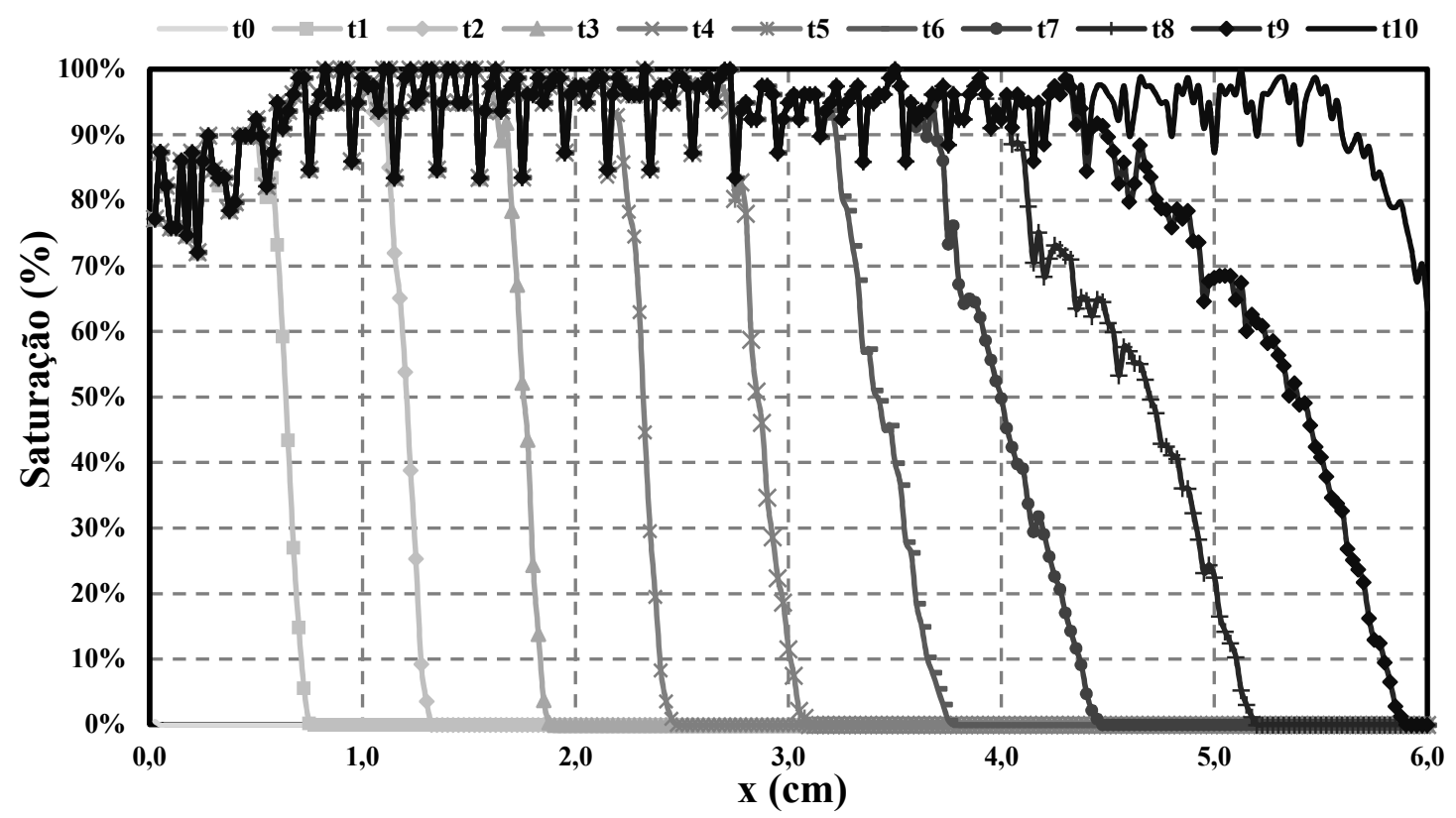

Figura 38 Simulação (2) - Curva de saturação em função da posição no eixo x para diferentes instantes de tempo. 
Tabela 4 - Simulação (3) - Parâmetros e resultados finais obtidos para o escoamento de um fluido Newtoniano

\begin{tabular}{|c|c|c|}
\hline & Parâmetro & Valor \\
\hline \multirow{3}{*}{ 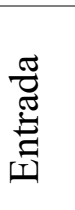 } & Viscosidade do fluido injetado & $10^{-3}$ Pa.s \\
\hline & Viscosidade do óleo & $1,78.10^{-2} \mathrm{~Pa} . \mathrm{s}$ \\
\hline & Vazão de entrada & $10^{-6} \mathrm{~m}^{3} / \mathrm{s}$ \\
\hline \multirow{5}{*}{ 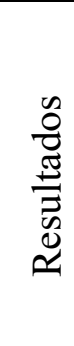 } & Número de Capilaridade & 0,52 \\
\hline & Saturação final de água & $83,42 \%$ \\
\hline & Volume poroso injetado & 0,70 \\
\hline & Tempo de escoamento & $0,22 s$ \\
\hline & Número de iterações & 37105 \\
\hline
\end{tabular}

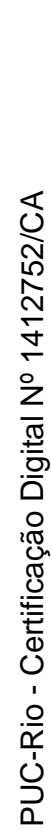
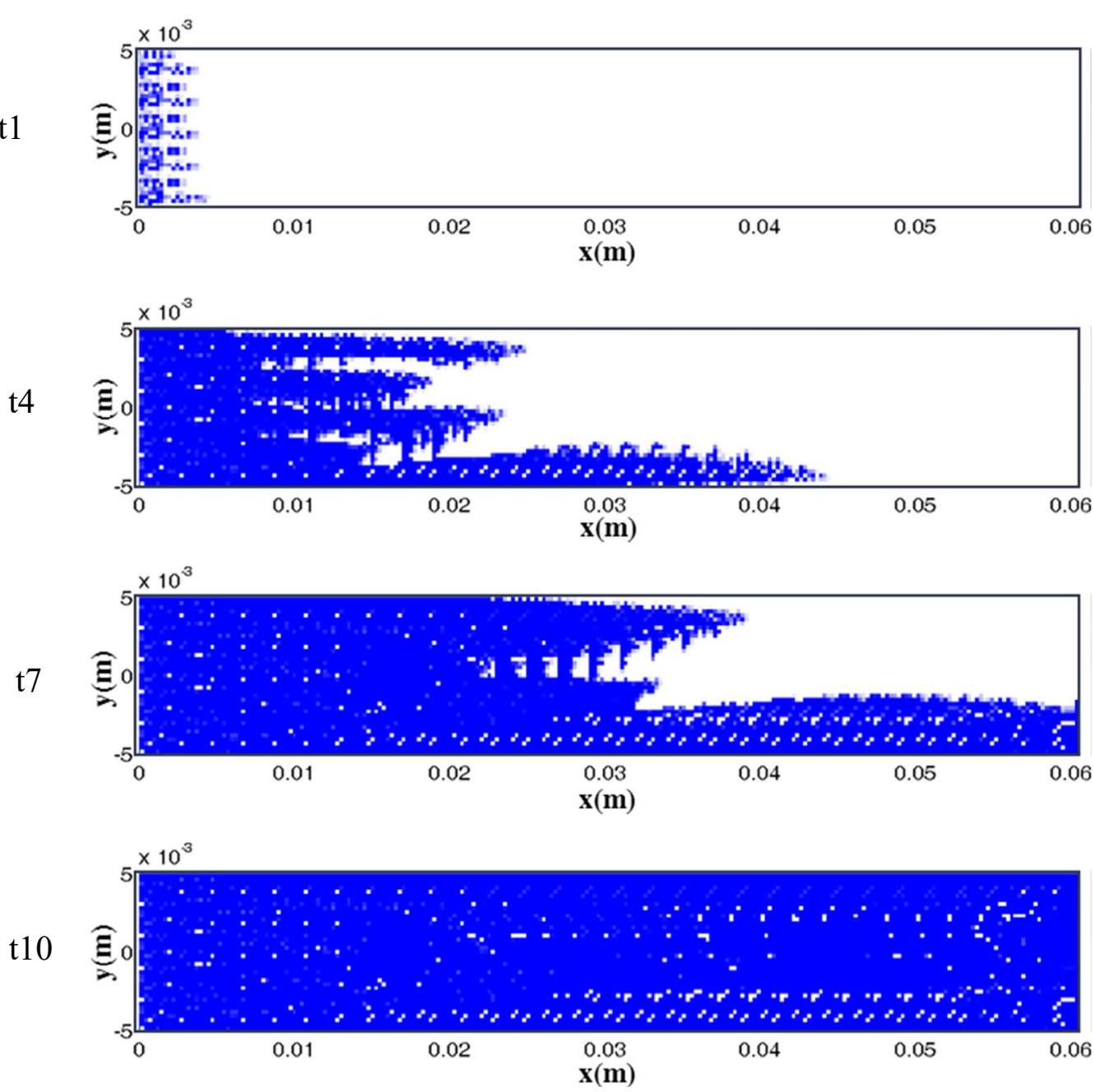

Figura 39 Simulação (3) - Mapa de saturação para um fluido Newtoniano em quatro instantes de tempo 

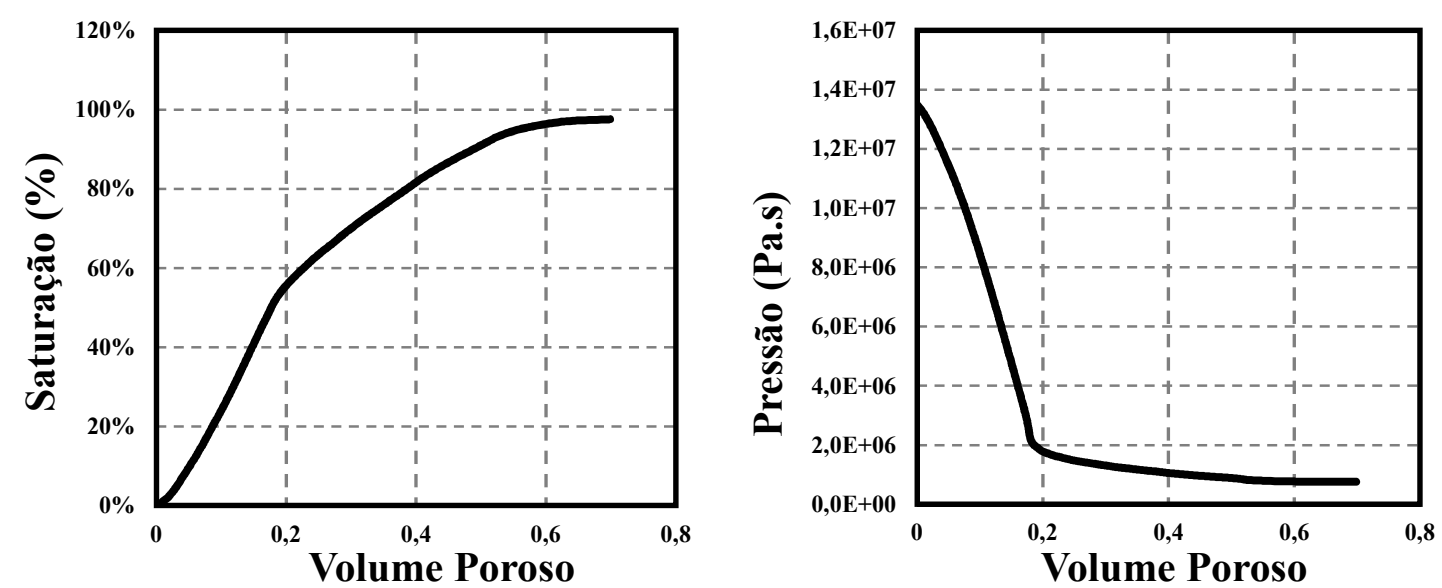

Figura 40 Simulação (3) - Curva de saturação e pressão de entrada em função do volume poroso injetado.

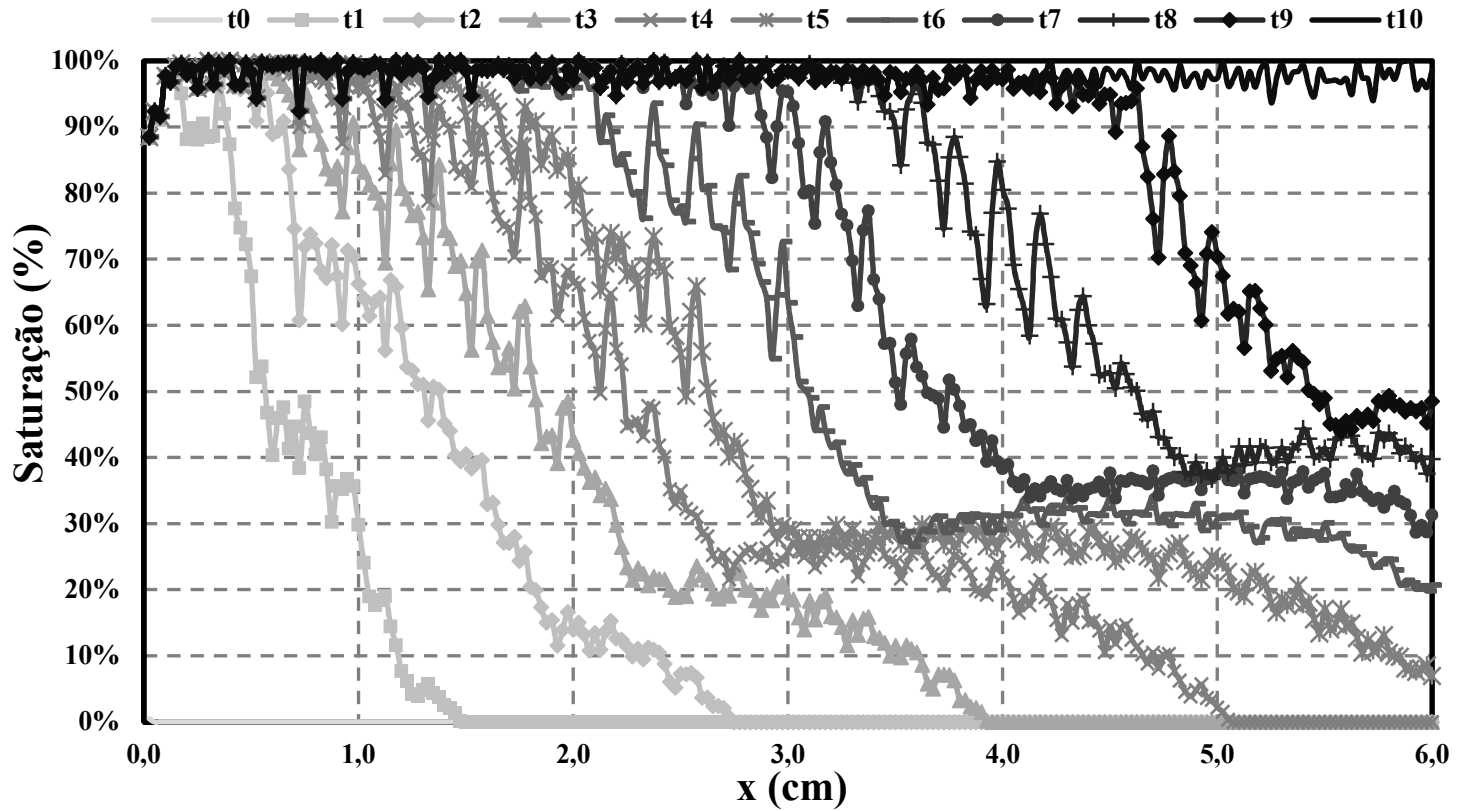

Figura 41 Simulação (3) - Curva de saturação em função da posição no eixo x para diferentes instantes de tempo. 
Tabela 5 - Simulação (4) - Parâmetros e resultados finais obtidos para o escoamento de um fluido Newtoniano

\begin{tabular}{|c|c|c|}
\hline & Parâmetro & Valor \\
\hline \multirow{3}{*}{ 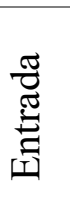 } & Viscosidade do fluido injetado & $10^{-3} \mathrm{~Pa} . \mathrm{S}$ \\
\hline & Viscosidade do óleo & 1,78.10 ${ }^{-2}$ Pa.s \\
\hline & Vazão de entrada & $10^{-4} \mathrm{~m}^{3} / \mathrm{s}$ \\
\hline \multirow{5}{*}{ 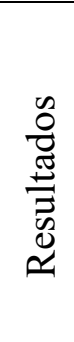 } & Número de Capilaridade & 52,6 \\
\hline & Saturação final de água & $85,32 \%$ \\
\hline & Volume poroso injetado & 0,97 \\
\hline & Tempo de escoamento & $2,7.10^{-4} s$ \\
\hline & Número de iterações & 36001 \\
\hline
\end{tabular}
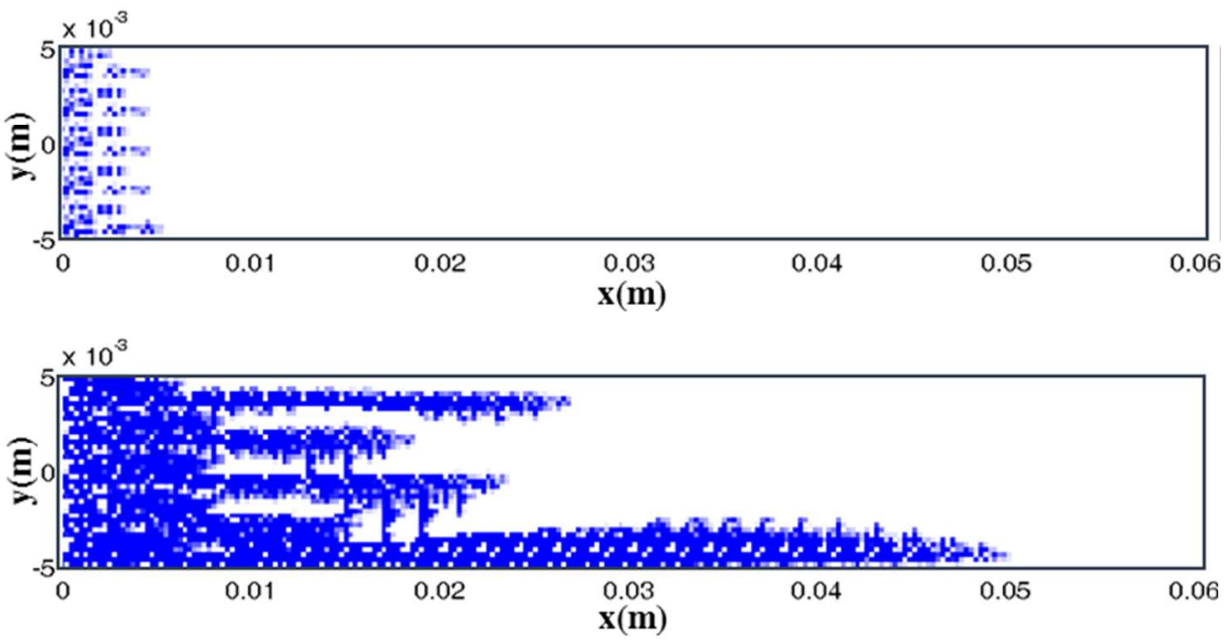

$\mathrm{t} 7$

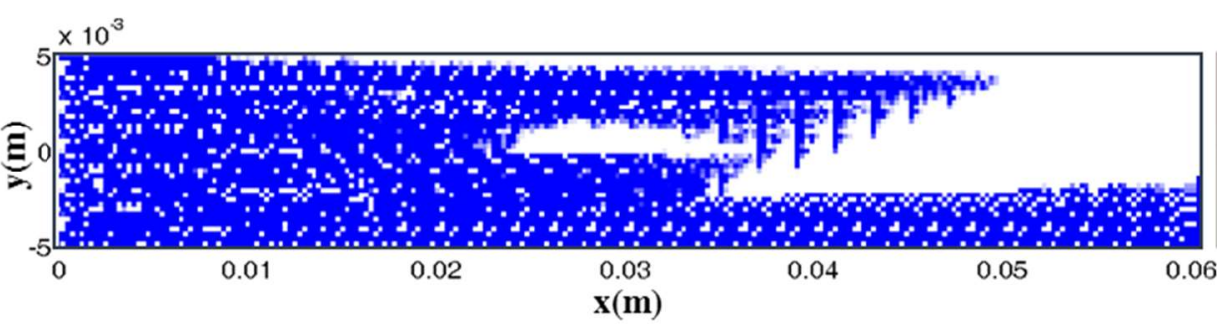

$\mathrm{t} 10$

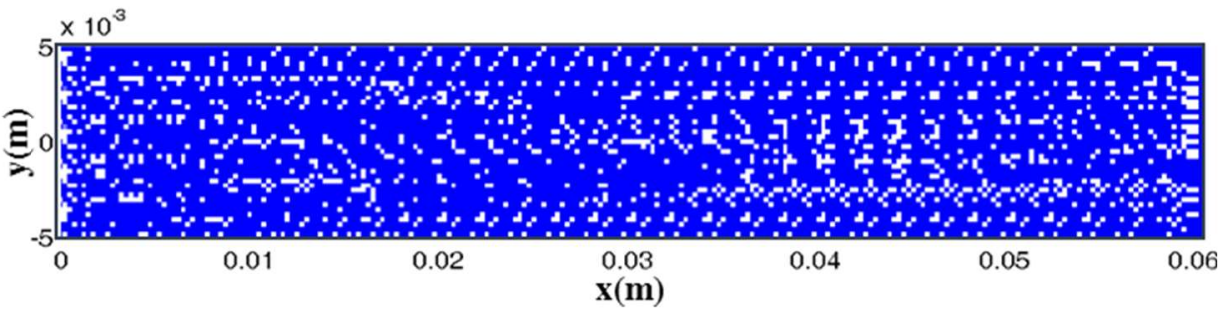

Figura 42 Simulação (4) - Mapa de saturação para um fluido Newtoniano em quatro instantes de tempo 

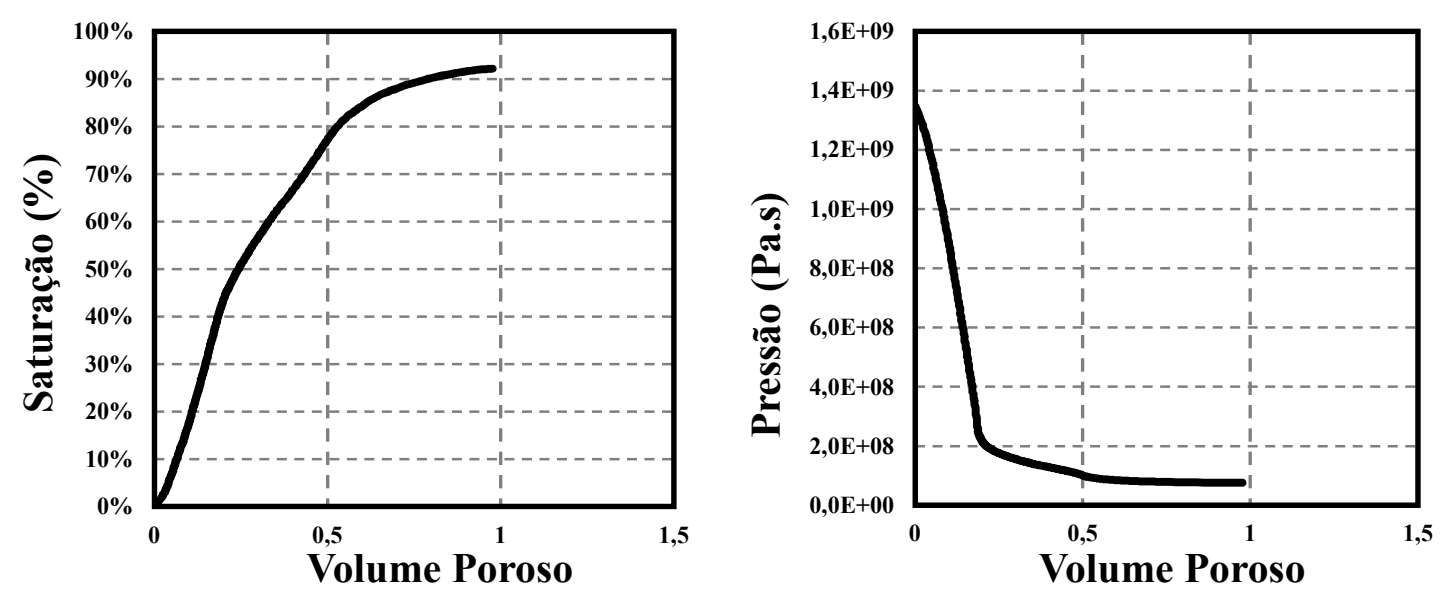

Figura 43 Simulação (4) - Curva de saturação e pressão de entrada em função do volume poroso injetado.

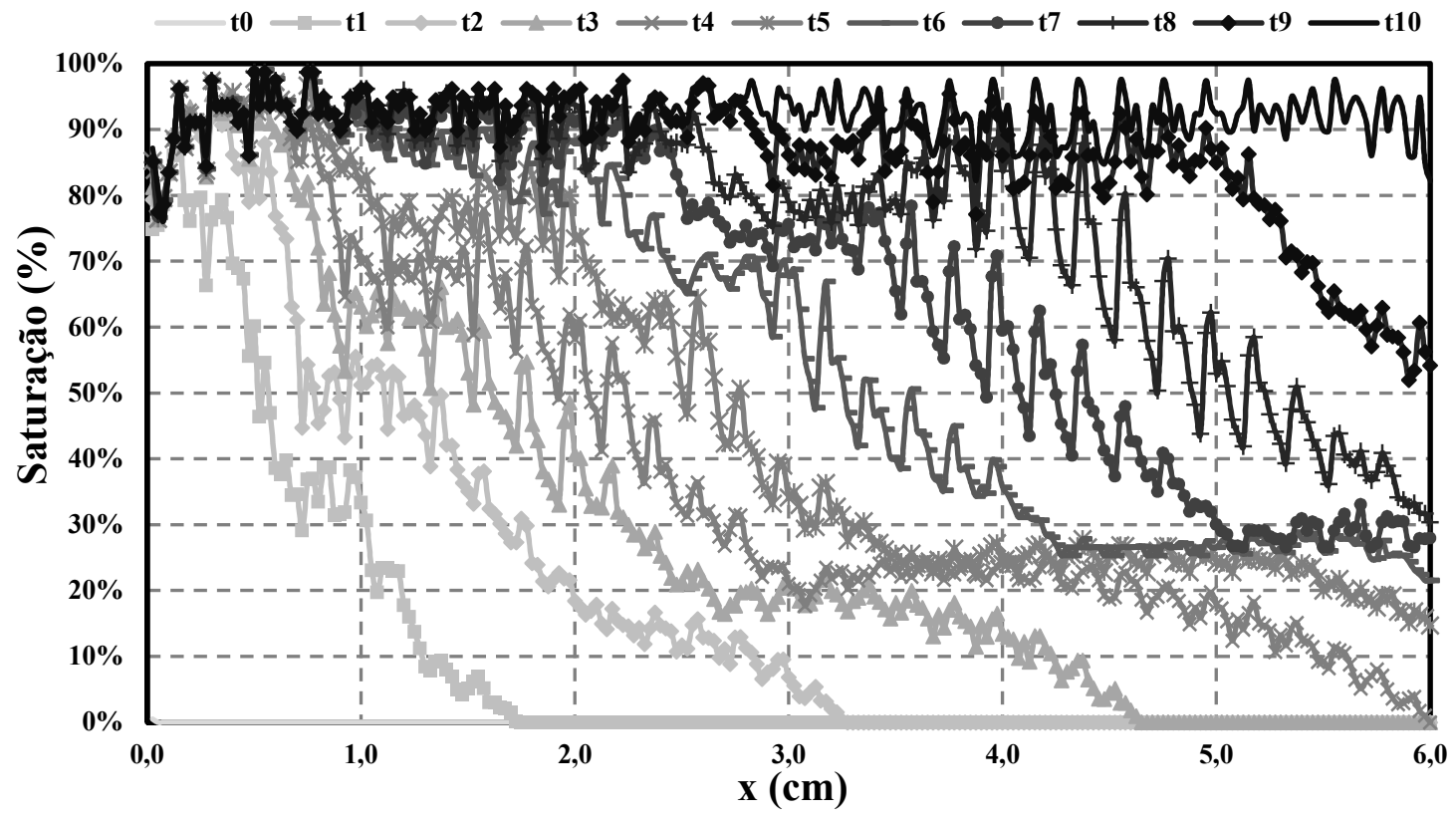

Figura 44 Simulação (4) - Curva de saturação em função da posição no eixo x para diferentes instantes de tempo. 
Tabela 6 - Simulação (5) - Parâmetros e resultados finais obtidos para o escoamento de um fluido Newtoniano

\begin{tabular}{|c|c|c|}
\hline & Parâmetro & Valor \\
\hline \multirow{3}{*}{ 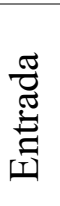 } & Viscosidade do fluido injetado & $10^{-3}$ Pa.s \\
\hline & Viscosidade do óleo & $1,78.10^{-2} \mathrm{~Pa} . \mathrm{s}$ \\
\hline & Vazão de entrada & $10^{-2} \mathrm{~m}^{3} / \mathrm{s}$ \\
\hline \multirow{5}{*}{ 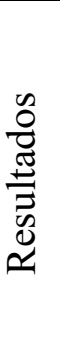 } & Número de Capilaridade & $5,26.10^{3}$ \\
\hline & Saturação final de água & $86,03 \%$ \\
\hline & Volume poroso injetado & 1,00 \\
\hline & Tempo de escoamento & $2,8.10^{-6} s$ \\
\hline & Número de iterações & 38769 \\
\hline
\end{tabular}

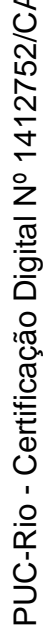
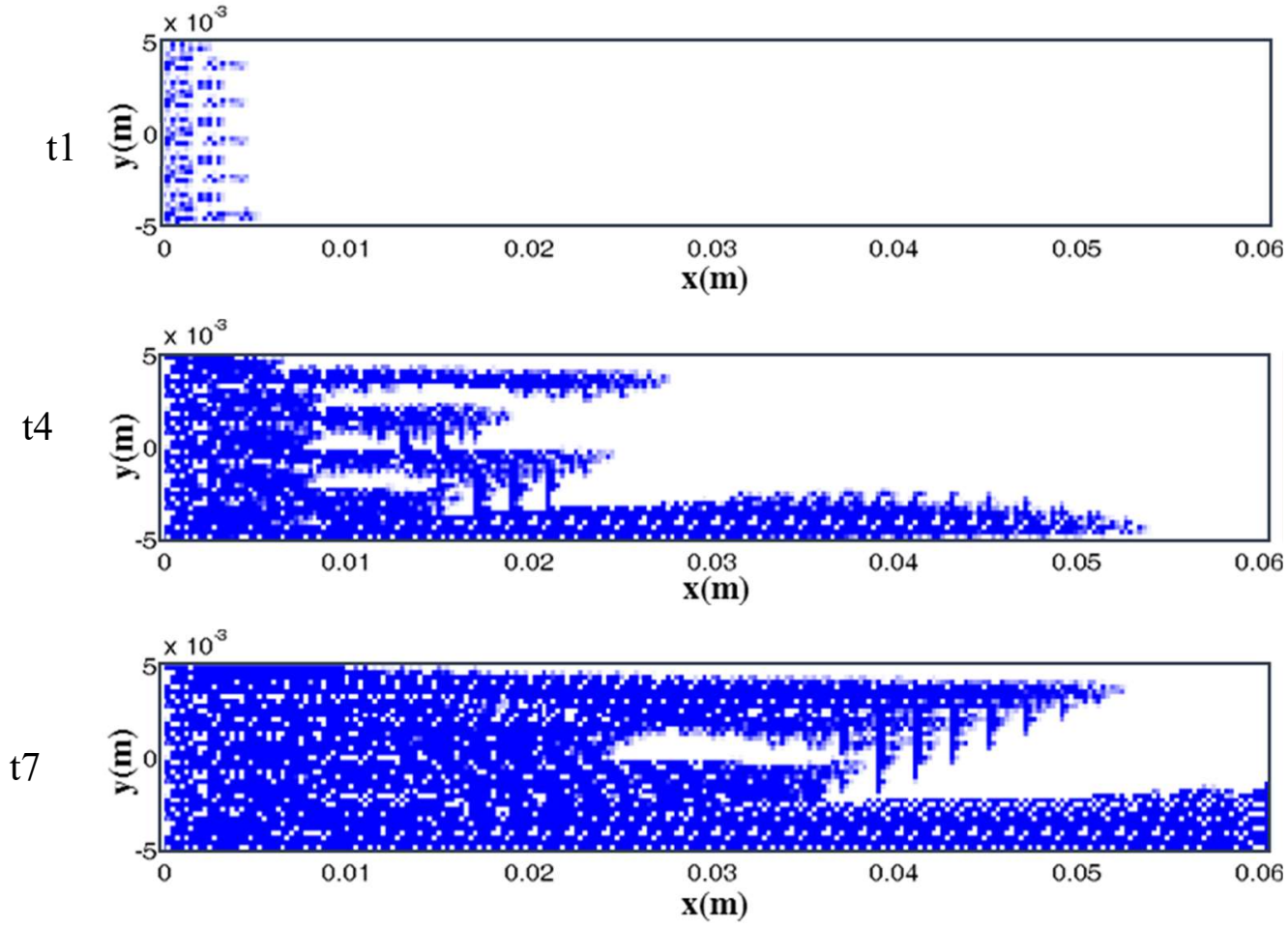

$\mathrm{t} 10$

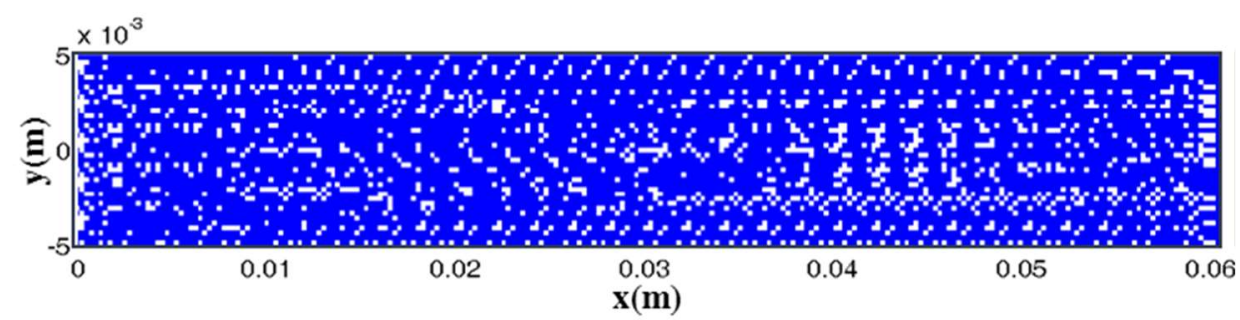

Figura 45 Simulação (5) - Mapa de saturação para um fluido Newtoniano em quatro instantes de tempo. 

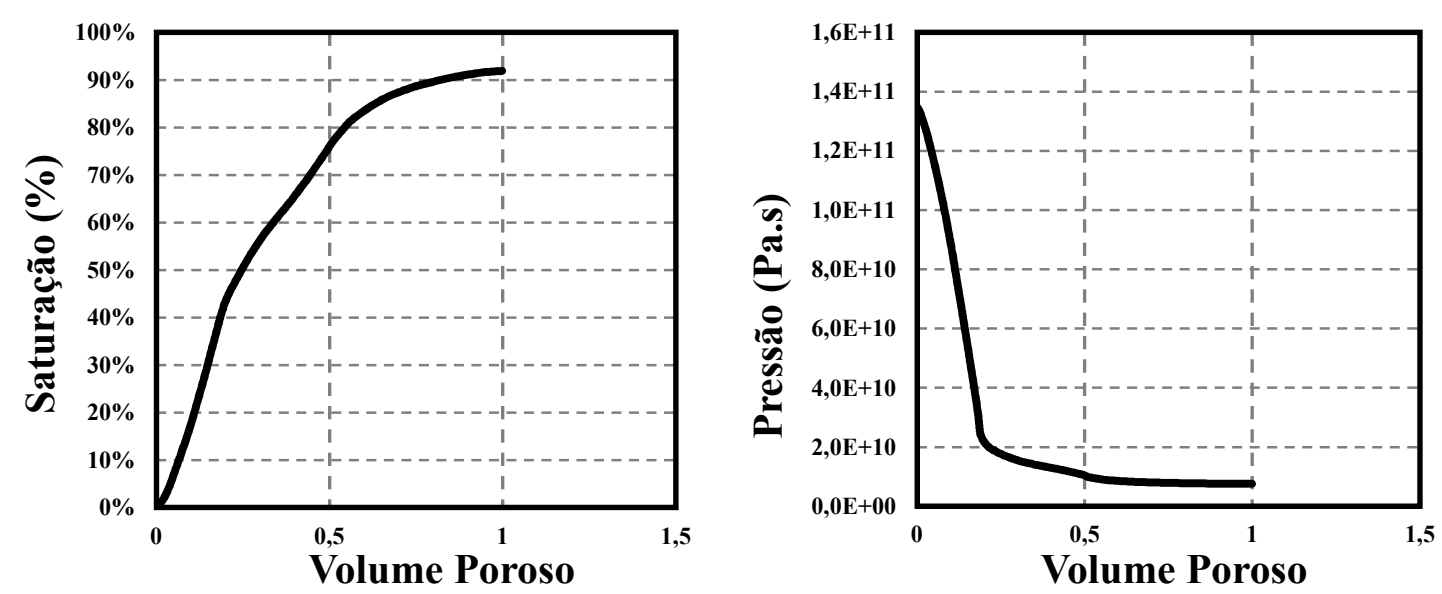

Figura 46 Simulação (5) - Curva de saturação e pressão de entrada em função do volume poroso injetado.

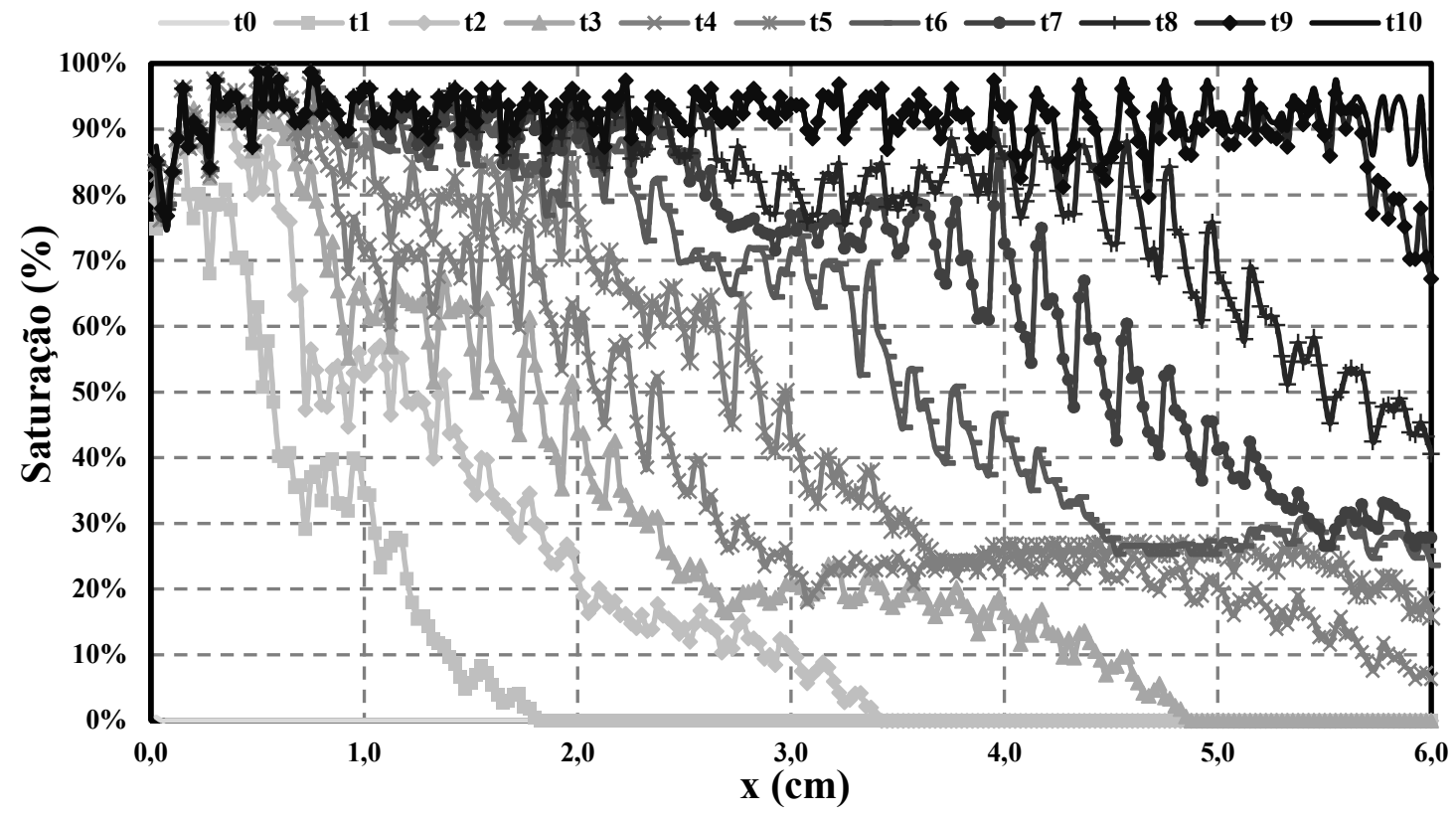

Figura 47 Simulação (5) - Curva de saturação em função da posição no eixo x para diferentes instantes de tempo. 


\subsubsection{Fluido não-Newtoniano}

Para um melhor entendimento do comportamento de fluidos não-Newtonianos, foram estudados mais dois casos usando soluções poliméricas com diferentes parâmetros reológicos ao longo do micromodelo saturado de óleo. Os fluidos em questão evidenciam um comportamento viscoelástico.

Para os dois casos não-Newtonianos, a simulação foi realizada considerando a viscosidade a baixa taxa de cisalhamento como sendo $\mu_{0}=10^{-3} \mathrm{~Pa}$. $\mathrm{S}$ e analisando o fluxo para cinco vazões de entrada diferentes.

O processo de invasão é ilustrado por uma sequência de mapas de saturação em quatro instantes de tempo, onde o óleo é representado pela cor branca e água pela cor azul no micromodelo. Para baixas vazões, o deslocamento do óleo pela solução polimérica tende a se manter uniforme.

O mapa de saturação para um fluido não-Newtoniano tem influência também da variação da viscosidade extensional. Para observar essa influência, um parâmetro foi criado para representar a viscosidade no mapa de saturação conforme definição a seguir:

$$
c=1-\frac{\mu}{\mu_{\infty}}
$$

O parâmetro c representa a viscosidade do fluido em cada capilar. Quando a viscosidade efetiva do fluido injetado é igual a viscosidade a alta taxa de cisalhamento, temos $c=0$, representado no mapa de viscosidade por um tom de azul mais escuro. Já para baixas viscosidades, quando $c \rightarrow 1$, é utilizado um tom de azul claro. Ou seja, a viscosidade varia entre 0 e 0,9 , conforme pode ser visto nos mapas apresentados nas figuras $48,52,56,60$ e 64 .

O primeiro caso contendo soluções poliméricas, simula o modelo de rede considerando a viscosidade a alta taxa de cisalhamento, $\mu_{\infty}=10^{-2} \mathrm{~Pa}$. S. Nas tabelas 7 , $8,9,10$ e 11, podemos ver melhor os resultados numéricos e os parâmetros utilizados em cada análise.

Fluidos viscoelásticos tornam-se mais difíceis de passar através dos capilares com restrição, como mostrado na análise para escoamento de fluidos monofásicos. Este efeito é observado nos capilares próximos a região onde a solução polimérica se encontra com 
o óleo. Para perceber melhor este efeito, foi dado um zoom destas áreas do mapa para todas as simulações conforme ilustrado nas figuras 49, 53, 57, 61 e 65.

Assim como no escoamento de um fluido Newtoniano, à medida em que a vazão aumenta o escoamento tende a se tornar menos uniforme como pode ser visto nos gráficos de saturação em relação a posição ao longo do micromodelo (figuras 51, 55, 59, 63 e 67). É importante observar também que o comportamento dos viscous fingers formados são menores que no caso de injeção de água.

As figuras 50, 54, 58, 62 e 66 mostram que o fluido não-Newtoniano injetado é menos viscosos que o óleo e, por isso, a pressão diminui em função do volume poroso injetado. 
Tabela 7 - Simulação (6) - Parâmetros e resultados finais obtidos para o escoamento de um fluido não-Newtoniano

\begin{tabular}{|c|c|c|}
\hline & Parâmetro & Valor \\
\hline \multirow{5}{*}{ 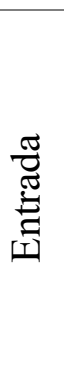 } & Viscosidade do óleo & 1,78. $10^{-2}$ Pa.s \\
\hline & Viscosidade infinita $\left(\boldsymbol{\mu}_{\infty}\right)$ & $10^{-2}$ Pa.s \\
\hline & Vazão de entrada & $10^{-10} \mathrm{~m}^{3} / \mathrm{s}$ \\
\hline & Índice de potência ( $\boldsymbol{n}$ ) & 0,7 \\
\hline & Tempo de relaxação $(\lambda)$ & $10^{-2} s^{-1}$ \\
\hline \multirow{5}{*}{ 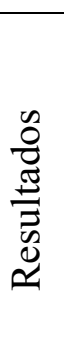 } & Número de Capilaridade & $5,26 \cdot 10^{-5}$ \\
\hline & Saturação final de água & $79,22 \%$ \\
\hline & Volume poroso injetado & 0,005 \\
\hline & Tempo de escoamento & $3,26 s$ \\
\hline & Número de iterações & 36807 \\
\hline
\end{tabular}

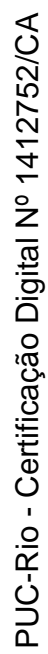
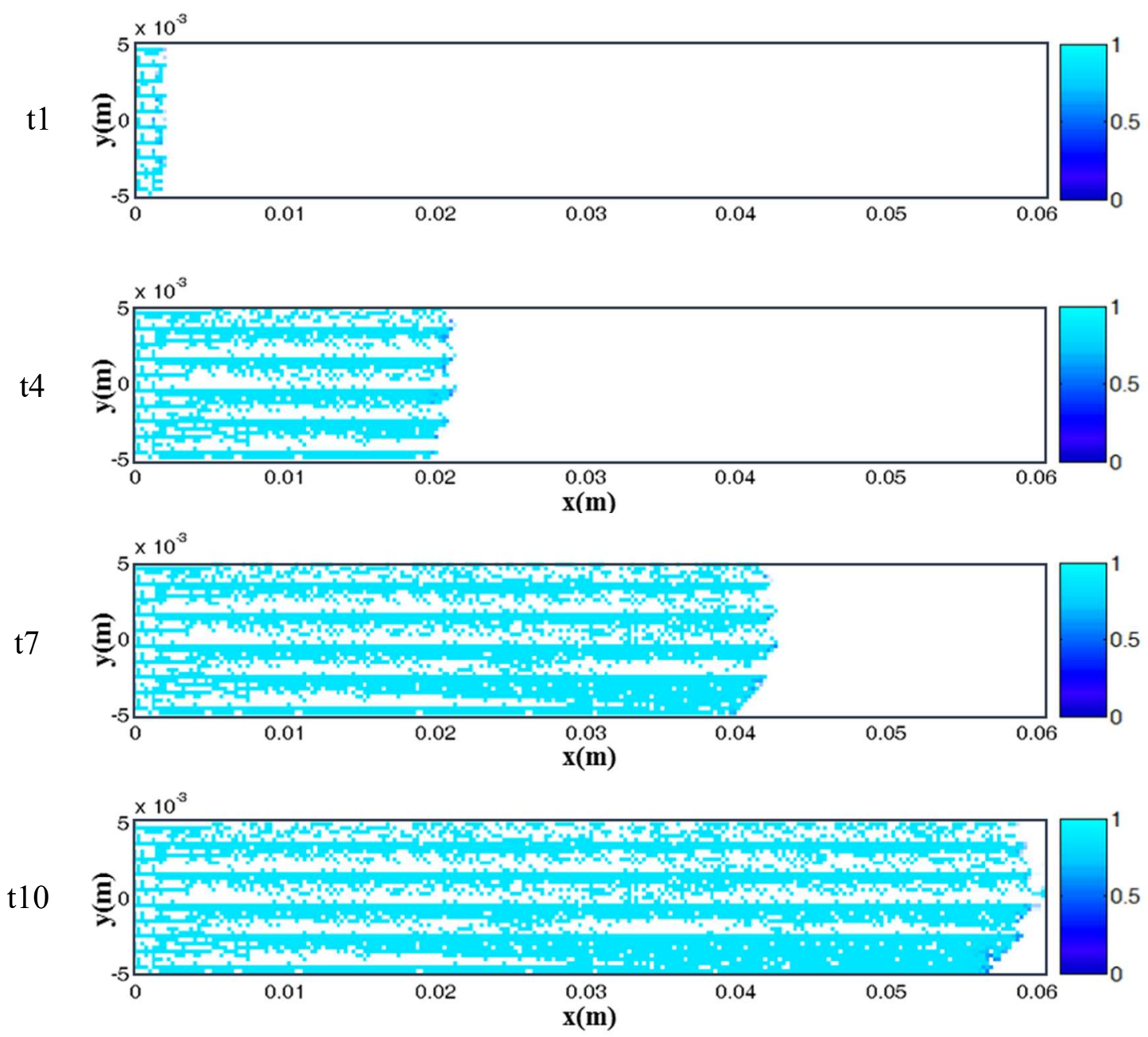

Figura 48 Simulação (6) - Mapa de saturação para um fluido Newtoniano em quatro instantes de tempo 


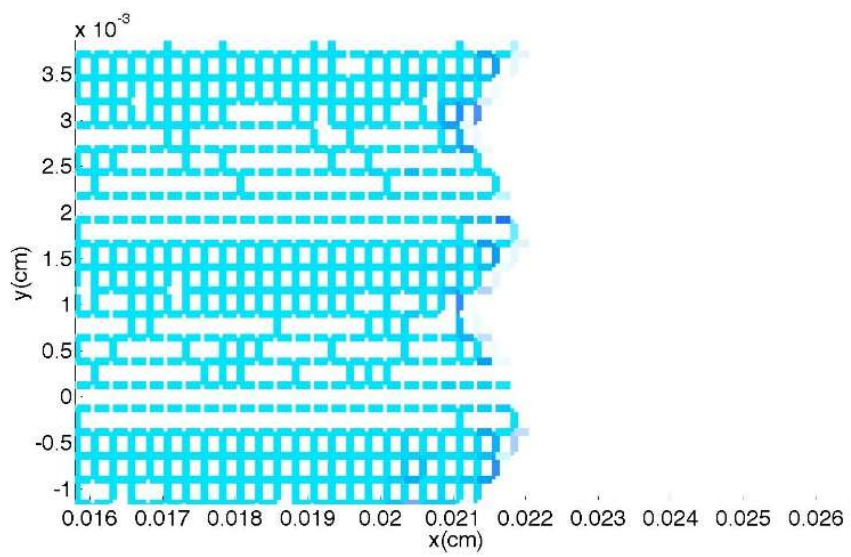

Figura 49 Simulação (6) - Zoom do mapa de saturação no segundo instante.

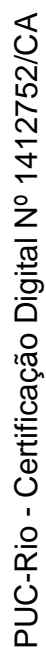
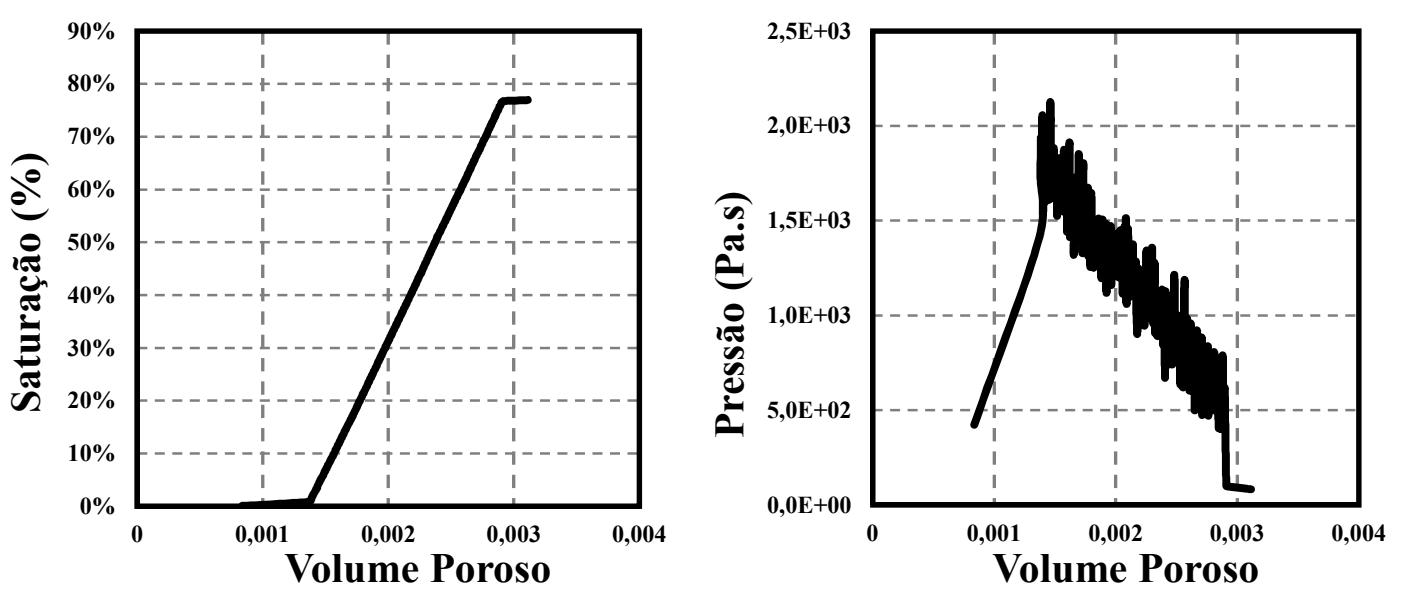

Figura 50 Simulação (6) - Curva de saturação e pressão de entrada em função do volume poroso injetado.

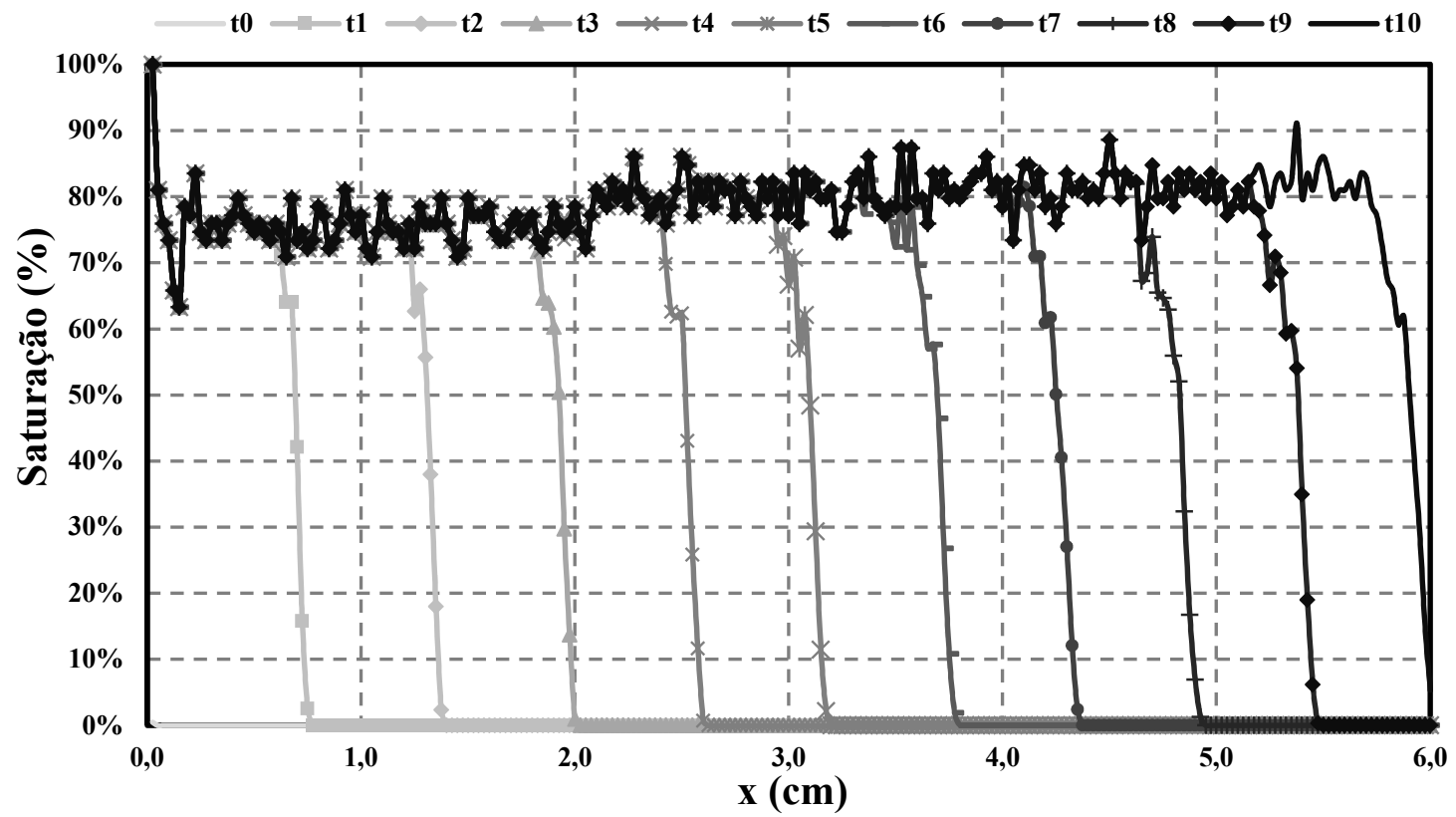

Figura 51 Simulação (6) - Curva de saturação em função da posição no eixo x para diferentes instantes de tempo. 
Tabela 8 - Simulação (7) - Parâmetros e resultados finais obtidos para o escoamento de um fluido não-Newtoniano

\begin{tabular}{|c|c|c|}
\hline & Parâmetro & Valor \\
\hline \multirow{5}{*}{ 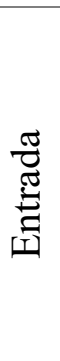 } & Viscosidade do óleo & $1,78.10^{-2}$ Pa.s \\
\hline & Viscosidade infinita $\left(\boldsymbol{\mu}_{\infty}\right)$ & $10^{-2}$ Pa.s \\
\hline & Vazão de entrada & $10^{-8} \mathrm{~m}^{3} / \mathrm{s}$ \\
\hline & Índice de potência $(\boldsymbol{n})$ & 0,7 \\
\hline & Tempo de relaxação $(\lambda)$ & $10^{-2} s^{-1}$ \\
\hline \multirow{5}{*}{ 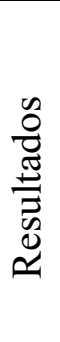 } & Número de Capilaridade & $5,26.10^{-3}$ \\
\hline & Saturação final de água & $81,51 \%$ \\
\hline & Volume poroso injetado & 0,10 \\
\hline & Tempo de escoamento & $0,27 s$ \\
\hline & Número de iterações & 37546 \\
\hline
\end{tabular}

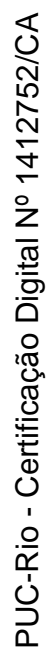
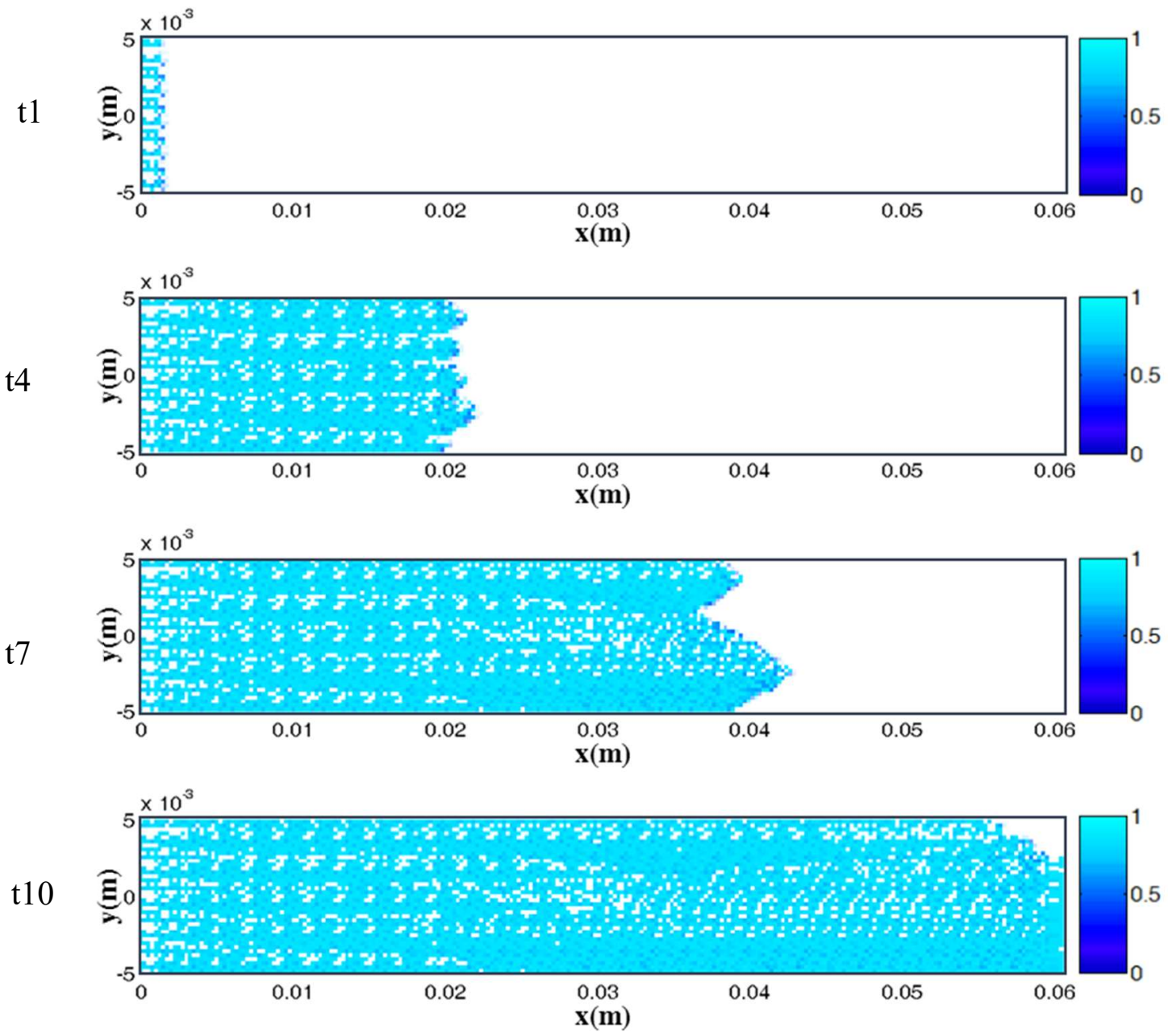

Figura 52 Simulação (7) - Mapa de saturação para um fluido não-Newtoniano em quatro instantes de tempo 


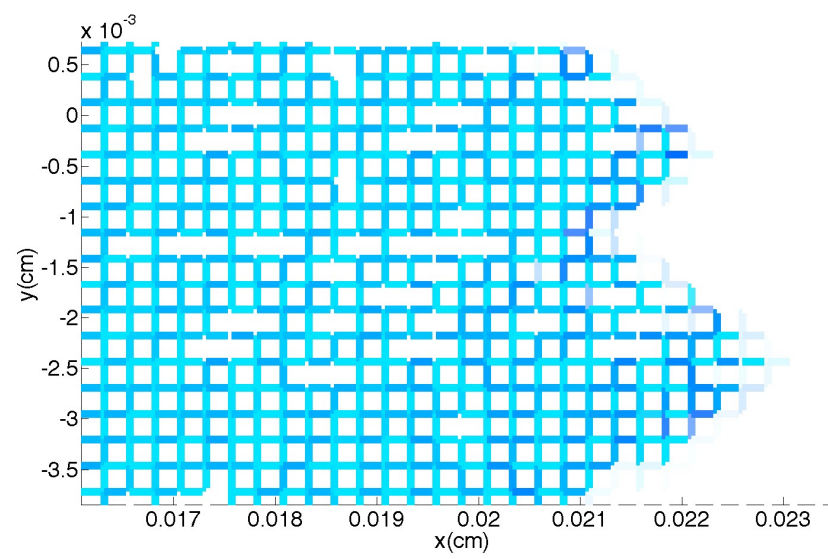

Figura 53 Simulação (7) - Zoom do mapa de saturação no segundo instante.

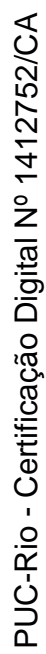
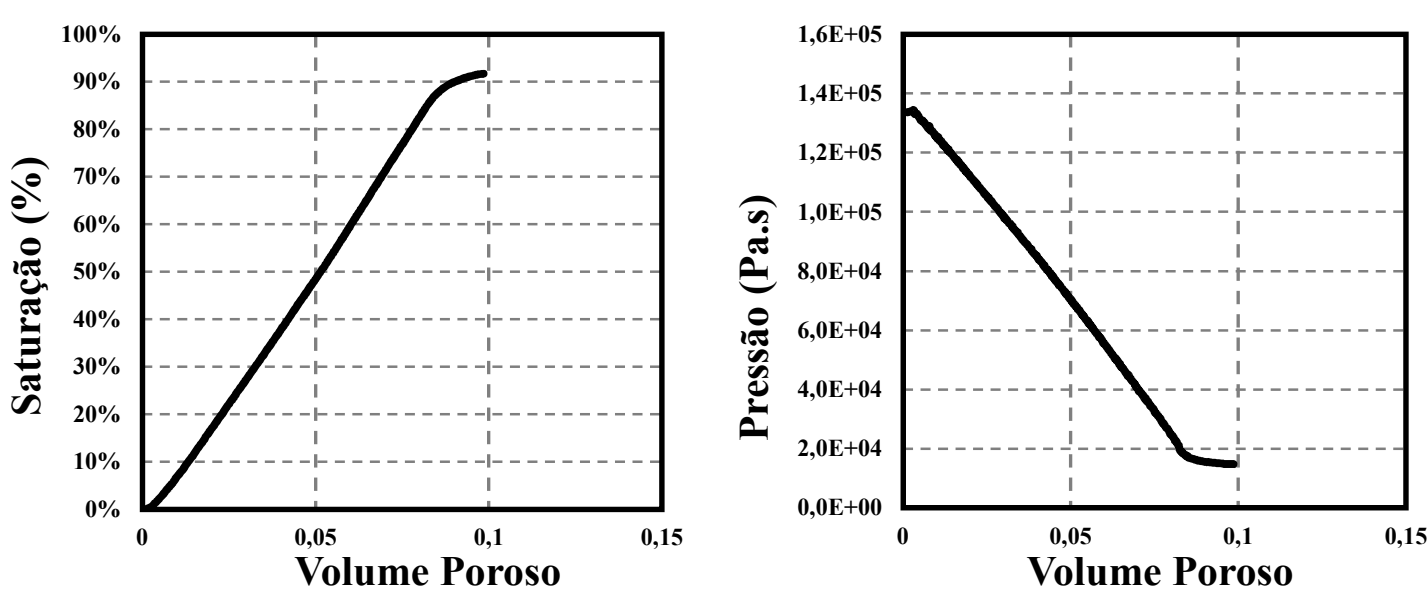

Figura 54 Simulação (7) - Curva de saturação e pressão de entrada em função do volume poroso injetado.

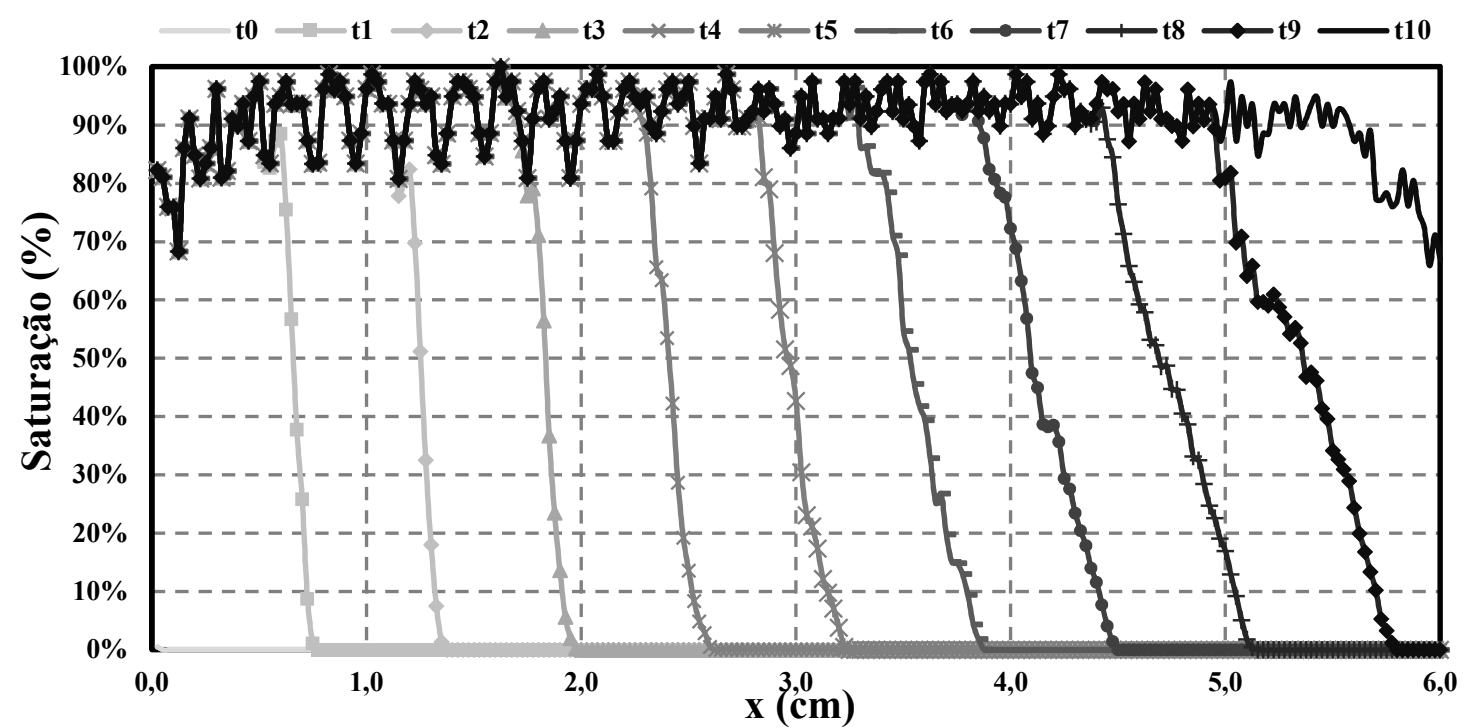

Figura 55 Simulação (7) - Curva de saturação em função da posição no eixo $x$ para diferentes instantes de tempo. 
Tabela 9 - Simulação (8) - Parâmetros e resultados finais obtidos para o escoamento de um fluido não-Newtoniano

\begin{tabular}{|c|c|c|}
\hline & Parâmetro & Valor \\
\hline \multirow{5}{*}{ 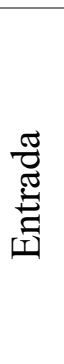 } & Viscosidade do óleo & 1,78. $10^{-2}$ Pa.s \\
\hline & Viscosidade infinita $\left(\boldsymbol{\mu}_{\infty}\right)$ & $10^{-2}$ Pa.s \\
\hline & Vazão de entrada & $10^{-6} \mathrm{~m}^{3} / \mathrm{s}$ \\
\hline & Índice de potência $(\boldsymbol{n})$ & 0,7 \\
\hline & Tempo de relaxação $(\lambda)$ & $10^{-2} s^{-1}$ \\
\hline \multirow{5}{*}{ 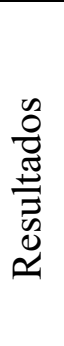 } & Número de Capilaridade & 0,52 \\
\hline & Saturação final de água & $87,74 \%$ \\
\hline & Volume poroso injetado & 0,54 \\
\hline & Tempo de escoamento & $0,014 s$ \\
\hline & Número de iterações & 34910 \\
\hline
\end{tabular}

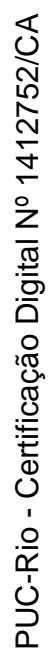
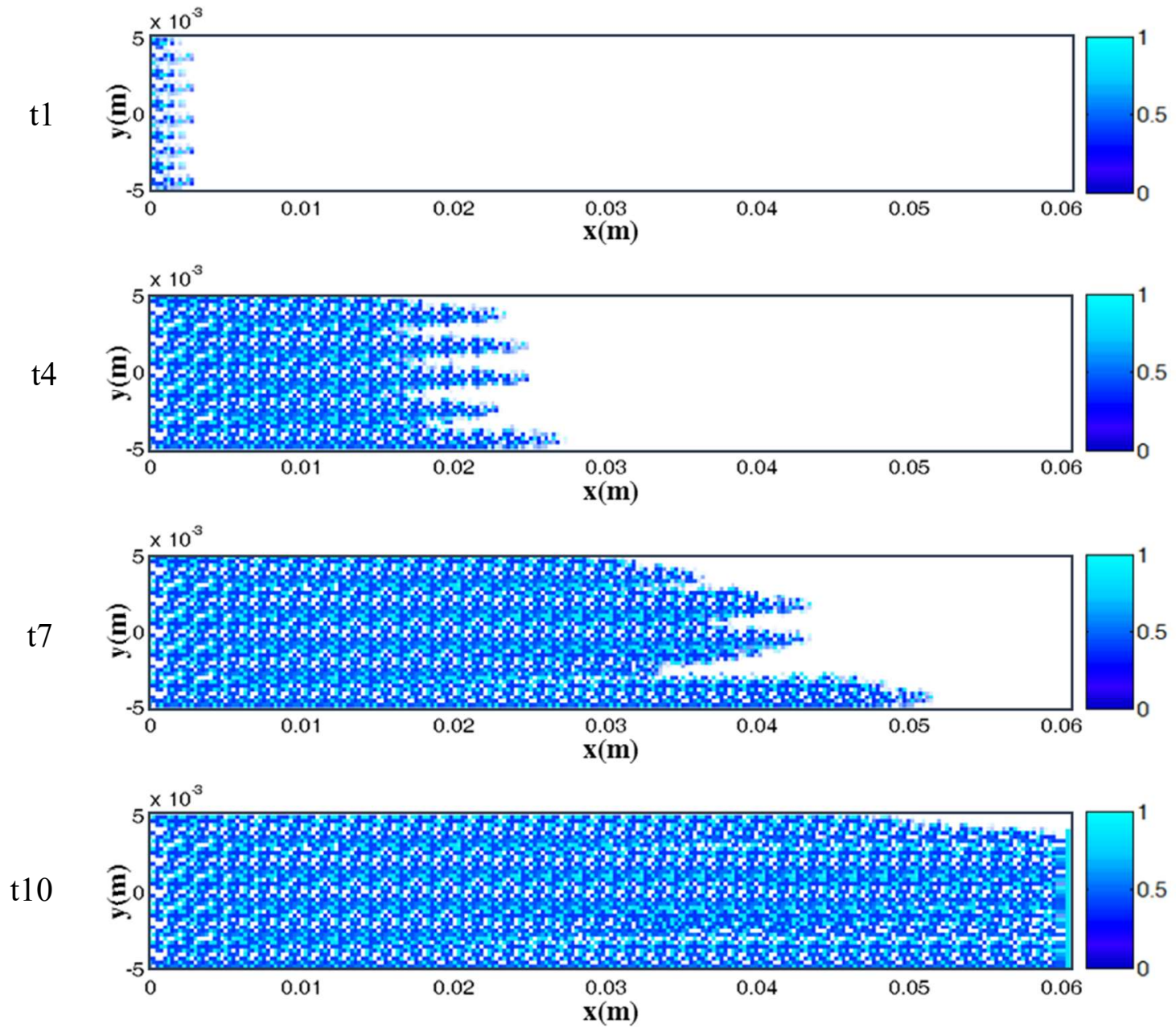

Figura 56 Simulação (8) - Mapa de saturação para um fluido não-Newtoniano em quatro instantes de tempo 


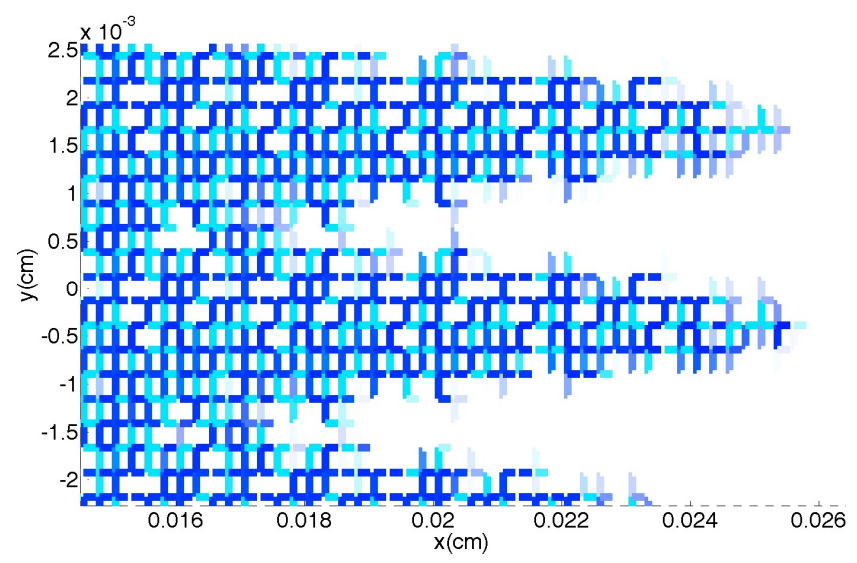

Figura 57 Simulação (8) - Zoom do mapa de saturação no segundo instante.

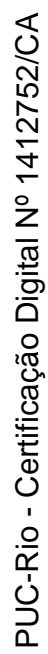
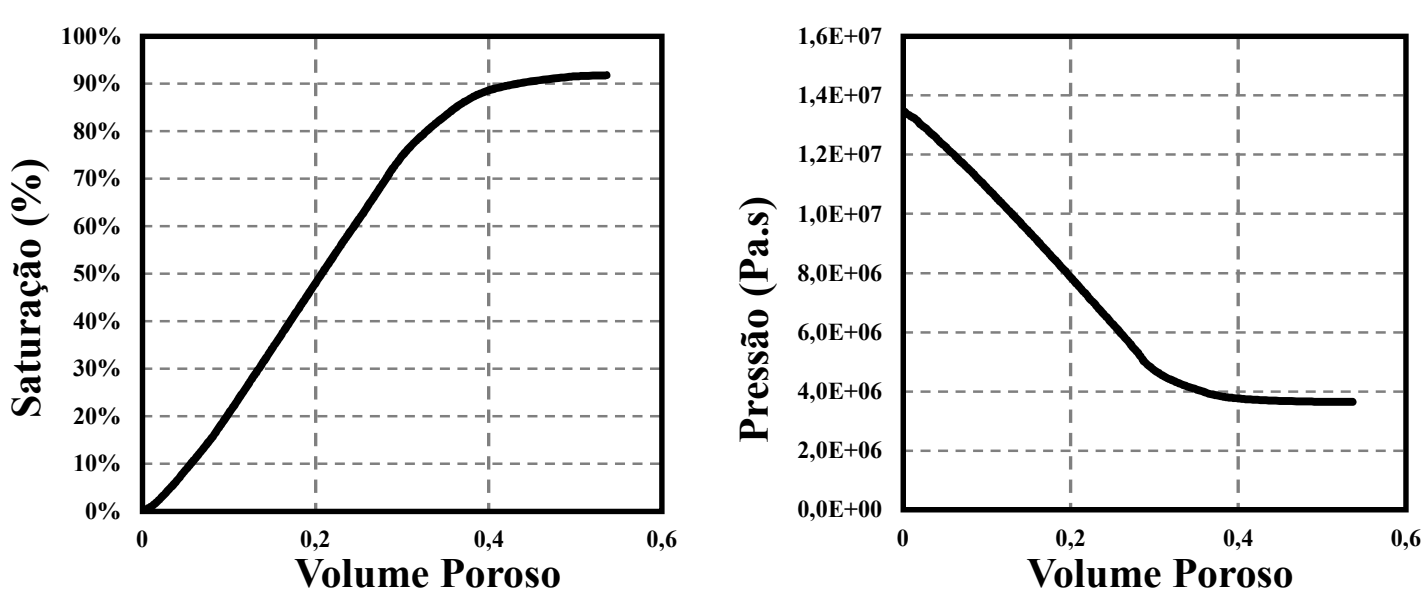

Figura 58 Simulação (8) - Curva de saturação e pressão de entrada em função do volume poroso injetado.

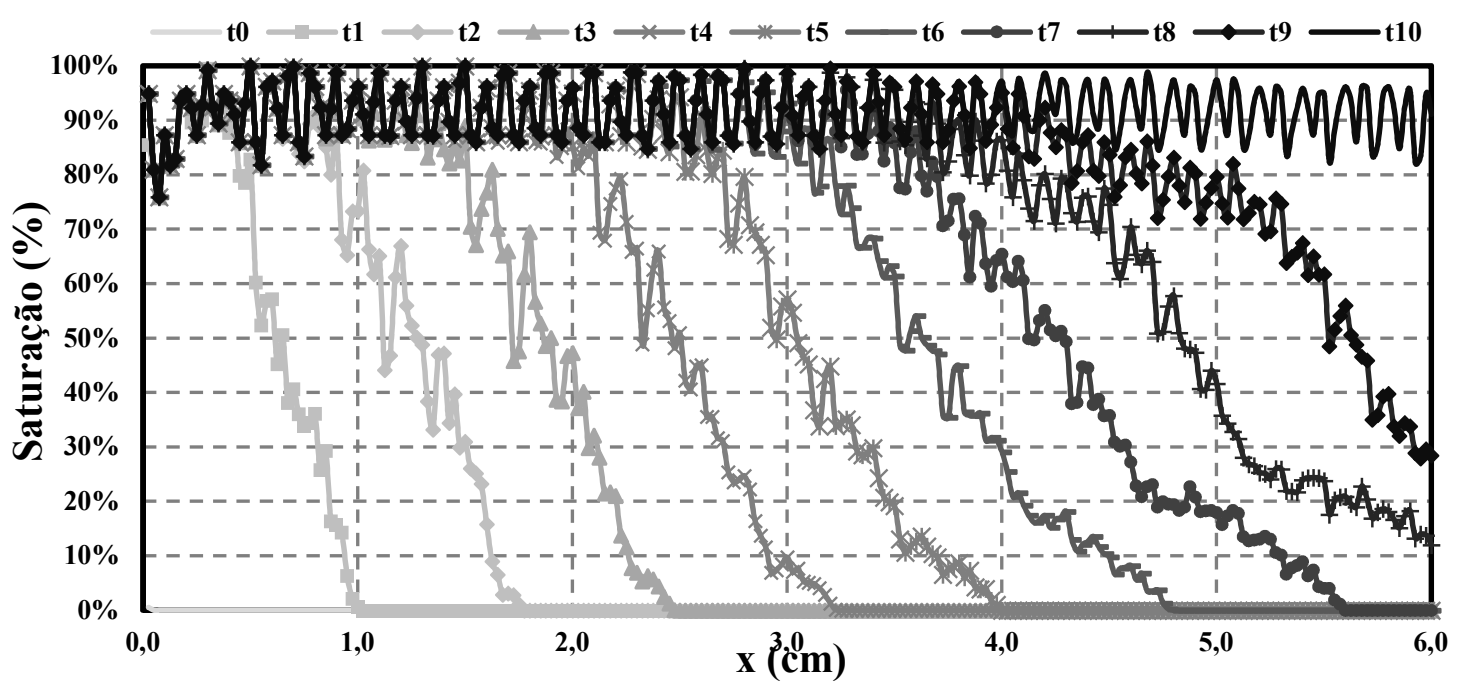

Figura 59 Simulação (8) - Curva de saturação em função da posição no eixo x para diferentes instantes de tempo. 
Tabela 10 - Simulação (9) - Parâmetros e resultados finais obtidos para o escoamento de um fluido não-Newtoniano

\begin{tabular}{|c|c|c|}
\hline & Parâmetro & Valor \\
\hline \multirow{5}{*}{ 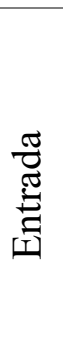 } & Viscosidade do óleo & $1,78.10^{-2}$ Pa.s \\
\hline & Viscosidade infinita $\left(\boldsymbol{\mu}_{\infty}\right)$ & $10^{-2}$ Pa.s \\
\hline & Vazão de entrada & $10^{-4} \mathrm{~m}^{3} / \mathrm{s}$ \\
\hline & Índice de potência ( $\boldsymbol{n}$ ) & 0,7 \\
\hline & Tempo de relaxação $(\lambda)$ & $10^{-2} s^{-1}$ \\
\hline \multirow{5}{*}{ 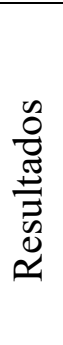 } & Número de Capilaridade & 52,6 \\
\hline & Saturação final de água & $90,20 \%$ \\
\hline & Volume poroso injetado & 0,59 \\
\hline & Tempo de escoamento & $1,74.10^{-4} s$ \\
\hline & Número de iterações & 34324 \\
\hline
\end{tabular}

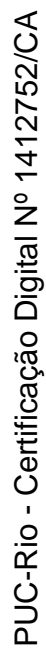
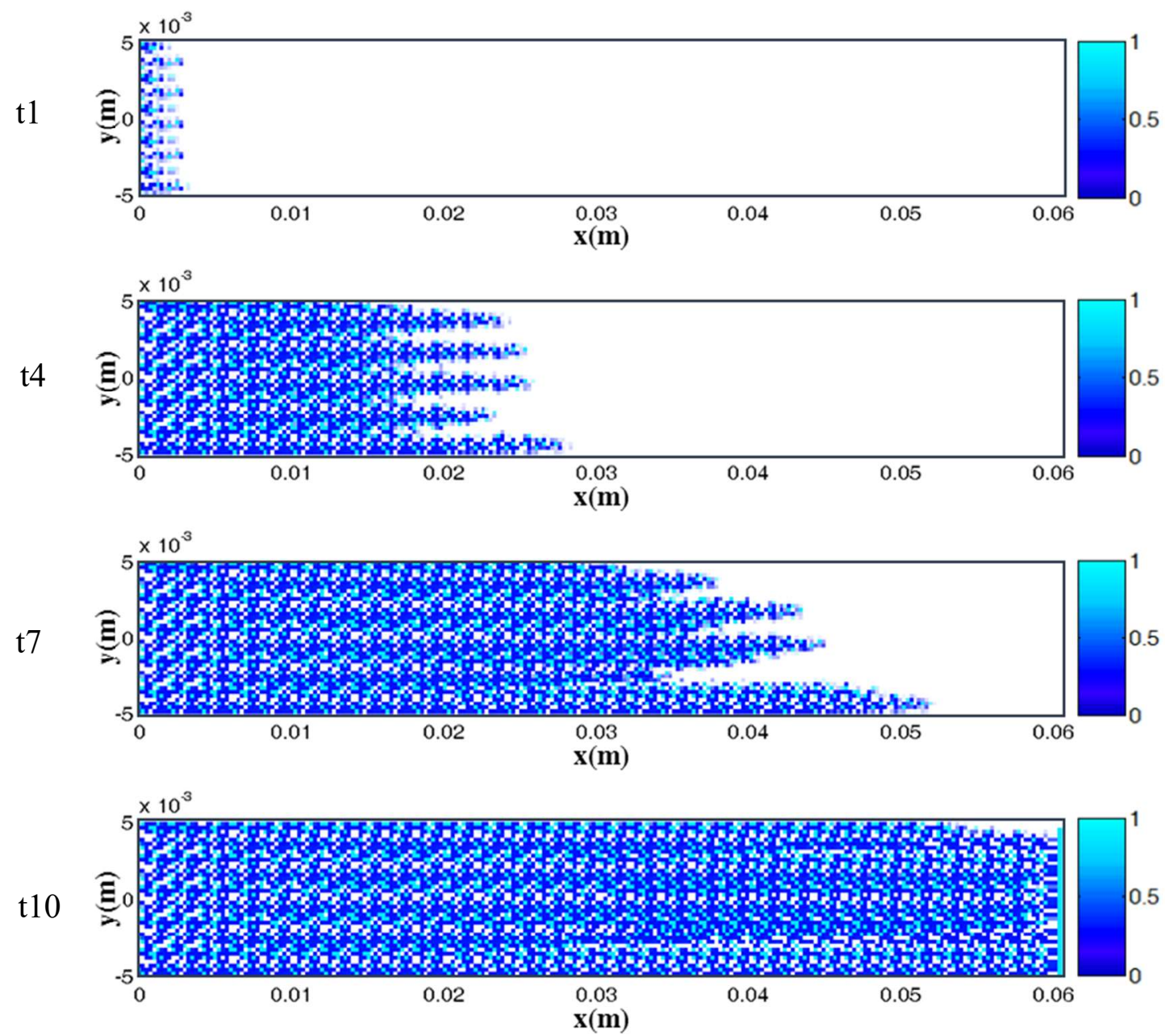

Figura 60 Simulação (9) - Mapa de saturação para um fluido não-Newtoniano em quatro instantes de tempo 


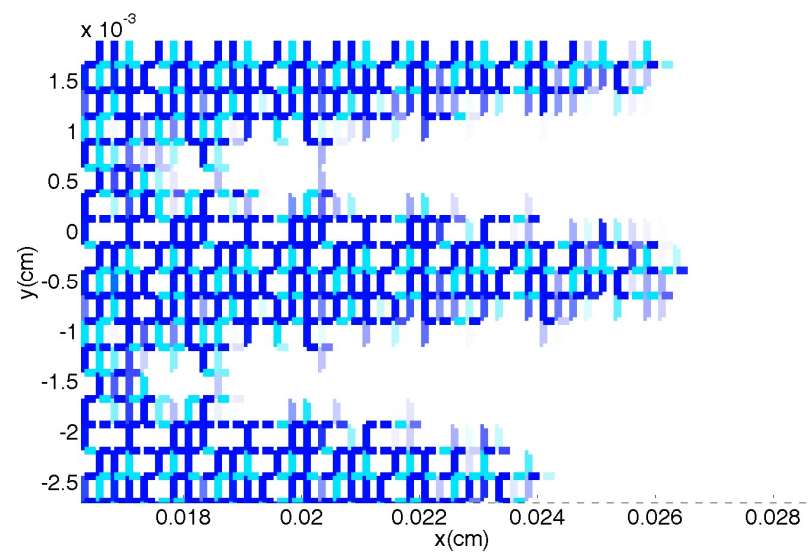

Figura 61 Simulação (9) - Zoom do mapa de saturação no segundo instante.

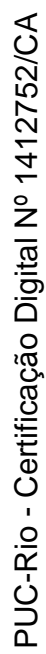
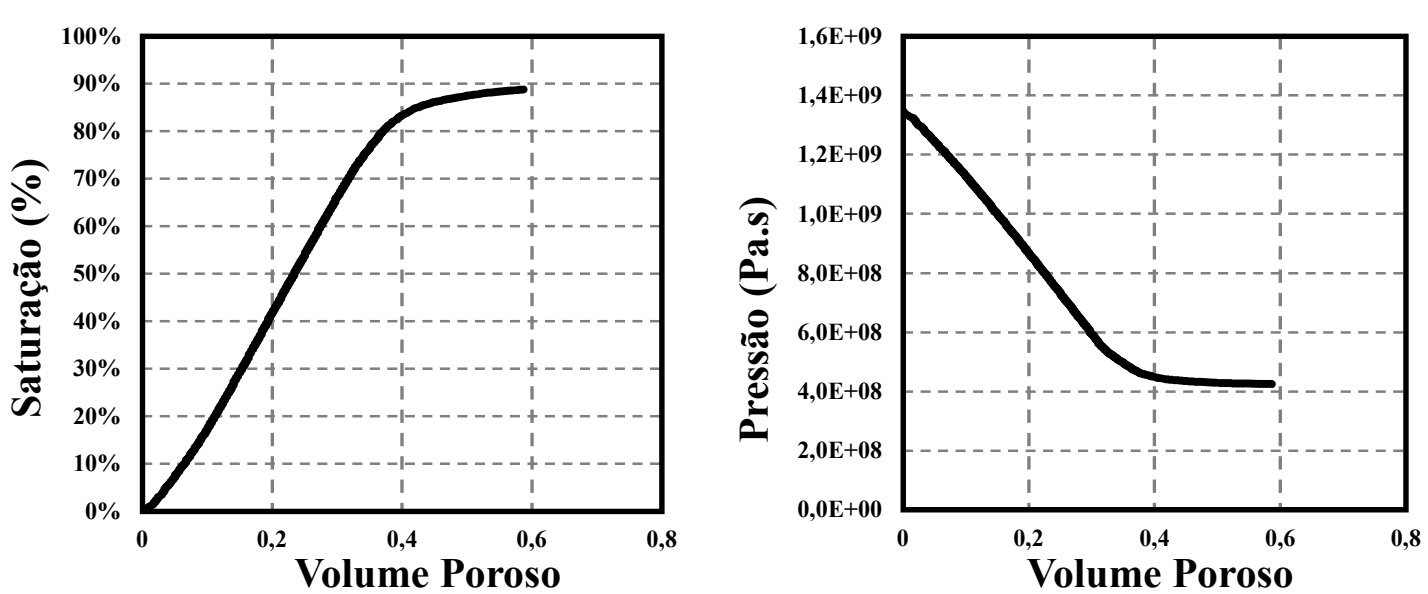

Figura 62 Simulação (9) - Curva de saturação e pressão de entrada em função do volume poroso injetado.

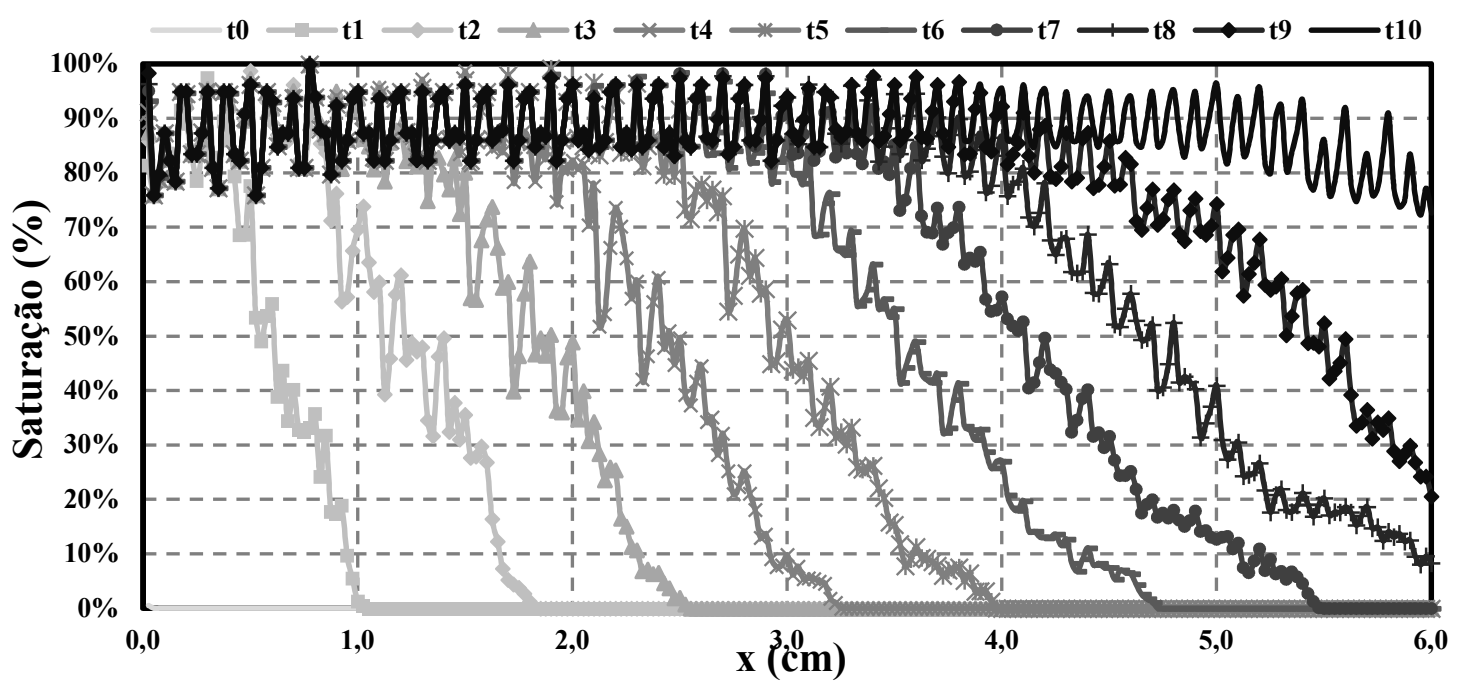

Figura 63 Simulação (9) - Curva de saturação em função da posição no eixo x para diferentes instantes de tempo. 
Tabela 11 - Simulação (10) - Parâmetros e resultados finais obtidos para o escoamento de um fluido não-Newtoniano

\begin{tabular}{|c|c|c|}
\hline & Parâmetro & Valor \\
\hline \multirow{5}{*}{ } & Viscosidade do óleo & $1,78.10^{-2}$ Pa.s \\
\hline & Viscosidade infinita $\left(\boldsymbol{\mu}_{\infty}\right)$ & $10^{-2}$ Pa.s \\
\hline & Vazão de entrada & $10^{-2} \mathrm{~m}^{3} / \mathrm{s}$ \\
\hline & Índice de potência $(\boldsymbol{n})$ & 0,7 \\
\hline & Tempo de relaxação $(\lambda)$ & $10^{-2} s^{-1}$ \\
\hline \multirow{5}{*}{ 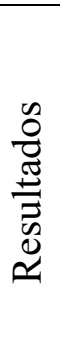 } & Número de Capilaridade & $5,26.10^{3}$ \\
\hline & Saturação final de água & $90,85 \%$ \\
\hline & Volume poroso injetado & 0,6 \\
\hline & Tempo de escoamento & $1,72.10^{-6} s$ \\
\hline & Número de iterações & 34249 \\
\hline
\end{tabular}

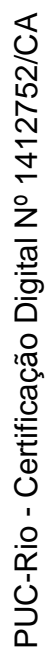

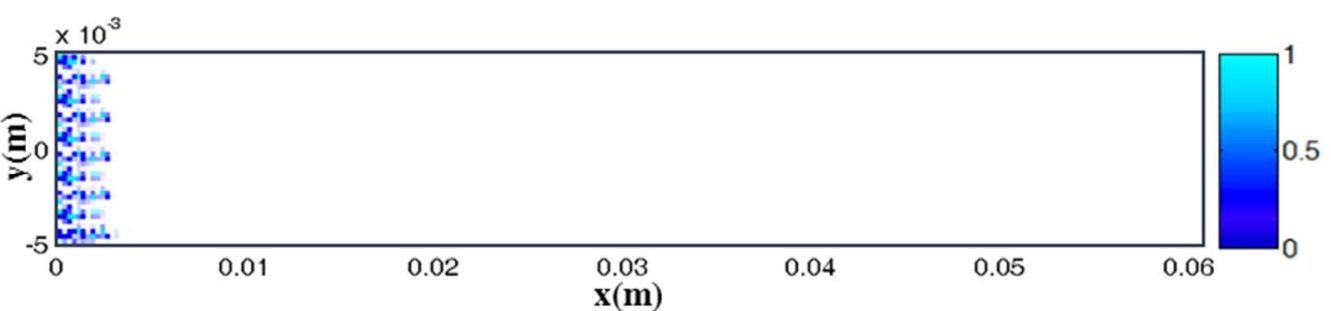

t4

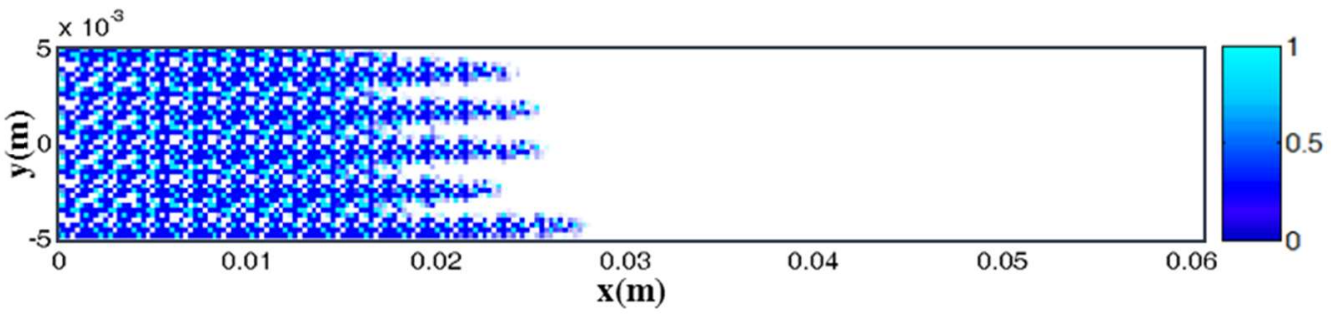

t7

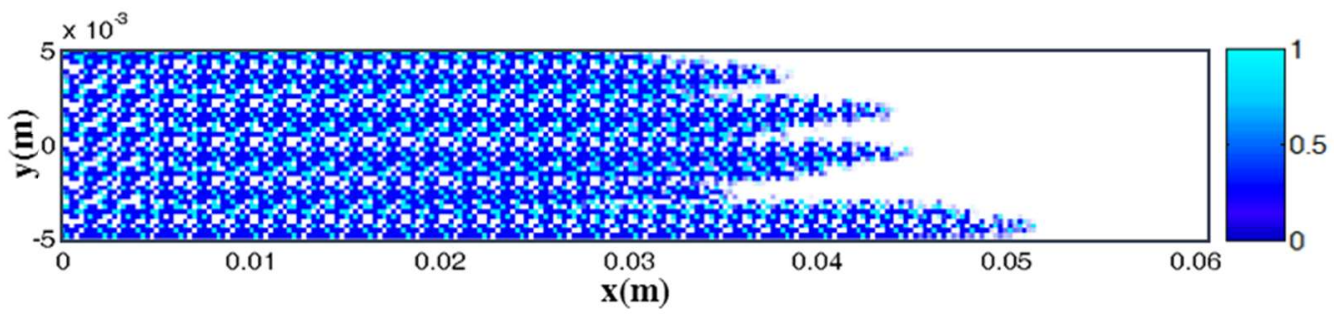

$\mathrm{t} 10$

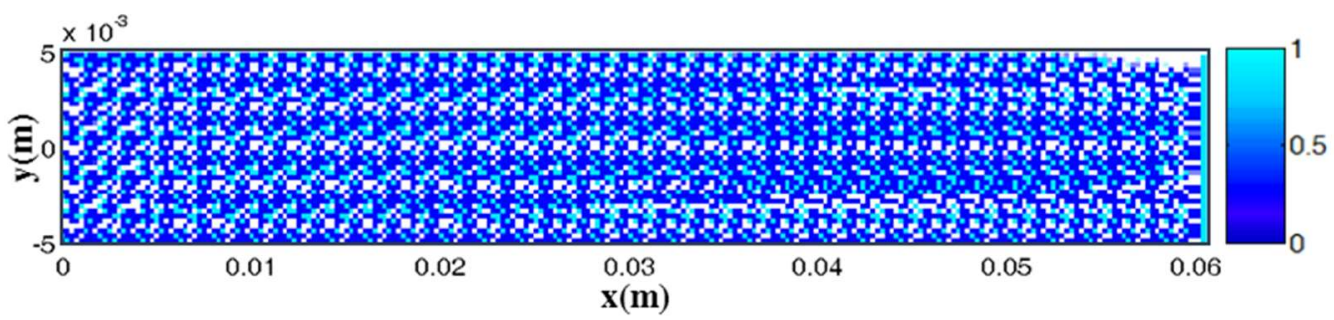

Figura 64 Simulação (10) - Mapa de saturação para um fluido não-Newtoniano em quatro instantes de tempo 


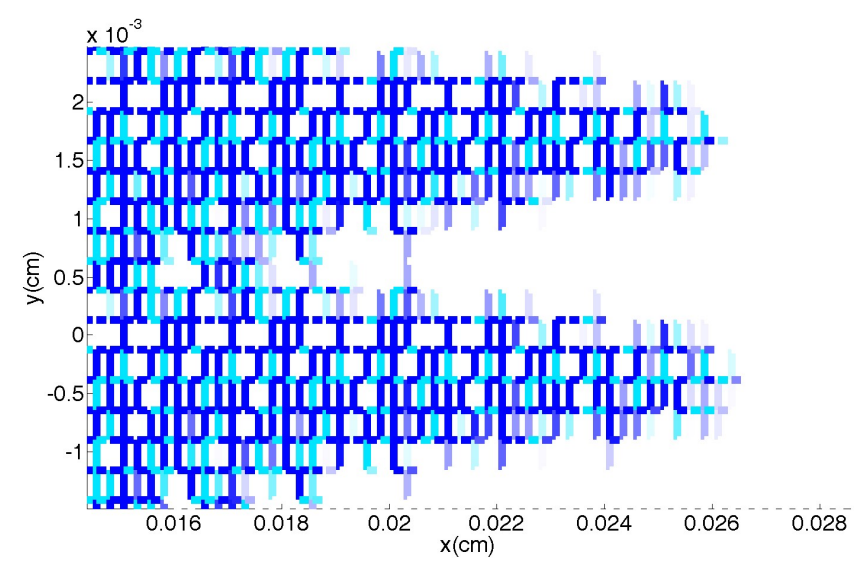

Figura 65 Simulação (10) - Zoom do mapa de saturação no segundo instante.
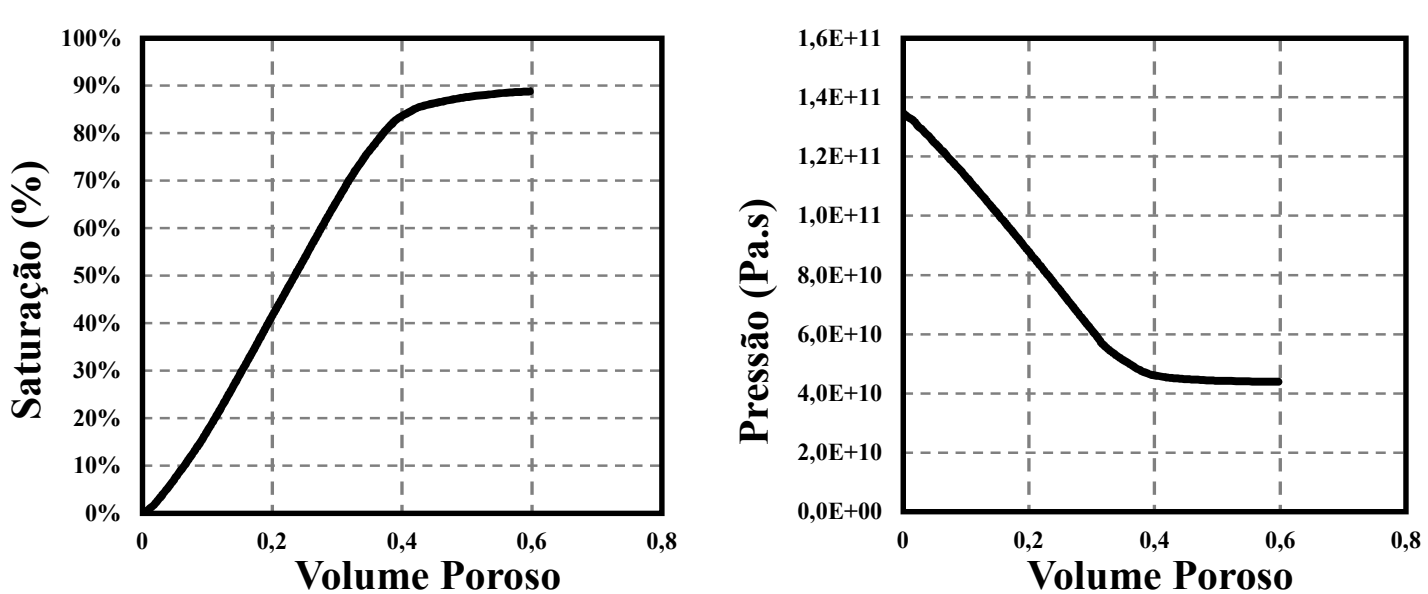

Figura 66 Simulação (10) - Curva de saturação e pressão de entrada em função do volume poroso injetado.

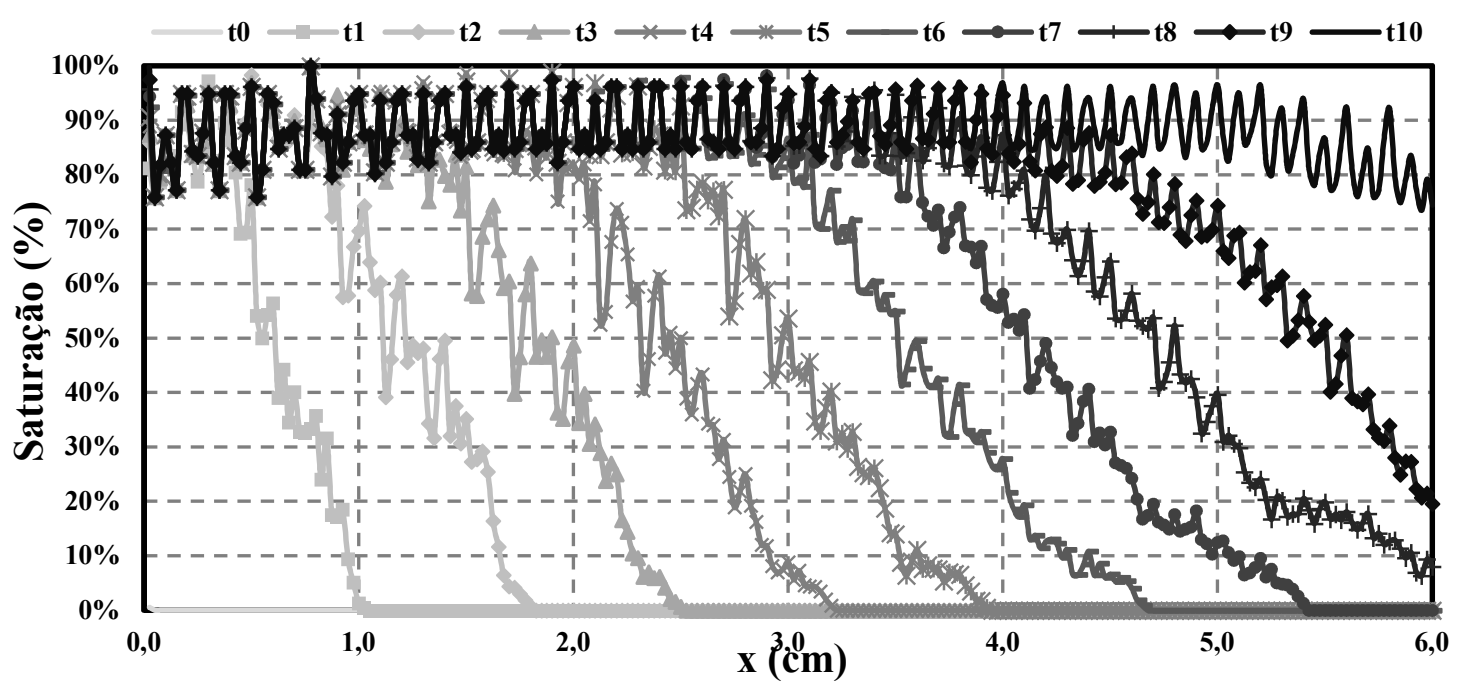

Figura 67 Simulação (10) - Curva de saturação em função da posição no eixo x para diferentes instantes de tempo. 
O terceiro caso analisado, simula o modelo de rede escoando um fluido viscoelástico considerando a viscosidade a alta taxa de cisalhamento, $\mu_{\infty}=10^{-1} \mathrm{~Pa}$.s e cinco vazões de entrada diferentes. Nas tabelas 12,13,14, 15 e 16, podemos ver melhor os resultados numéricos e os parâmetros utilizados nesta análise.

Neste caso, a viscosidade da solução é maior que nos dois casos anteriores. A viscosidade desta solução polimérica está contida no intervalo entre $0,001<\mu<$ 0,1Pa.s, ou seja, em alguns momentos ela será maior ou igual a viscosidade do fluido deslocado $\left(\mu_{o}=1,78 \cdot 10^{-2}\right.$ Pa.s $)$.

Para as duas menores vazões $Q_{1}=10^{-10} \mathrm{~m}^{3} / \mathrm{s}$ e $Q_{2}=10^{-8} \mathrm{~m}^{3} / \mathrm{s}$, a viscosidade extensional se mantém abaixo da viscosidade do óleo e à medida que o fluido é saturado a pressão diminui como pode ser visto nas figuras 67 e 71. Já para as outras três maiores vazões, a viscosidade da solução polimérica é maior que a viscosidade do óleo, e à medida que a saturação do fluido injetado aumenta, a pressão de entrada na rede também aumenta como apresentado nas figuras 78,82 e 86 . O escoamento é dominado pelas forças viscosas nas frentes do fluido invasor e as forças capilares se tornam menos importantes.

Devido as altas viscosidades do fluido injetado, a frente do fluido viscoelástico é mais uniforme para as 5 vazões simuladas como pode ser visto nos gráficos (figura 71, 75, 79, 83 e 87) de saturação em relação a posição ao longo do micromodelo.

As figuras 68 e 72 mostram que a viscosidade efetiva do fluido injetado é baixa. Pode-se observar ainda que a viscosidade ao longo dos capilares é mais uniforme nestes dois casos. Observa-se também que as viscosidades efetivas nos capilares da extremidade da frente de avanço são maiores que no restante da rede devido às forças extensionais como verificado nas figuras 69 e 73 .

As figuras 76, 80 e 84 mostram que as viscosidades do fluido injetado são elevadas e predominantemente maiores que a viscosidade do óleo ao longo da rede. 
Tabela 12 - Simulação (11) - Parâmetros e resultados finais obtidos para o escoamento de um fluido não-Newtoniano

\begin{tabular}{|c|c|c|}
\hline & Parâmetro & Valor \\
\hline \multirow{5}{*}{ 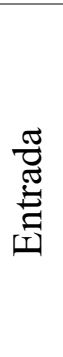 } & Viscosidade do óleo & 1,78. $10^{-2}$ Pa.s \\
\hline & Viscosidade infinita $\left(\boldsymbol{\mu}_{\infty}\right)$ & $10^{-1}$ Pa.s \\
\hline & Vazão de entrada & $10^{-10} \mathrm{~m}^{3} / \mathrm{s}$ \\
\hline & Índice de potência $(\boldsymbol{n})$ & 0,7 \\
\hline & Tempo de relaxação $(\lambda)$ & $10^{-2} s^{-1}$ \\
\hline \multirow{5}{*}{ 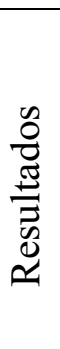 } & Número de Capilaridade & $5,26 \cdot 10^{-5}$ \\
\hline & Saturação final de água & $82,23 \%$ \\
\hline & Volume poroso injetado & 0,004 \\
\hline & Tempo de escoamento & $1,15 s$ \\
\hline & Número de iterações & 39431 \\
\hline
\end{tabular}
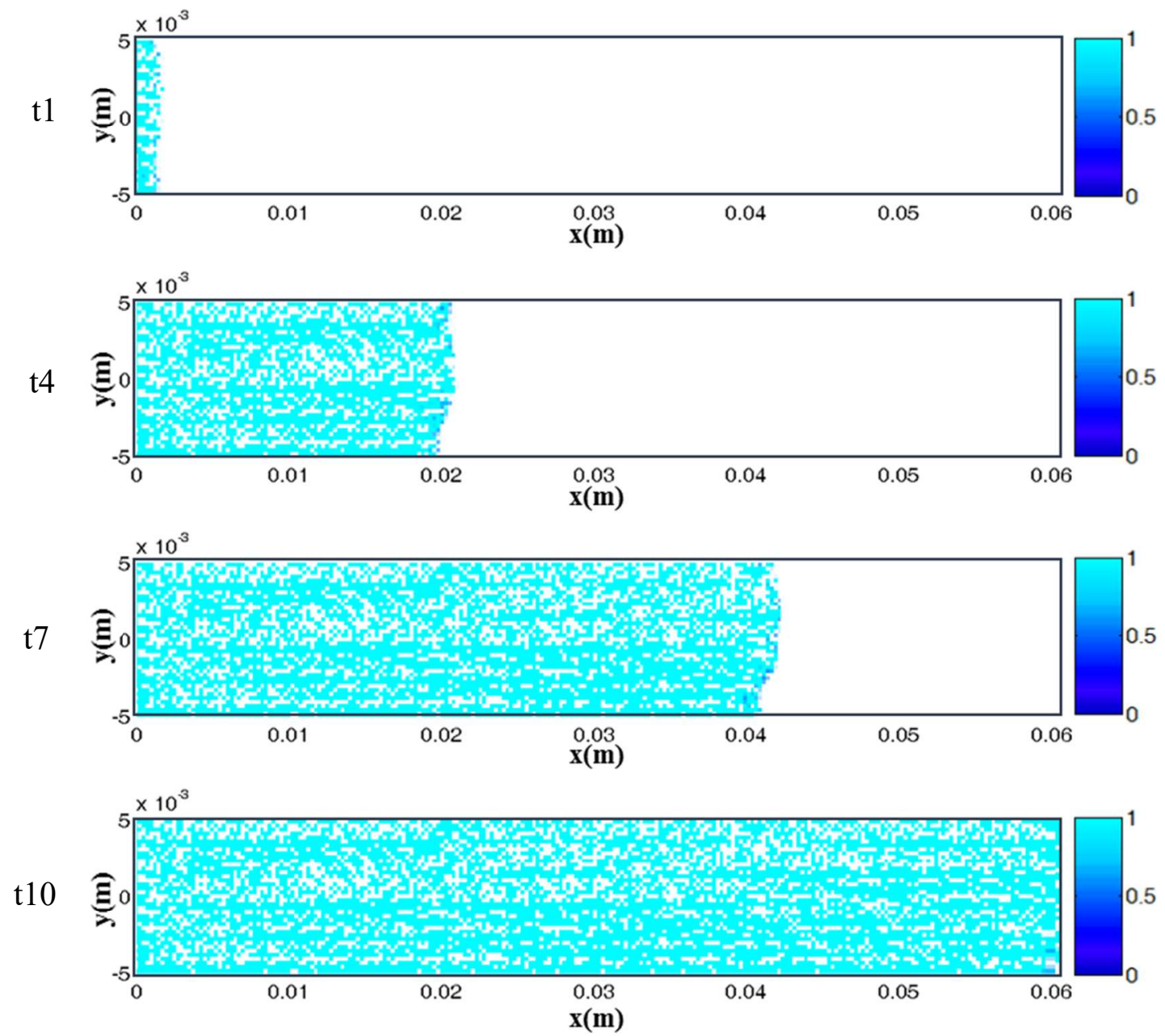

Figura 68 Simulação (11) - Mapa de saturação para um fluido Newtoniano em quatro instantes de tempo 


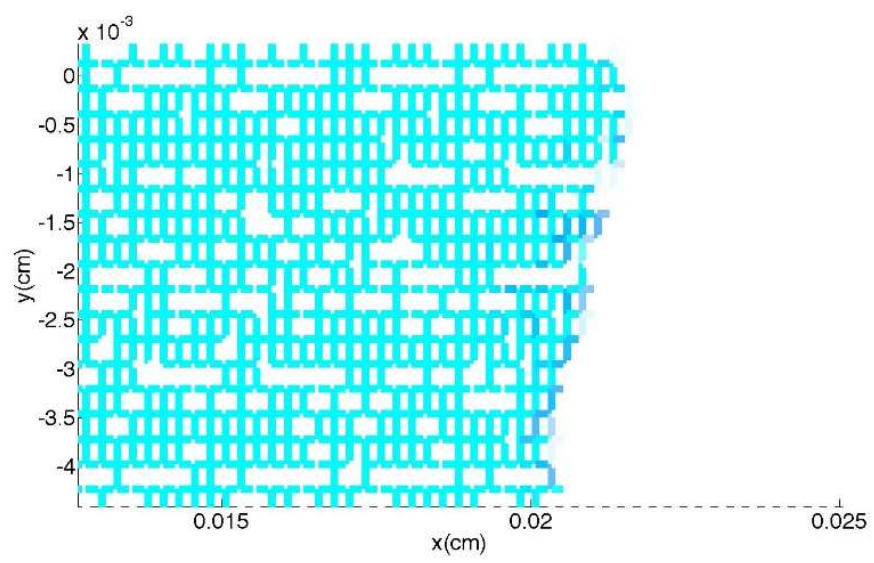

Figura 69 Simulação (11) - Zoom do mapa de saturação no segundo instante.

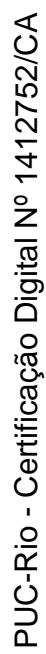
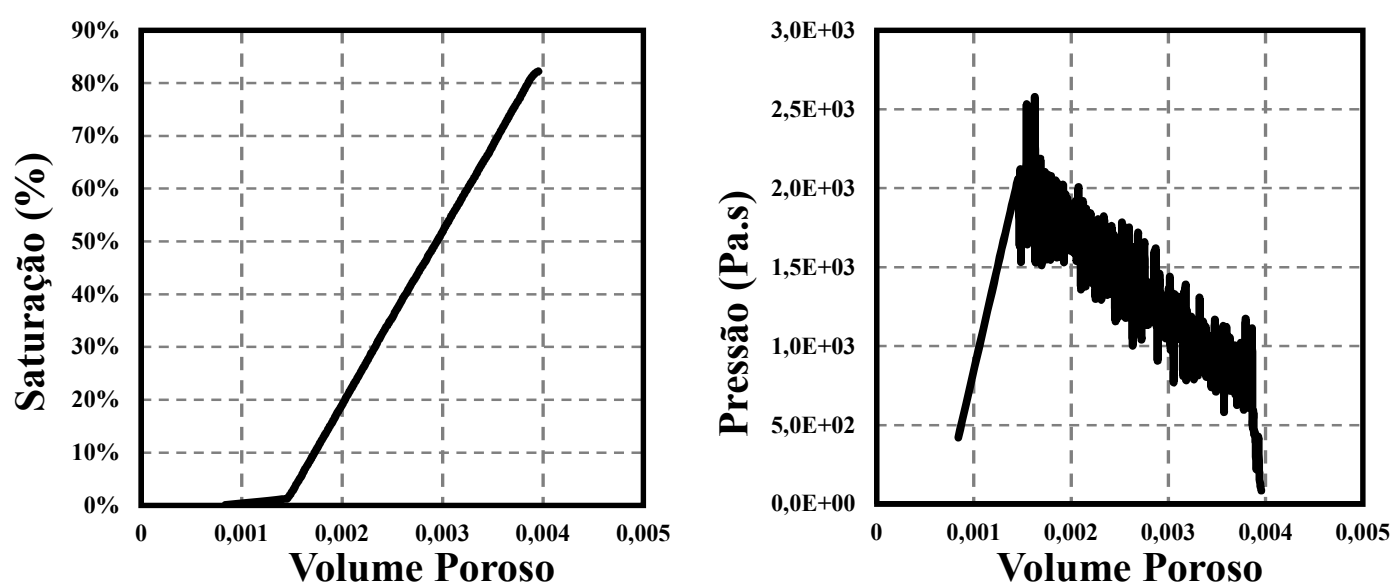

Figura 70 Simulação (11) - Curva de saturação e pressão de entrada em função do volume poroso injetado.

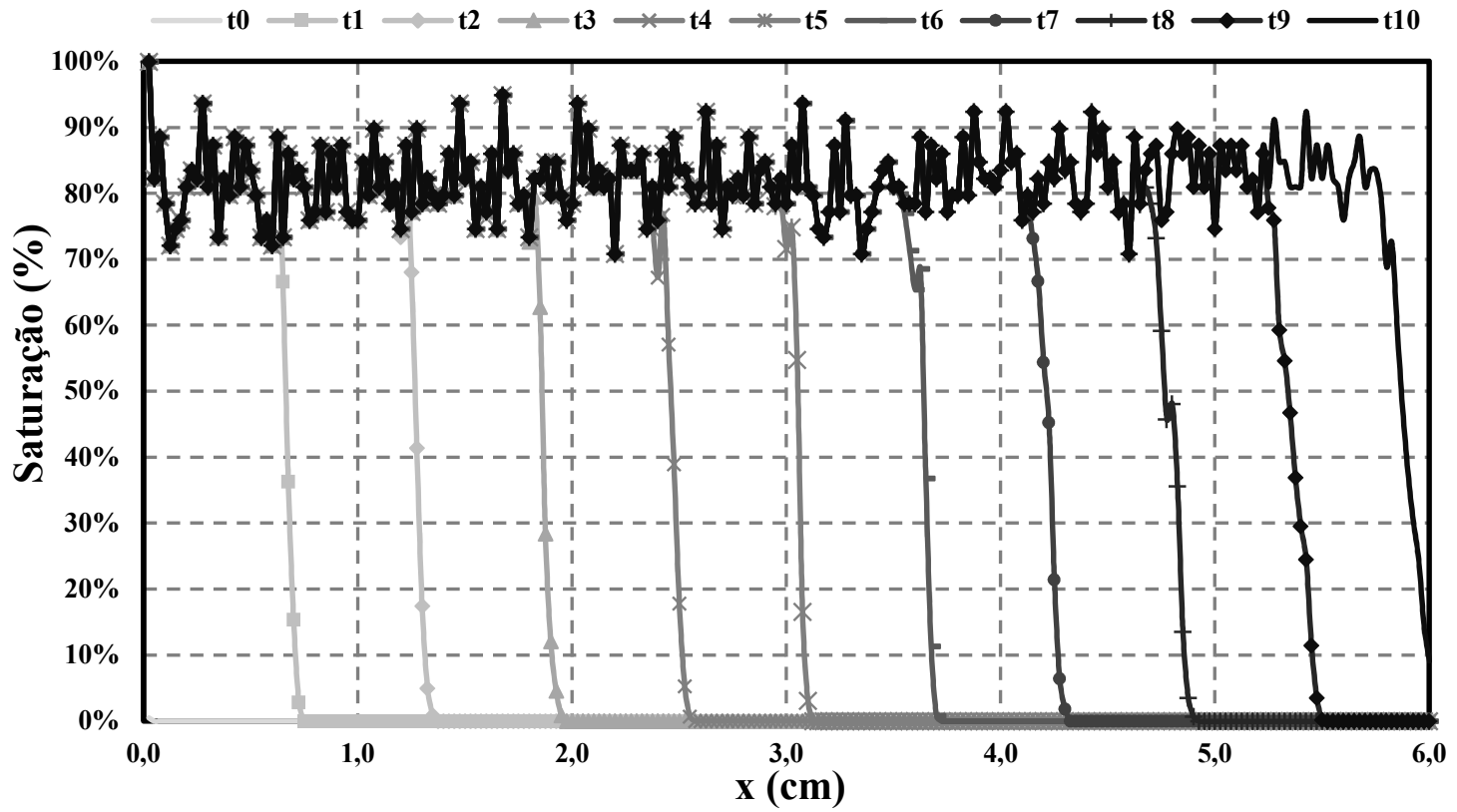

Figura 71 Simulação (11) - Curva de saturação em função da posição no eixo $x$ para diferentes instantes de tempo. 
Tabela 13 - Simulação (12) - Parâmetros e resultados finais obtidos para o escoamento de um fluido não-Newtoniano

\begin{tabular}{|c|c|c|}
\hline & Parâmetro & Valor \\
\hline \multirow{5}{*}{ 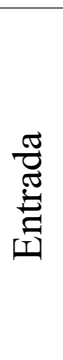 } & Viscosidade do óleo & 1,78. $10^{-2}$ Pa.s \\
\hline & Viscosidade infinita $\left(\boldsymbol{\mu}_{\infty}\right)$ & $10^{-1}$ Pa.s \\
\hline & Vazão de entrada & $10^{-8} \mathrm{~m}^{3} / \mathrm{s}$ \\
\hline & Índice de potência ( $\boldsymbol{n}$ ) & 0,7 \\
\hline & Tempo de relaxação $(\lambda)$ & $10^{-2} s^{-1}$ \\
\hline \multirow{5}{*}{ 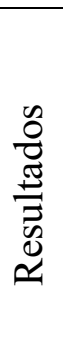 } & Número de Capilaridade & $5,26.10^{-3}$ \\
\hline & Saturação final de água & $83,50 \%$ \\
\hline & Volume poroso injetado & 0,18 \\
\hline & Tempo de escoamento & $0,52 s$ \\
\hline & Número de iterações & 38575 \\
\hline
\end{tabular}

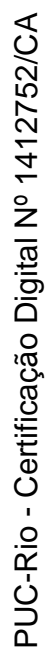
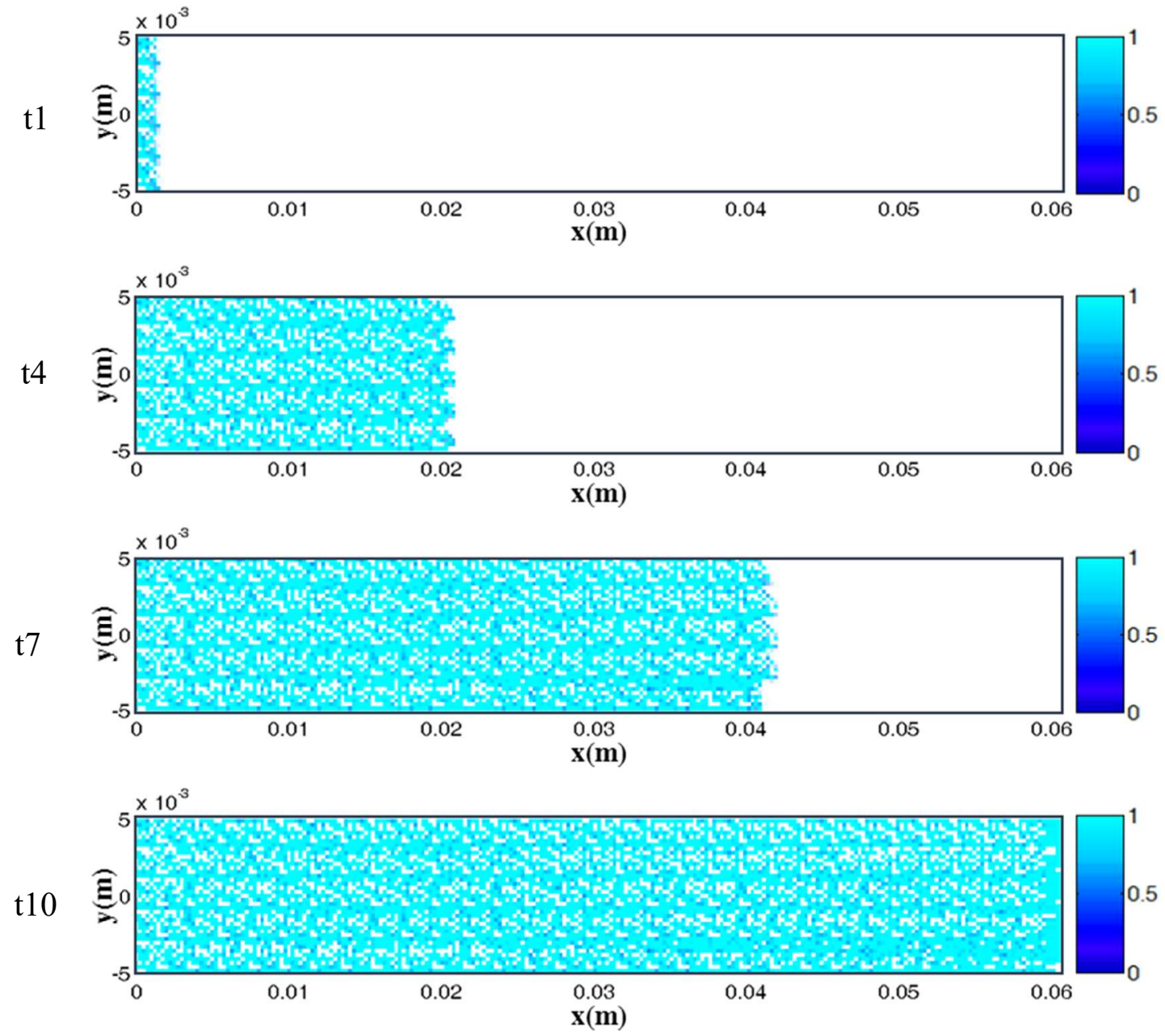

Figura 72 Simulação (12) - Mapa de saturação para um fluido não-Newtoniano em quatro instantes de tempo 


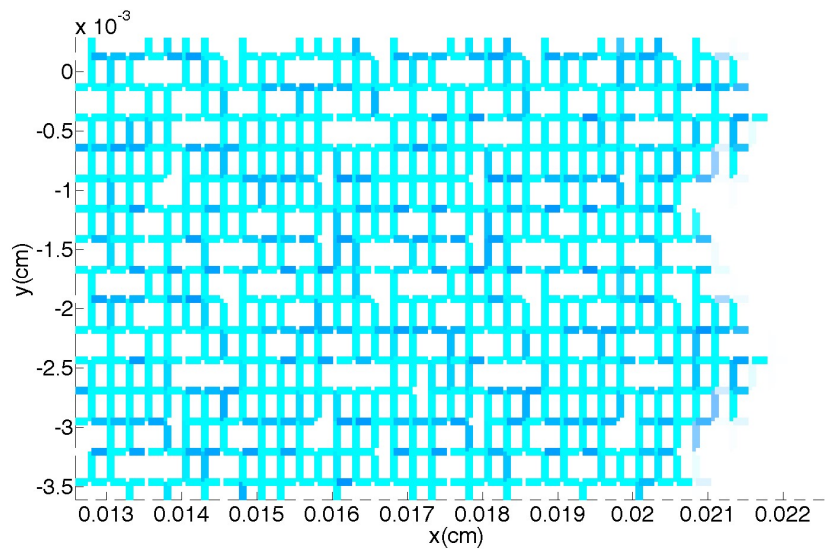

Figura 73 Simulação (12) - Zoom do mapa de saturação no segundo instante.
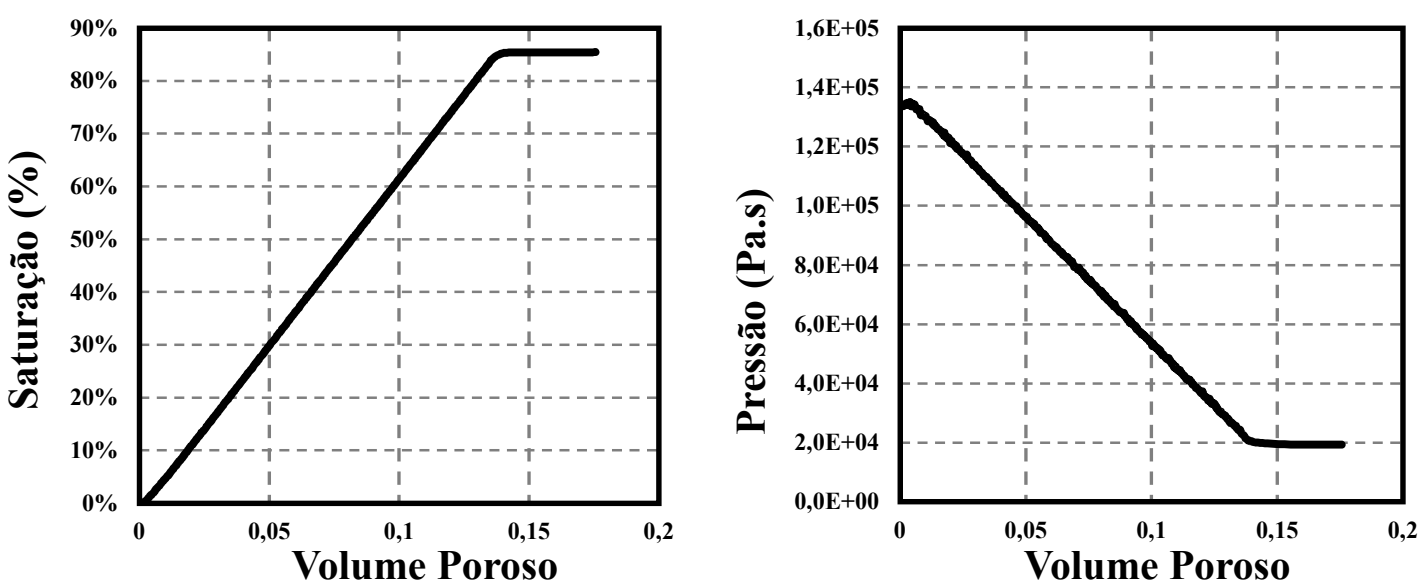

Figura 74 Simulação (12) - Curva de saturação e pressão de entrada em função do volume poroso injetado.

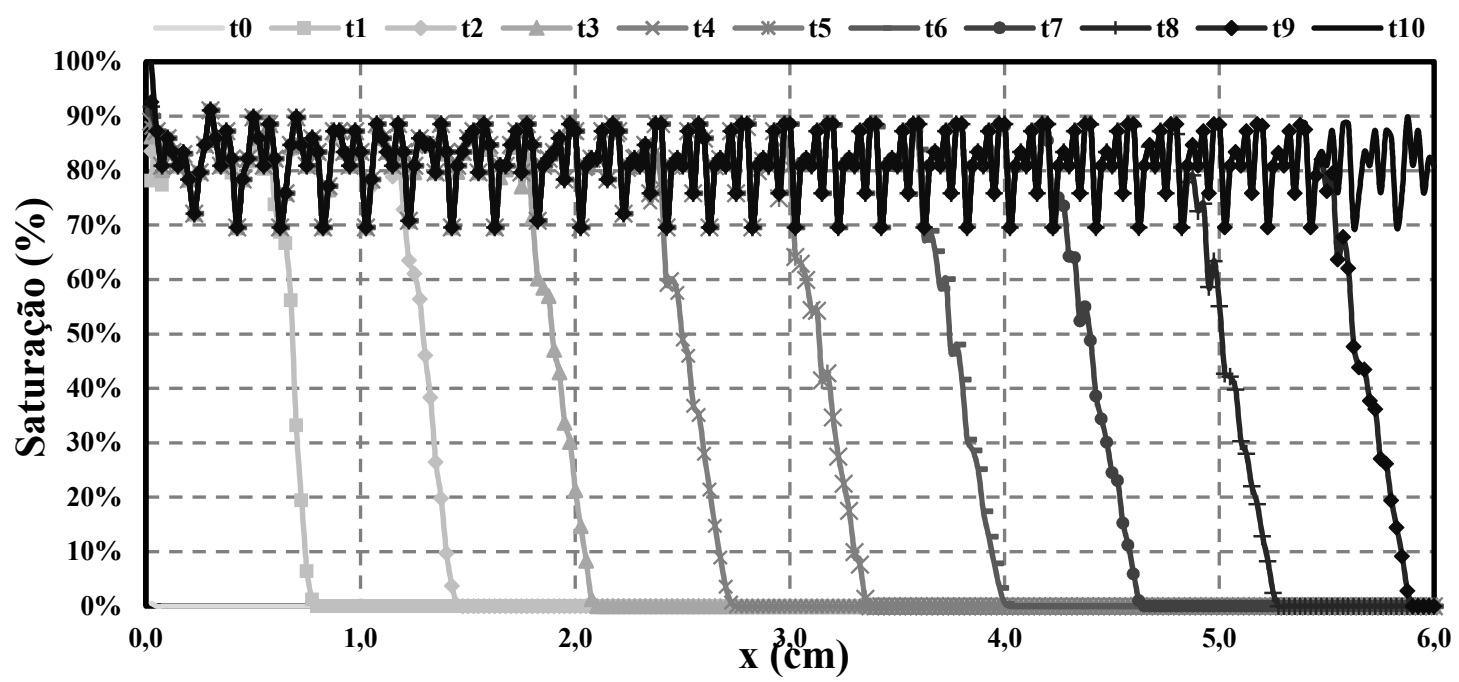

Figura 75 Simulação (12) - Curva de saturação em função da posição no eixo x para diferentes instantes de tempo. 
Tabela 14 - Simulação (13) - Parâmetros e resultados finais obtidos para o escoamento de um fluido não-Newtoniano

\begin{tabular}{|c|c|c|}
\hline & Parâmetro & Valor \\
\hline \multirow{5}{*}{ 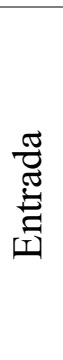 } & Viscosidade do óleo & $1,78.10^{-2}$ Pa.s \\
\hline & Viscosidade infinita $\left(\boldsymbol{\mu}_{\infty}\right)$ & $10^{-1}$ Pa.s \\
\hline & Vazão de entrada & $10^{-6} \mathrm{~m}^{3} / \mathrm{s}$ \\
\hline & Índice de potência ( $\boldsymbol{n}$ ) & 0,7 \\
\hline & Tempo de relaxação $(\lambda)$ & $10^{-2} s^{-1}$ \\
\hline \multirow{5}{*}{ 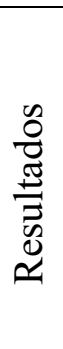 } & Número de Capilaridade & 0,526 \\
\hline & Saturação final de água & $91,74 \%$ \\
\hline & Volume poroso injetado & 0,89 \\
\hline & Tempo de escoamento & $0,0267 s$ \\
\hline & Número de iterações & 35025 \\
\hline
\end{tabular}

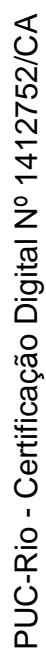
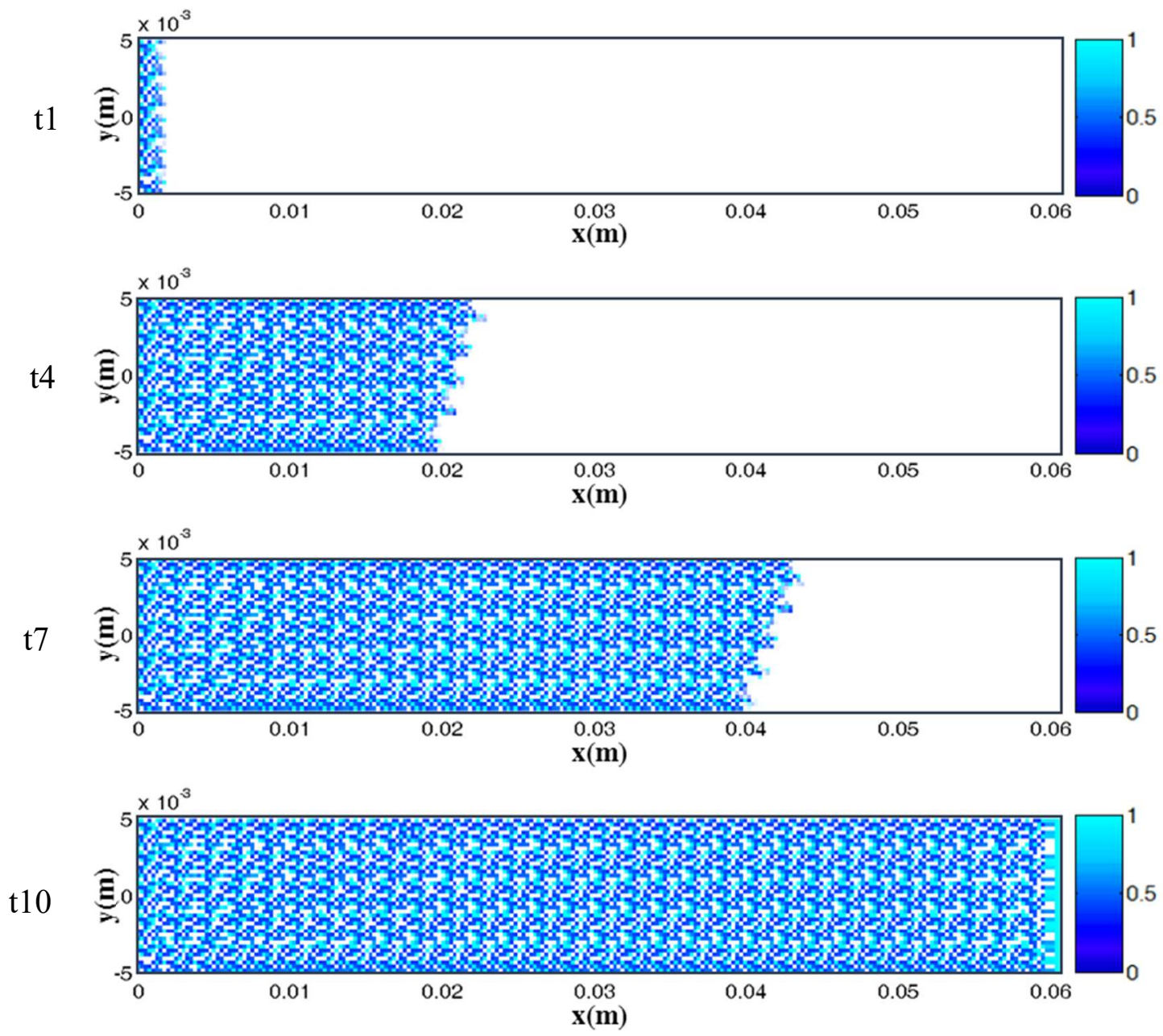

Figura 76 Simulação (13) - Mapa de saturação para um fluido não-Newtoniano em quatro instantes de tempo 


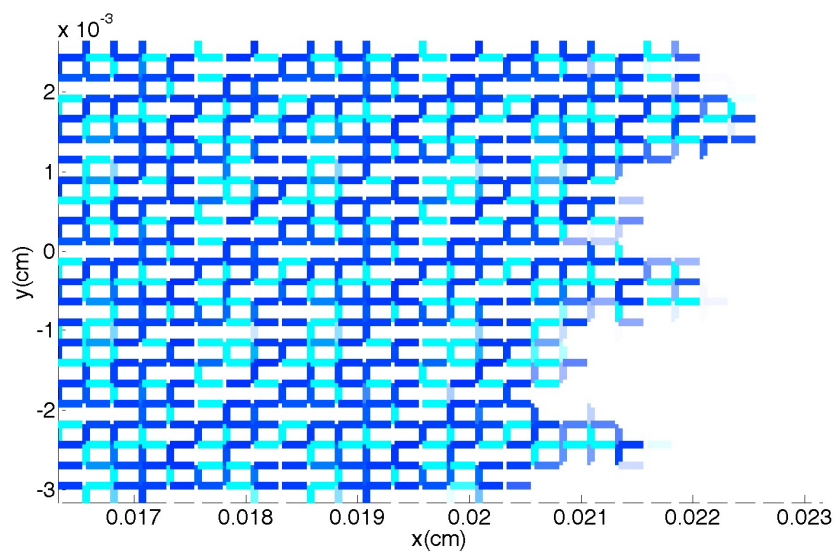

Figura 77 Simulação (13) - Zoom do mapa de saturação no segundo instante.
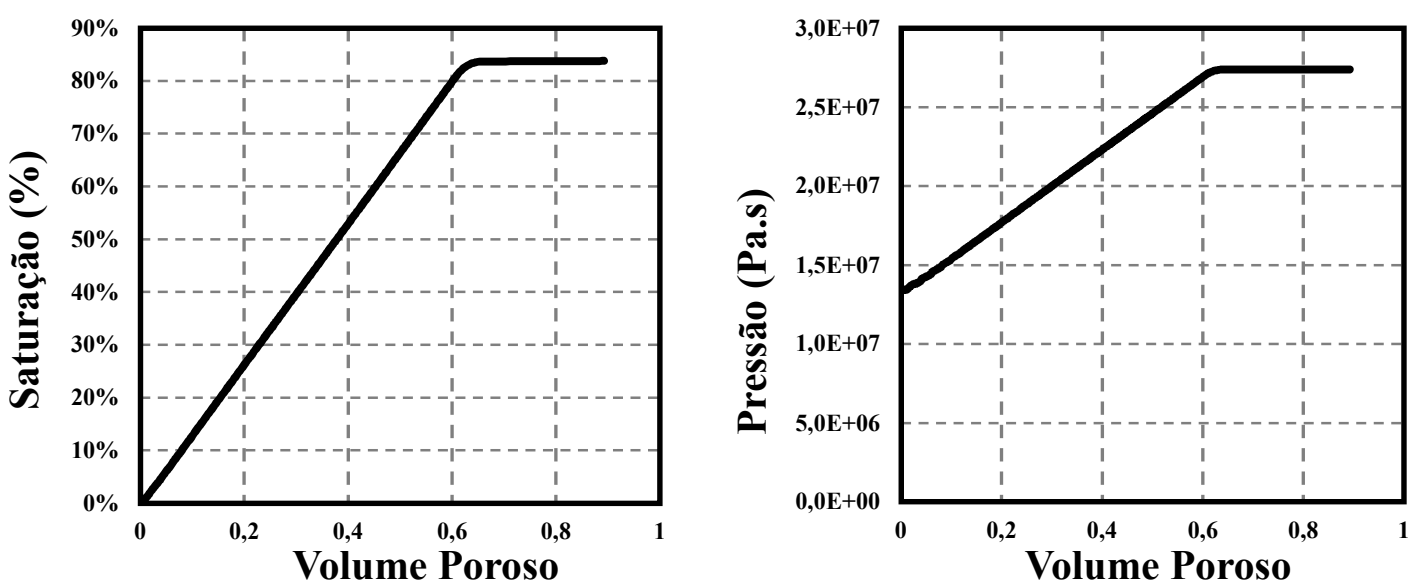

Figura 78 Simulação (13) - Curva de saturação e pressão de entrada em função do volume poroso injetado.

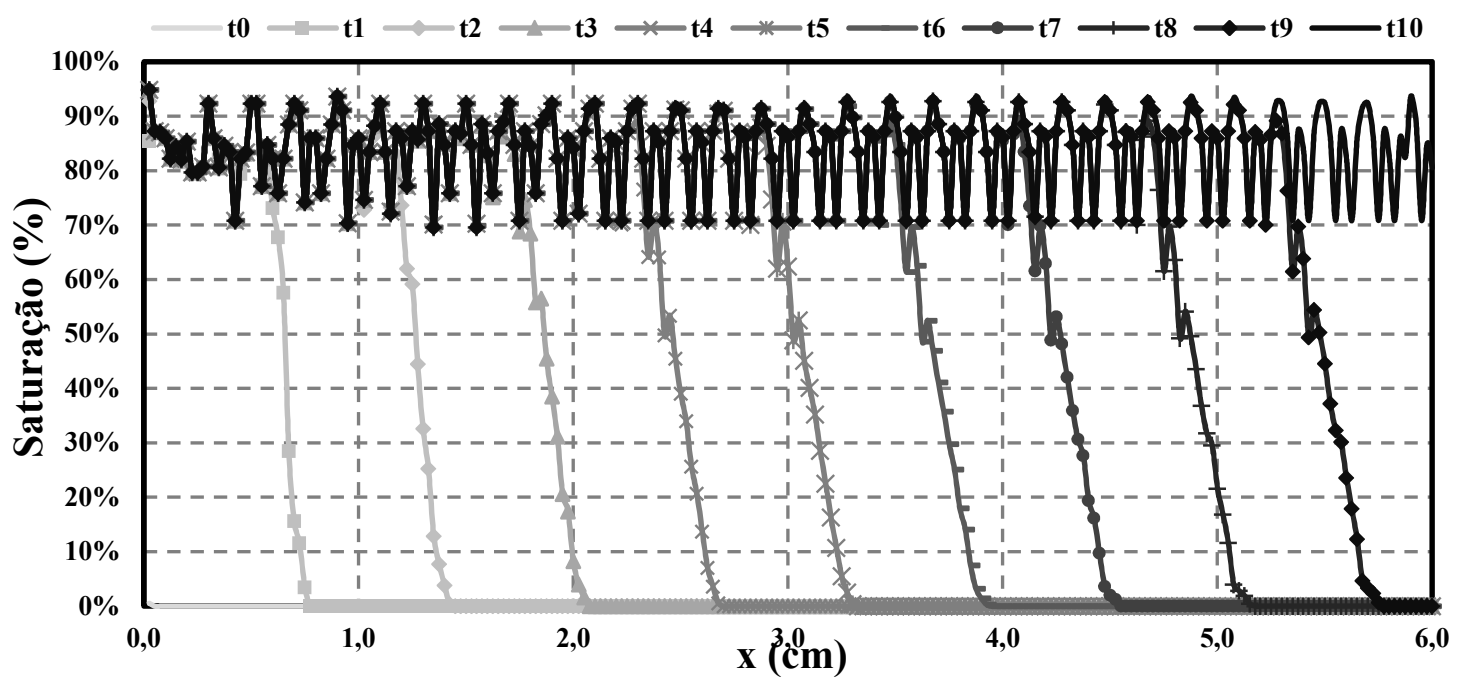

Figura 79 Simulação (13) - Curva de saturação em função da posição no eixo x para diferentes instantes de tempo.

Tabela 15 - Simulação (14) - Parâmetros e resultados finais obtidos para o escoamento de um fluido não-Newtoniano 


\begin{tabular}{|c|c|c|}
\hline & Parâmetro & Valor \\
\hline \multirow{5}{*}{ 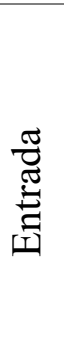 } & Viscosidade do óleo & 1,78. $10^{-2}$ Pa.s \\
\hline & Viscosidade infinita $\left(\boldsymbol{\mu}_{\infty}\right)$ & $10^{-1}$ Pa.s \\
\hline & Vazão de entrada & $10^{-4} \mathrm{~m}^{3} / \mathrm{s}$ \\
\hline & Índice de potência ( $\boldsymbol{n}$ ) & 0,7 \\
\hline & Tempo de relaxação $(\lambda)$ & $10^{-2} s^{-1}$ \\
\hline \multirow{5}{*}{ 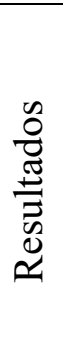 } & Número de Capilaridade & 52,6 \\
\hline & Saturação final de água & $92,20 \%$ \\
\hline & Volume poroso injetado & 0,84 \\
\hline & Tempo de escoamento & $2,5 \cdot 10^{-4} s$ \\
\hline & Número de iterações & 34193 \\
\hline
\end{tabular}

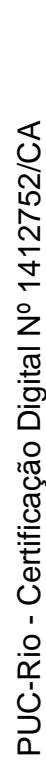
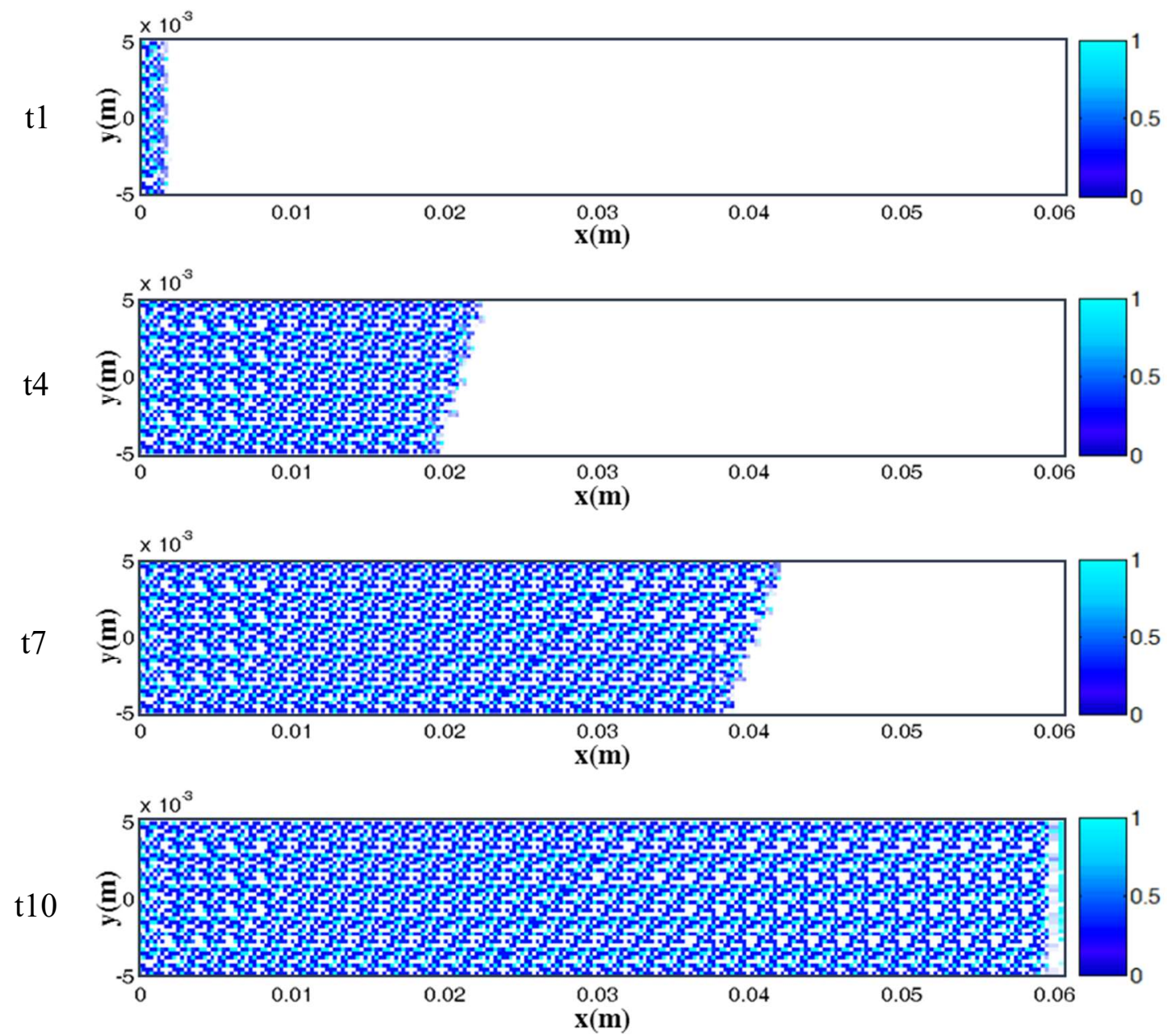

Figura 80 Simulação (14) - Mapa de saturação para um fluido não-Newtoniano em quatro instantes de tempo 


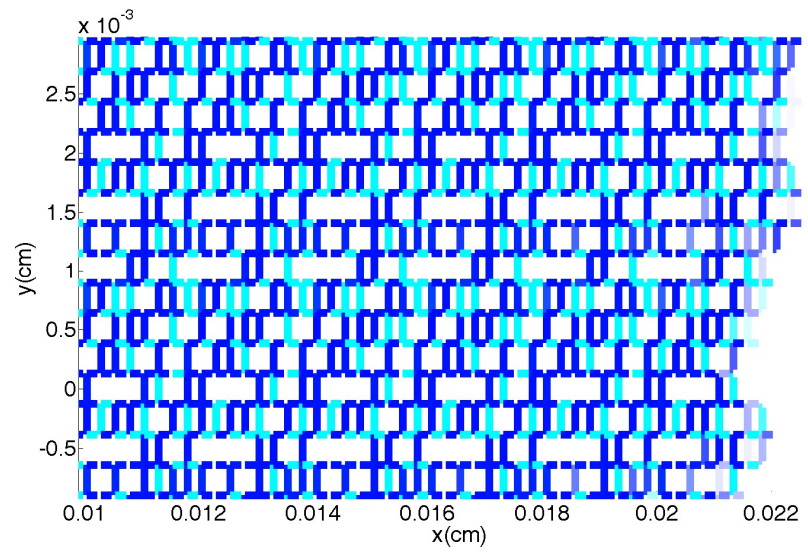

Figura 81 Simulação (14) - Zoom do mapa de saturação no segundo instante.
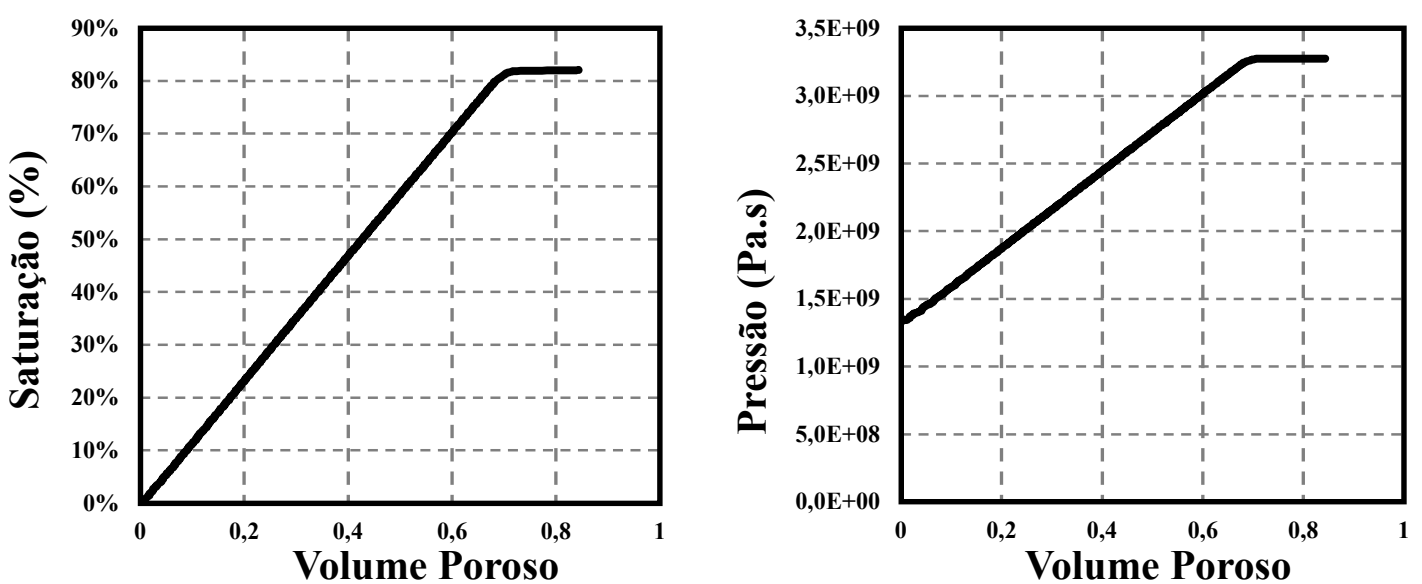

Figura 82 Simulação (14) - Curva de saturação e pressão de entrada em função do volume poroso injetado.

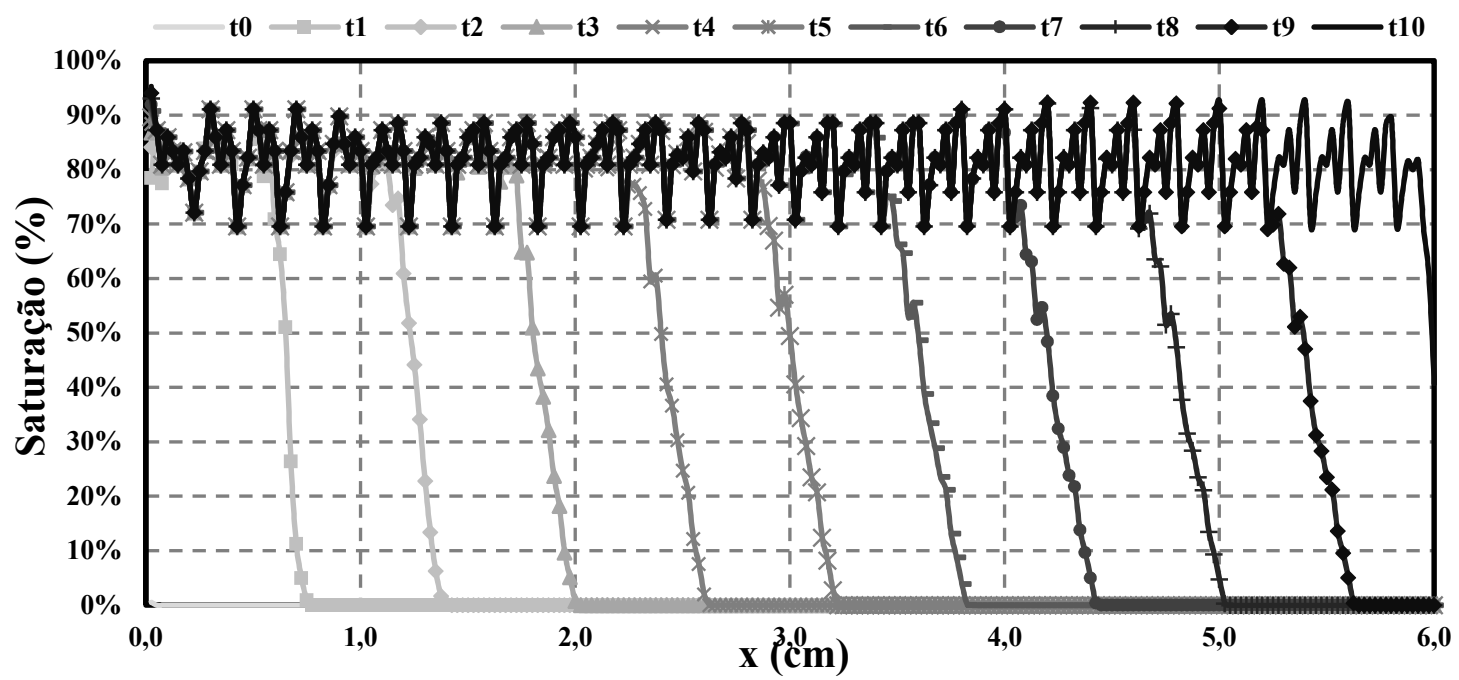

Figura 83 Simulação (14) - Curva de saturação em função da posição no eixo x para diferentes instantes de tempo.

Tabela 16 - Simulação (15) - Parâmetros e resultados finais obtidos para o escoamento de um fluido não-Newtoniano 


\begin{tabular}{|c|c|c|}
\hline & Parâmetro & Valor \\
\hline \multirow{5}{*}{ 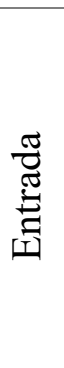 } & Viscosidade do óleo & $1,78.10^{-2}$ Pa.s \\
\hline & Viscosidade infinita $\left(\boldsymbol{\mu}_{\infty}\right)$ & $10^{-1}$ Pa.s \\
\hline & Vazão de entrada & $10^{-2} \mathrm{~m}^{3} / \mathrm{s}$ \\
\hline & Índice de potência ( $\boldsymbol{n}$ ) & 0,7 \\
\hline & Tempo de relaxação $(\lambda)$ & $10^{-2} s^{-1}$ \\
\hline \multirow{5}{*}{ 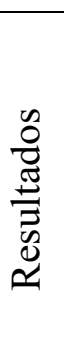 } & Número de Capilaridade & $5,26.10^{3}$ \\
\hline & Saturação final de água & $93,14 \%$ \\
\hline & Volume poroso injetado & 0,74 \\
\hline & Tempo de escoamento & $2,22 \cdot 10^{-6} s$ \\
\hline & Número de iterações & 36849 \\
\hline
\end{tabular}

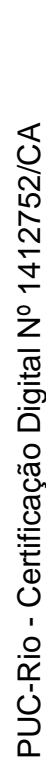

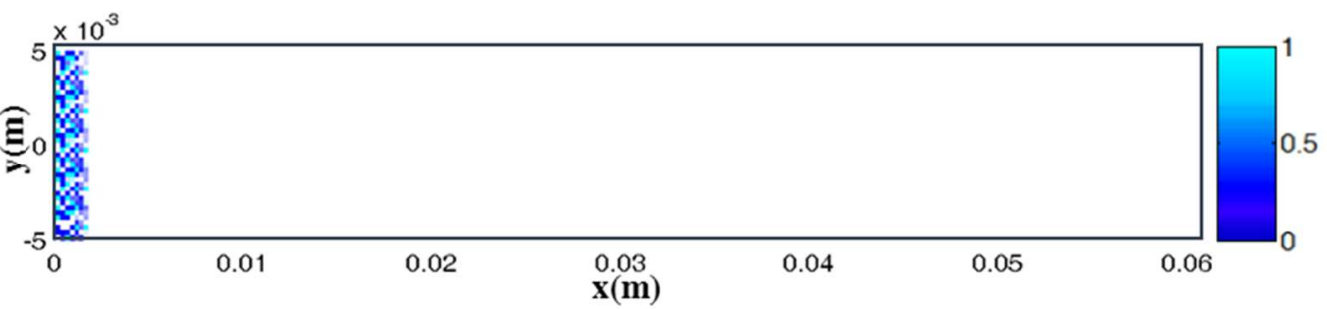

t4

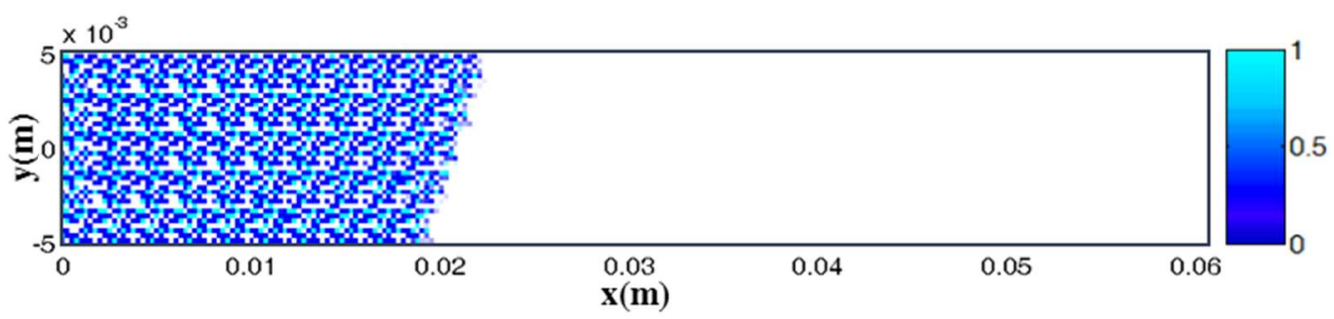

t7

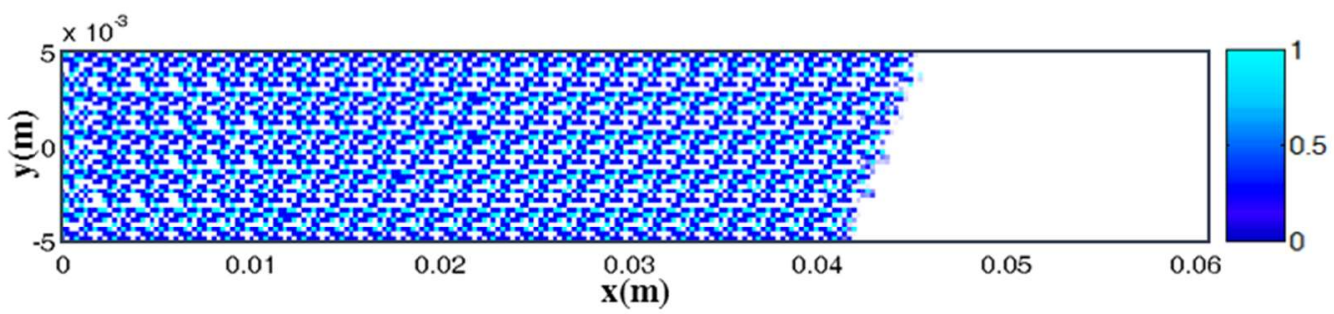

t10

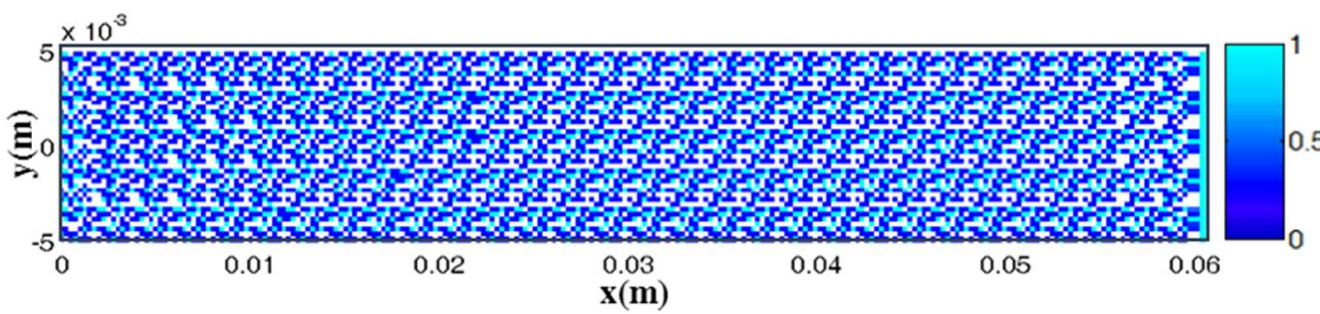

Figura 84 Simulação (15) - Mapa de saturação para um fluido não-Newtoniano em quatro instantes de tempo 


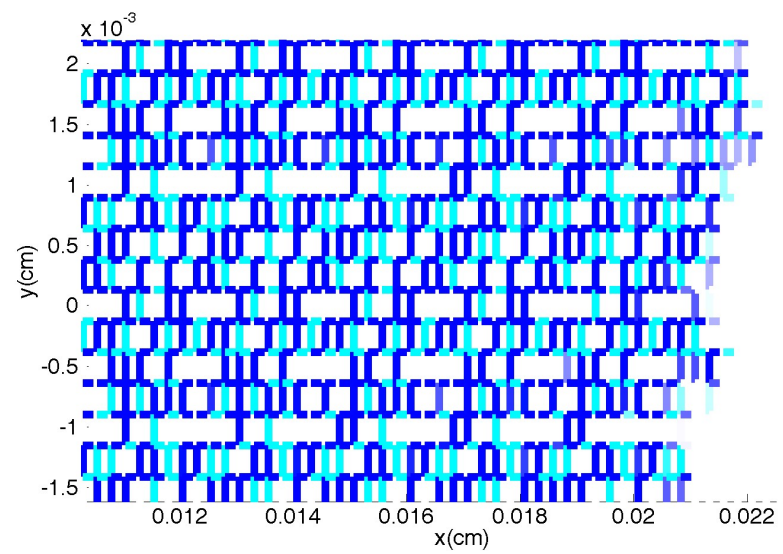

Figura 85 Simulação (15) - Zoom do mapa de saturação no segundo instante.
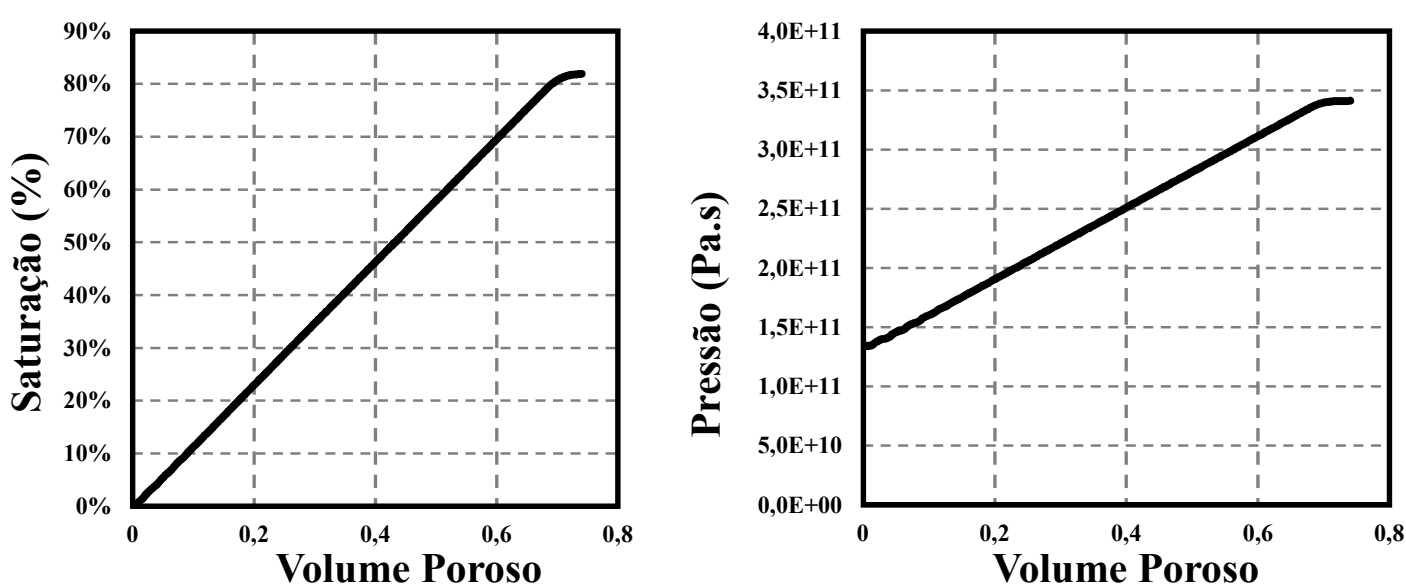

Figura 86 Simulação (15) - Curva de saturação e pressão de entrada em função do volume poroso injetado.

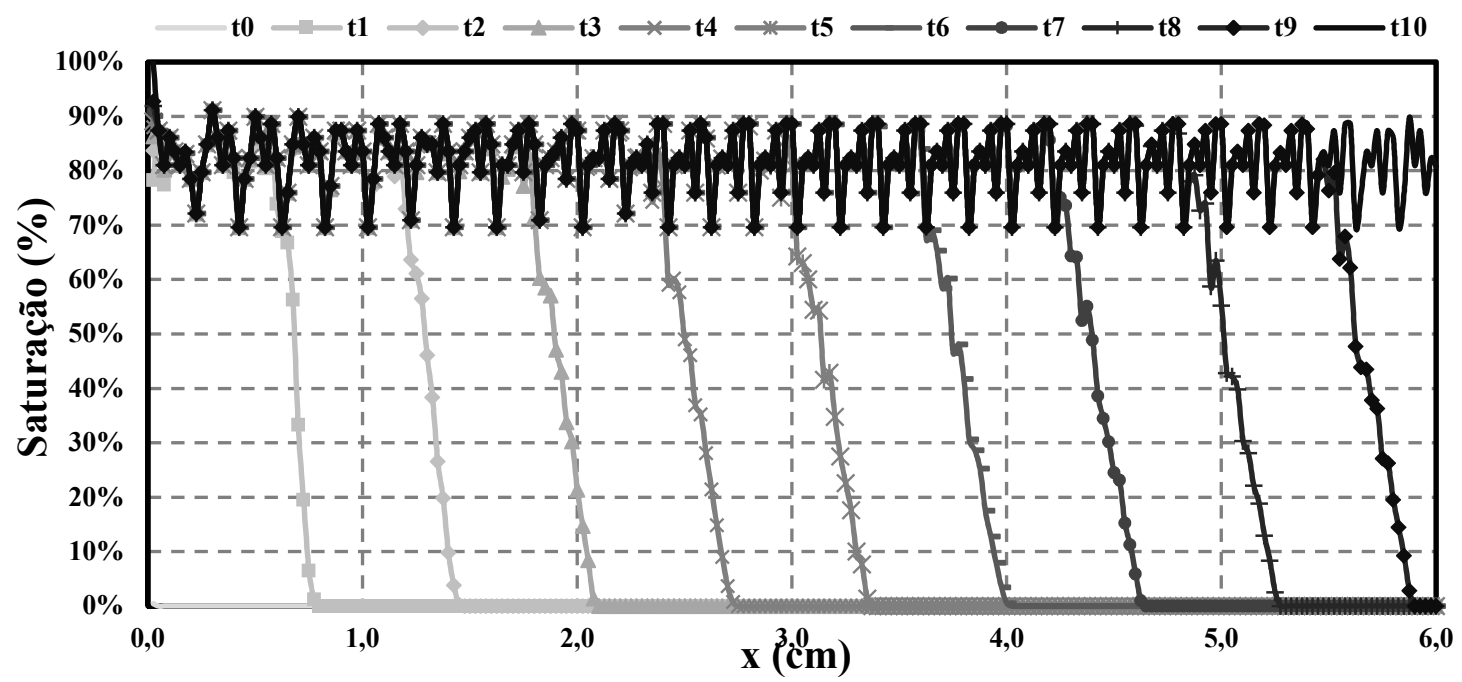

Figura 87 Simulação (15) - Curva de saturação em função da posição no eixo x para diferentes instantes de tempo. 


\subsubsection{Efeito de capilaridade}

As saturações médias de todas as regiões em função do número de capilaridade para as três fases aquosas testadas são apresentadas na figura 88. Para números de capilaridade muito baixos, a saturação residual não depende fortemente da vazão.

Comparando as curvas para os três fluidos testados, observa-se, como esperado, que a saturação residual de óleo é menor no caso da injeção da solução polimérica com viscosidade variando entre $\mu_{0}=10^{-3} \mathrm{~Pa} . \mathrm{s}$ e $\mu_{\infty}=10^{-1} \mathrm{~Pa}$.s. A maior viscosidade leva a diferenças de pressão maiores na fase aquosa, contribuindo para mobilização de gânglios de óleo e consequente redução na saturação residual de óleo. Para todas as vazões, a saturação residual de óleo obtida na injeção de água foi mais alta do que a de solução polimérica. A medida que a vazão aumenta, a saturação de óleo decai para todos os casos.

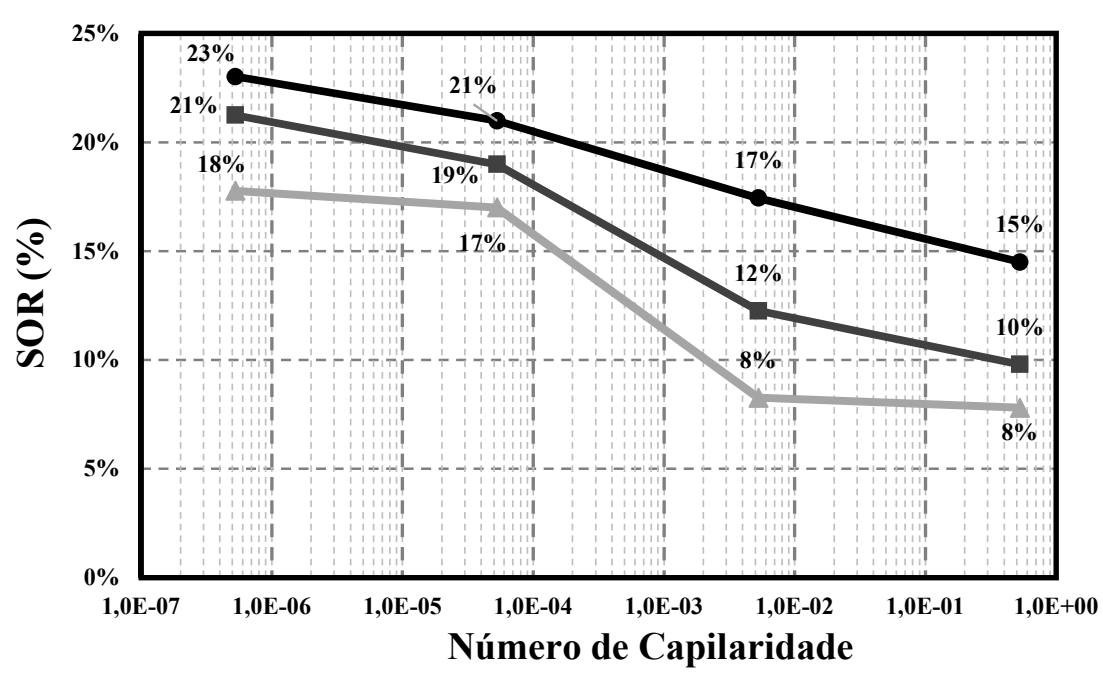

$\longrightarrow$ Newt $\rightarrow$ m=0,01 $\rightarrow \mathbf{m}=0,1$

Figura 88 Curvas de saturação em função do número de capilaridade

Os parâmetros utilizados para fazer as 3 análises a seguir são apresentados na tabela 17. Foram aplicadas 4 vazões diferentes para entender o comportamento do efeito de capilaridade em relação a saturação residual do óleo entre eles: $Q_{1}=10^{-6} \mathrm{~m}^{3} / \mathrm{s}, Q_{2}=$ $10^{-8} \mathrm{~m}^{3} / \mathrm{s}, Q_{3}=10^{-10} \mathrm{~m}^{3} / \mathrm{s}$ e $Q_{4}=10^{-12} \mathrm{~m}^{3} / \mathrm{s}$. Os parâmetros utilizados para gerar as curvas de capilaridade foram os mesmos apresentados nas simulações do capítulo anterior. 
Tabela 17 - Parâmetros e resultados finais obtidos para entender os números de capilaridade

\begin{tabular}{lllll}
\hline & & Newt. & N. Newt. & N. Newt. \\
$\mathbf{Q}\left(m / s^{3}\right)$ & N Cap. & $\mu=10^{-3}$ Pa.s & $\begin{array}{l}\mu_{\infty}=1^{-2} \text { Pa. } s \\
\mu_{0}=1^{-3} \text { Pa. } s\end{array}$ & $\begin{array}{l}\mu_{\infty}=10^{-1} \text { Pa. } s \\
\mu_{0}=1^{-3} \text { Pa. } s\end{array}$ \\
\hline $10^{-12} m^{3} / s$ & $5,3.10^{-7}$ & $23 \%$ & $21 \%$ & $18 \%$ \\
$10^{-10} m^{3} / s$ & $5,3.10^{-5}$ & $21 \%$ & $19 \%$ & $17 \%$ \\
$10^{-8} m^{3} / s$ & $5,3.10^{-3}$ & $17 \%$ & $12 \%$ & $8 \%$ \\
$10^{-6} m^{3} / s$ & $5,3.10^{-1}$ & $15 \%$ & $10 \%$ & $8 \%$ \\
\hline
\end{tabular}




\section{Considerações finais}

Foi desenvolvido um modelo de rede para estudar o escoamento monofásico e bifásico das soluções poliméricas. A geometria da rede utilizada descreve um microchip 2-D utilizado para simular as gargantas e poros de um meio poroso. O modelo foi desenvolvido no software MATLAB e o custo computacional para cada simulação de escoamento monofásico foi de 5 minutos enquanto para a simulação de escoamento bifásico foi de aproximadamente 2 horas.

A relação macroscópica entre a diferença de pressão e a vazão é determinada combinando o fluxo não-Newtoniano em cada capilar. Os diferentes comportamentos não-Newtonianos considerados são: (a) fluido viscoso e inelástico e (b) fluido de Boger, com viscosidade de cisalhamento constante e comportamento elástico. Os resultados podem ser utilizados para derivar as equações de Darcy para descrever o fluxo nãoNewtoniano em meios porosos.

O modelo foi ampliado para o estudo do escoamento bifásico com uma fase oleosa e uma aquosa, contendo água ou solução polimérica. Para este modelo, foi estudado o efeito da viscosidade extensional no escoamento de soluções poliméricas. O estudo realizado permitiu a análise das influências da vazão de injeção, variação das viscosidades e volume injetado de soluções poliméricas sobre a redução da mobilidade. Em virtude das análises realizadas neste trabalho, permite-se um avanço no entendimento do escoamento de soluções poliméricas em meios porosos, contribuindo para o desenvolvimento de processos de injeção de solução polimérica como uma forma de reduzir a razão de mobilidade água-óleo.

Os resultados do modelo desenvolvido podem ser utilizados na construção de modelos macroscópicos para serem empregados na simulação dos escoamentos que ocorrem na escala de reservatório. O perfeito entendimento do escoamento de soluções poliméricas pode levar a uma otimização do processo de controle de mobilidade através do uso de polímeros e, consequentemente, um aumento da eficiência de varrido do meio poroso pode promover um aumento considerável na eficiência de recuperação de petróleo, aumentando a fração de petróleo recuperável. 
Como trabalho futuro, propomos a comparação direta da evolução de saturação das fases com dados experimentais para diferentes condições de escoamento e propriedade dos líquidos utilizados. 
Referência bibliográfica

AFSHARPOOR, Ali e colab. CFD modeling of the effect of polymer elasticity on residual oil saturation at the pore-scale. Journal of Petroleum Science and Engineering, v. 94-95, p. 79-88, 2012. Disponível em: $<$ http://dx.doi.org/10.1016/j.petrol.2012.06.027>.

AKER, Eyvind e colab. A Two-Dimensional Network Simulator for Two-Phase Flow in Porous Media. Transport in Porous Media, v. 32, n. 2, p. 163-186, 1998. Disponível em: <http://dx.doi.org/10.1023/A:1006510106194>.

AL HASHMI, A. R. e colab. Rheology and mechanical degradation of highmolecular-weight partially hydrolyzed polyacrylamide during flow through capillaries. Journal of Petroleum Science and Engineering, v. 105, p. 100-106, 2013. Disponível em: <http://dx.doi.org/10.1016/j.petrol.2013.03.021>.

BIRD, R Byron e ARMSTRONG, Robert C e HASSAGER, Ole. Dynamics of polymeric liquids. Volume 1: fluid mechanics. A Wiley-Interscience Publication, John Wiley \& Sons, 1987.

BLUNT, Martin J. Flow in porous media-pore-network models and multiphase flow. Current opinion in colloid \& interface science, v. 6, n. 3, p. 197 207, 2001.

BLUNT, Martin J. e KING, Michael e SCHER, Harvey. Simulation and theory of two-phase flow in porous media. Physical Review A, v. 46, n. 12, p. 7680-7699, 1992.

BLUNT, Martin J. e KING, Peter. Relative permeabilities from two-and threedimensional pore-scale network modelling. Transport in porous media, v. 6, n. 4, p. 407-433, 1991.

BLUNT, Martin J. e KING, Peter. Scaling structure of viscous fingering. Physical Review A, v. 37, n. 10, p. 3935, 1988.

BOGER, D.V. A highly elastic constant-viscosity fluid. [S.1.]: Fluid Mech. 3, 1978. v. 3.

CARMAN, P. C. Fluid flow through a granular bed. Transactions, Institution of Chemical Engineers, London, p. 150-166, 1937.

CARREAU, Pierre J. Rheological equations from molecular network theories. Transactions of The Society of Rheology (1957-1977), v. 16, n. 1, p. 99-127, 1972.

DULLIEN, Francis A L. Porous media: fluid transport and pore structure. AcademicPress, SanDiego, v. 1, p. 992, 1992.

FATT, Irving. The Network Model of Porous Media. Petroleum Transactions, AIME, v. 207, p. 144-181, 1956.

FETTKE, Charles R. The Bradford Oil Field, Pennsylvania And New York. . 
[S.1: s.n.], 1938.

GREEN, D W e WILLHITE, G P. Enhanced oil Recovery. SPE Textbook Series, v. 6, 1998.

INTERNATIONAL ENERGY AGENCY. Key World Energy Statistics 2015. p. $81,2015$.

JAMES, David F. Boger Fluids. Annual Review of Fluid Mechanics, v. 41, n. 1, p. 129-142, 2009.

KUMAR GUNDA, Naga Siva e colab. Reservoir-on-a-Chip (ROC): A new paradigm in reservoir engineering. Lab on a Chip, EXPERIMENTAL, v. 11, $\mathrm{n}$. 22, p. 3785-3792, 2011.

LARSON, Ronald G. Constitutive Equations for Polymer Melts and Solutions: Butterworths Series in Chemical Engineering. [S.1.]: Butterworth-Heinemann, 2013.

LIMA, Nicole M. e CARVALHO, Marcio S. Pore-scale analysis of oil displacement by polymer solution. 23rd ABCM International Congress of Mechanical Engineering. Anais...Rio de Janeiro, 2015.

MAN, H. N. e JING, X. D. Network modelling of wettability and pore geometry effects on electrical resistivity and capillary pressure. Journal of Petroleum Science and Engineering, v. 24, n. 2-4, p. 255-267, 1999.

ØREN, Pål-Eric e BAKKE, Stig. Reconstruction of Berea sandstone and porescale modelling of wettability effects. Journal of Petroleum Science and Engineering, v. 39, n. 3, p. 177-199, 2003.

PEARSON, J.R.a. e TARDY, P.M.J. Models for flow of non-Newtonian and complex fluids through porous media. Journal of Non-Newtonian Fluid Mechanics, v. 102, n. 2, p. 447-473, 2002.

PRASAD, Dhruva e colab. Pilot to Full-field Polymer Application in One of the Largest Onshore Field in India. SPE Improved Oil Recovery Symposium, n. mD, p. 1-13, 2014.

ROTHSTEIN, Jonathan P. e MCKINLEY, Gareth H. Extensional flow of a polystyrene Boger fluid through a 4:1:4 axisymmetric contraction/expansion. Journal of Non-Newtonian Fluid Mechanics, v. 86, n. 1-2, p. 61-88, 1999.

SANDIFORD, B.B. Laboratory and Field Studies of Water Floods Using Polymer Solutions to Increase Oil Recoveries. Journal of Petroleum Technology, v. 16, n. 8, p. 917-922, 1964.

VARGAS, Kelly Margarita Colmenares. Processo de Deslocamento de Óleo em Micro Modelos de Meios Porosos por Injeção de Emulsão de Óleo em Água. 2014. Departamento de Engenharia Mecânica, PUC-Rio, 2014.

WANG, Demin e colab. Study of the Mechanism of Polymer Solution With Visco-Elastic Behavior Increasing Microscopic Oil Displacement Efficiency and the Forming of Steady "Oil Thread" Flow Channels. Proceedings of SPE Asia Pacific Oil and Gas Conference and Exhibition, p. 1-9, 2001. 